\title{
Sinopsis de las Thelypteridaceae de Brasil central y Paraguay
}

\author{
Mónica Ponce ${ }^{1}$
}

Recibido: 28.09.2006; acepto: 28.06.2007

\begin{abstract}
Synopsis of Thelypteridaceae in Central Brazil and Paraguay). Although the Thelypteridaceae has been treated for North America, Mesoamerica, Guayanas, Ecuador, Peru, Argentina, and the South and Southeast of Brazil, the central region of South America still requires updating. With this aim, the Thelypteridaceae of Paraguay and central Brazil were studied and comprise two genera, five subgenera, and 55 specific and infraspecific taxa. A general key for the groups and their entities, distribution, ecology, and illustrations are also provided. A new combination, new synonymys, and expanded distributions are included, and nomenclatural problems and taxonomic questions are discussed. Although the studied area is larger than other well studied regions, the total number of species is smaller in agreement with the low richness of environments.
\end{abstract}

Key words: Central South America, diversity, Macrothelypteris, Thelypteris

RESUMEN - (Sinopsis de las Thelypteridaceae de Brasil central y Paraguay). Aunque las Thelypteridaceae han sido tratadas en forma actualizada para Norteamérica, Mesoamérica, Guayanas, Ecuador, Perú, Argentina y sur y sudeste de Brasil, la región central de Sudamérica aún requería de una puesta al día. Con este motivo se estudiaron las especies de Thelypteridaceae de Paraguay y Brasil central, encontrándose 55 taxones, entre especies e infraespecíficos, comprendidos en dos géneros y cinco subgéneros. Se brinda una clave general para los grupos y sus entidades, con datos de distribución, ecología e ilustraciones. Se incluyen una nueva combinación, nuevos sinónimos y extensiones de área, se resuelven problemas nomenclaturales y discuten cuestiones taxonómicas. Pese a que el área estudiada es muy amplia se destaca que el número total de especies es menor respecto a las regiones conocidas en concordancia con la menor riqueza de ambientes. Palabras clave: Diversidad, Macrothelypteris, Sudamérica central, Thelypteris

\section{Introducción}

El tratamiento de las Thelypteridaceae en los territorios de Paraguay y centro de Brasil, comprende a las entidades de esta familia presentes en una región biogeográfica fuera de sus áreas de alta diversidad. El área estudiada corresponde a las provincias fitogeográficas del Cerrado y Chaqueña, con remanentes de bosques Paranaense y Atlántico y la zona limítrofe con la provincia Amazónica (Cabrera \& Willink 1973, Oliveira \& Marquis 2002). Las regiones de concentración de las Thelypteridaceae son los Andes tropicales y subtropicales ("Yungas"), los bosques montanos a lo largo de la costa atlántica ("Mata Atlântica") y del planalto meridional de Brasil. El territorio estudiado posee características ambientales diferentes a las de esas regiones, la extensa topografía es plana o levemente ondulada, con serranías rodeadas de depresiones y valles fluviales, el rango altitudinal es de 50-1.800 m s.m., con algunos picos que sobrepasan esa altura en el Planalto central.
En toda la región se encuentran lagunas aisladas o encadenadas y la vegetación se compone de un mosaico de sabanas, campos rupestres, arbustales y bosques semidecíduos estacionales en las regiones altas y bosques en galería ("matas ciliares") y pantanos en las regiones bajas. En menor proporción se encuentran sectores de bosques húmedos como al nordeste de Paraguay y al este de Minas Gerais. En general en los pastizales y pantanales la proporción de helechos es menor ya que la diversidad de este grupo de plantas se relaciona directamente con la heteregoneidad ambiental, siendo el componente ecológico determinante en la distribución y riqueza específica. La grandes planicies y humedales resultan ser demasiado homogéneas para los helechos, encontrándose ambientes más propicios en los bosques montanos o serranos (Moran 1995).

La familia Thelypteridaceae agrupa cerca de 900 especies distribuidas mundialmente en regiones tropicales y subtropicales, y en escasa proporción en zonas templadas. Son helechos terrestres, higrófilos y

1. Instituto de Botánica Darwinion, Labardén 200, Casilla de Correo 22, 1642 San Isidro, Argentina (mponce@darwin.edu.ar) 
heliófilos, con numerosos taxones palustres o epipétricos en lechos de torrentes. La clasificación de esta familia varía en la delimitación del número de géneros, según diferentes criterios son aceptados de 1-35 géneros. En general el tratamiento seguido en América reconoce a 2 géneros, Macrothelypteris, con una especie, y el resto de los taxones se ubican dentro de Thelypteris dividido en subgéneros (Ponce 1988(1987), Smith 1977, 1980, 1983, 1992, 1993, 1995 , Salino, 2002a, 2004). Estudios cladísticos recientes comprueban que la familia es monofilética y que el reconocimiento de un número intermedio de géneros sería la tendencia taxonómica esperable (Smith \& Cranfill 2002).

El objetivo de este trabajo fue inventariar las especies, resolver algunas posiciones taxonómicas, confeccionar claves para su determinación, ampliar y actualizar la distribución geográfica de las Thelypteridaceae presentes en el centro-este de Sudamérica.

\section{Materiales y métodos}

El área estudiada abarca los territorios de Paraguay y los estados de Goiás, Minas Gerais, Distrito Federal, Mato Grosso y Mato Grosso do Sul de Brasil. En especies poco representadas o raras se cita material de estados limítrofes. Se analizó material de los herbarios BM, BHCB, CTES, G, FCQ, ICN, HB, LIL, LP, MO, PY, RB, SJRP, SI y UC. Además para el estudio de los ejemplares tipo se consultaron los herbarios B, BM, C, HB, K, LP, R, RB, S, SI, SP y UC.

Para la delimitación de las especies se analizaron comparativamente caracteres morfológicos de reconocido valor diagnóstico a nivel de especies y taxones subespecíficos, como: tipo de rizoma, forma y pilosidad de las escamas rizomáticas, ápice y base de la lámina, indumento (tipo, longitud, ubicación y densidad), forma y posición de los soros, presencia y particularidad de los indusios, presencia de aeróforos y de yemas. Los caracteres observados corresponden al estado de cada uno en la planta adulta y en la parte media del pecíolo, lámina, pinnas y segmentos. Para el reconocimiento de los taxones válidos se usó en la mayoría de los casos la metodología tipológica, revisándose material tipo o imágenes de los mismos.

Se presentan claves para los géneros, subgéneros y especies. Se dan a conocer una nueva combinación, un nuevo nombre, nuevos sinónimos y extensiones del área distribución. Los taxones se listan en forma sinóptica por orden alfabético dentro de cada subgénero, dando las referencias bibliográficas, iconográficas, distribucionales y endemismos, incluyéndose observaciones taxonómicas y material estudiado. Sólo cuando se trata de novedades o entidades poco conocidas se cita el material tipo. Se ilustran además la mayoría de los taxones.

\section{Resultados}

En el área estudiada se han encontrado 55 entidades de Thelypteridaceae, habiéndose observado que varía la magnitud y composición de especies dentro de los subgéneros respecto a las áreas de alta diversidad. Mientras en los bosques montano-lluviosos con más del doble de especies, Amauropelta representa alrededor del $60 \%$ de las especies de Thelypteris, en la región central de Sudamérica su proporción baja a cerca del 35\%. Le siguen en tamaño Goniopteris (26\%), Cyclosorus (16\%), Meniscium (14\%) y Steiropteris (8\%), además de dos especies restringidas a Brasil que no se encuentran delimitadas subgenéricamente (Salino 2003). Como era de esperar, dadas las características ambientales de la región, predominan los taxones palustres, presentes en todos los grupos. Además debido a las características edáficas y geomorfológicas particulares de los "cerrados", con sequías prolongadas y fuegos recurrentes, se encuentran numerosos taxones endémicos o de área restringidas.

Clave de géneros

1. Láminas 2-3-pinnado-pinnatífidas; costas planas adaxialmente; venas siempre libres, furcadas, no alcanzando el margen Macrothelypteris torresiana

1. Láminas 1-pinnado-pinnatífidas, menos comunmente 1-pinnado; costas surcadas adaxialmente; venas libres o anastomosadas, en general simples, raramente furcadas, terminando en el margen 
Clave de subgéneros y especies de Thelypteris

1 Pelos ramificados o estrellados, pedicelados, presentes por lo menos en el raquis, y/o costas adaxiales, y/o en las escamas de la base del pecíolo (subgen. Goniopteris)

2. Lámina terminada en una pinna conforme o subconforme con las laterales, libre; base de las pinnas laterales cuneada a largamente cuneadas

3. Láminas pinnadas, pinnas apenas lobuladas o incisas hasta $1 / 5$ de la distancia a la costa, base de las pinnas cuneada; indusios ausentes o incospicuos; láminas glabras o escasamente pilosas sobre los ejes

4. Pinnas pocas, 5-7 pares, margen crenado o crenado-aserrado, láminas verrugosas; venas de los segmentos adyacentes libres o conniventes en el seno

T. juruensis

4. Pinnas numerosas; 6-10 pares, margen entero a aserrado; láminas no verrugosas; venas de los segmentos adyacentes unidas en una venilla excurrente al seno.....

3. Láminas pinnado-pinnatífidas; pinnas incisas hasta un 1/2-2/3 de la costa; láminas glabras o densamente pilosas

5. Todas las pinnas (notoriamente las proximales) largamente cuneadas en la base; láminas glabras o moderadamente pilosas; pelos aciculares, hialinos T. tristis

5. Pinnas proximales truncadas o subtruncadas en la base; láminas pilosas a densamente pilosa; pelos aciculares y ramificados, a menudo rojizos

T. biformata

2. Laminas con ápice pinnatífido, gradual o abruptamente reducido, o una pinna subconforme y subconfluente con las laterales

6. Láminas 1-pinnadas, margen de las pinnas lobulado-aserrado o crenado, glabras; pinnas subcuneado-auriculadas o auriculadas en la base; venas basales de los segmentos adyacentes unidas en una venilla excurrente al seno; indusios ausentes

7. Pinnas crenadas; yemas presentes en el par de pinnas basales

T. abbiatae

7. Pinnas lobulado-aserradas; yemas ausentes T. riograndensis

6. Láminas 1-pinnado-pinnatífidas, incisas hasta 1/2-2/3 de la distancia a la costa o más, glabras o pilosas; pinnas truncadas o pinnas medias truncadas o subtruncadas y basales cuneadas, auriculadas o no; venas libres, conniventes o anastomosadas; indusios presentes 8. Láminas glabras, excepto en las costas y raquis; indusios pequeños, espatulados o reniformes glandulares

9. Rizomas rastreros T. scabra

9. Rizomas erectos T. semirii

8. Láminas moderado a densamente pilosas en lámina y ejes; indusios reniformes, pilosos

10. Láminas abaxiales completamente cubiertas con pelos estrellados cortos a menudo adpresos

11. Pinnas sésiles; segmentos basales elongados en las pinnas medias; venas basales de los segmentos adyacentes conniventes

T. montana

11. Pinnas cortamente pecioluladas; segmentos basales reducidos u obsoletos; venas basales de los segmentos adyacentes unidas en venilla excurrente T. biolleyi

10. Láminas abaxiales con pelos estrellados sólo en las costas y cóstulas, el resto de la superficie con pelos simples

12. Pinnas 12-22 pares, incisas más de $2 / 3$ de la distancia a la costa; plantas con numerosas yemas

12. Pinnas hasta 10 pares (raro 12), incisas no más de $1 / 2$ de la distancia a la costa; yemas a veces presentes

13. Pinnas no auriculadas, las proximales con los segmentos basales reducidos, no reflexas T. abrupta

13. Pinnas auriculadas, las proximales reflexas 
14. Rizomas erectos o suberectos (decumbente en la parte vieja); pinnas arqueadas, fuertemente auriculadas, largamente agudas

14. Rizomas rastreros; pinnas derechas, levemente auriculadas, cortamente agudas T. schwackeana

1. Pelos de otros tipos, simples, 1-pluricelulares, aciculares, uncinulados, crespados, fasiculados; raramente ausentes

15. Láminas pinnadas; venas transversales unidas formando areolas y dando origen a una venilla inclusa; soros oblongos o lunulares sobre las venas anastomosadas (subgen. Meniscium)

16. Margen de las pinnas uncino-aserrado, por lo menos en el sector distal T. serrata

16. Margen de las pinnas crenulado, ondulado o subentero, raramente dentado

17. Pinnas angostas, generalmente menores de $2(2,5) \mathrm{cm}$ lat., base cuneada o largamente cuneada, simétrica; costa abaxial con pelos adpresos y curvados; areolas 4-10seriadas; yemas ausentes. T. angustifolia

17. Pinnas más anchas de $2-7 \mathrm{~cm}$ lat., redondeado-truncadas o cuneadas en la base, subsimétricas, las proximales pecioluladas (2-10 mm long.); costas abaxiales moderado a densamente pilosas, pelos derechos o crispados; areolas 13-22 seriadas; yemas presentes o ausentes

18. Láminas abaxiales con pelos glandulares, amarillentos o hialinos; receptáculos y esporangios glabros T. maxoniana

18. Láminas abaxiales con pelos aciculares o cortamente crispados, muy densos o esparcidos; receptáculos y esporangios glabros o pilosos

19. Pinnas elípticas a anchamente elípticas (hasta $7 \mathrm{~cm}$ lat.); de ápice acuminado; soros oblongo-arqueados dispuestos a lo largo de las venillas transversales T. chrysodioides

19. Pinnas angostamente elípticas a largamente oblongas (hasta $4 \mathrm{~mm}$ lat.); de ápice agudo a atenuado; soros de contorno ovado, reniformes o cortamente oblongos, en posición central en la unión de las venillas

20. Pinnas estériles hasta $22 \mathrm{~cm}$ long. por 2-2,5(3) $\mathrm{cm}$ lat., fuertemente oblicuas; escasamente pilosas, pelos cortos crispados; receptáculo y esporangios glabros, acrosticoides a la madurez. A menudo con yemas en la axila de las pinnas proximales T. salzmannii

20. Pinnas a menudo de más de $30 \mathrm{~cm}$ long. por 2,5-4 cm lat., normalmente oblicuas, moderado a densamente pilosas, pelos aciculares de diferentes longitudes; esporangios y receptáculos pilosos; yemas ausentes

21. Base de las pinnas truncada o redondeada, las basales cortamente pecioluladas (2-5 mm long.); margen subcrenulado T. arborescens

21. Base de las pinnas redondeado-cuneadas o cuneadas, las basales largamente pecioluladas (5-10 mm long.); margen entero o subentero

T. longifolia

15. Láminas pinnado-pinnatífidas; venas libres o solamente el par de venas proximales conniventes o unidas, formando o no una vena excurrente al seno; soros circulares o elípticos sobre las venas laterales

22. Pinnas basales no reducidas o 2-3 pares moderado a levemente reducidos

23. Venas basales libres o más o menos conniventes con un quilla (carina) entre ellas dirigida de la costa al seno, o venas libres alcanzando el margen por arriba del seno sin quilla; base abaxial de las pinnas generalmente con aeróforos, a veces presentes en la base de los segmentos. Indusios presentes o ausentes..... (subgen. Steiropteris)

24. Quilla prominente, venas basales por debajo del seno 
25. Aeróforos ausentes; segmentos basales de las pinnas proximales reducidos; pinnas elípticas T. gardneriana

25. Aeróforos presentes; segmentos basales de las pinnas proximales no reducidos; pinnas triangulo-lineales

26. Indusios pilosos T. leprieurii var. leprieurii

26. Indusios glandulosos T. leprieurii var. glandifera

24. Quilla ausente, venas basales por arriba del seno

27. Indusios ausentes; aeróforos presentes en la base de las pinnas y pecíolos; costas y costulas abaxiales pilosas T. decussata var. brasiliensis

27. Indusios presentes; aeróforos ausentes

28. Pinnas basales reflexas y arqueadas T. hatschbachii

28. Pinnas basales derechas y perpendiculares al raquis T. mexiae

23. Venas basales libres, conniventes o anastomosadas alcanzando el margen en el seno o debajo del mismo, sin quilla (carina); aeróforos ausentes. Indusios presentes (subgen. Cyclosorus)

29. Venas basales de los segmentos adyacentes anastomosadas formando una venilla excurrente al seno de 1-4 mm long.

30. Rizomas largamente rastreros, negruzcos, desnudos; frondes remotas sobre el rizoma; pinnas incisas hasta la mitad de la distancia a la costa; con escamas ovadas en la costa abaxial; pelos glandulares sésiles o ausentes..... T. interrupta

30. Rizomas erectos o rastreros, escamosos por lo menos en el ápice; frondes fasciculadas o aproximadas sobre el rizoma; pinnas incisas hasta $2 / 3$ o más de la distancia a la costa, escamas ausentes; pelos glandulares ausentes o si presentes, pedicelados

31. Pilosidad corta y uniforme, menores de $0,2 \mathrm{~mm}$ long.; pecíolos castaños o castaño-purpúreos T. dentata

31. Pilosidad de diferentes longitudes, pelos en general mayores de $0,3 \mathrm{~mm}$ long., normalmente más de $0,5 \mathrm{~mm}$ long., aciculares; pecíolos pajizos o castaño claros T. hispidula

29. Venas basales libres, conniventes o no en el seno, si anastomosadas no forman vena excurrente

32. Pinnas basales reducidas, 2 o más pares; superficie adaxial pilosa; venas basales libres, conniventes y/o anastomosadas en la misma planta T. conspersa

32. Pinnas proximales no reducidas, más o igual de largas que las siguientes; superficie adaxial glabra o escasamente pilosa; venas libres

33. Segmentos proximales igual o de mayor tamaño que los siguientes, a menudo elongados y sectados; apice de lámina gradualmente reducido; rizoma erectos o rastreros

34. Rizomas rastreros; pelos glandulares pedicelados a menudo presentes en ambas caras

34. Rizomas erectos; cara adaxial de los segmentos glabra o con escasos pelos simples en la cóstula; venas libres

35. Indusios glabros o glandulosos T. patens var. dissimilis

35. Indusios pilosos o glanduloso-pilosos

36. Cóstulas y venas glabras adaxialmente; escamas rizomáticas glabras T. patens var. patens

36. Cóstulas y venas pilosas o esparcidamente pilosas. Escamas rizomáticas pilosas T. patens var. smithiana

33. Primeros pares de segmentos muy reducidos u obsoletos o 2 do. y 3 er. par levemente reducidos; ápice de lámina abruptamente reducido; rizomas rastreros 
37. Pinnas medias de 8-25 cm long. $\times$ 0,8-2 $(2,5) \mathrm{cm}$ lat., segundo y tercer par de segmentos de menor tamaño. Indusios y ejes con diminutos pelos glandulares, 1-celulares, hialinos; a menudo con escasos pelos sedosos

T. berroi

37. Pinnas medias de $22-30 \mathrm{~cm}$ long. $\times 2-3,5 \mathrm{~cm}$ lat.; segmentos basales muy reducidos u obsoletos

38. Soros submarginales con indusios subglabros, papilosos, castaños. Pilosidad menor de 0,2 $\mathrm{mm}$ long. sobre cóstulas y venas T. grandis var. kunzeana

38. Soros medianos con indusios densamente pilosos, amarillentos. Pilosidad mayor de 0,2 mm long., a menudos también entre venas T. grandis var. pallescens

22. Numerosos pares de pinnas basales gradualmente reducidas (generalmente más de 4) los últimos pares con pinnas pequeñas, hastadas, auriculadas o glanduliformes. Par de venas basales libres, alcanzando el margen por encima del seno (subgen. Amauropelta)

39. Soros elípticos o lineales

40. Soros con indusios "athyrioides" " "subathyrioides"; láminas con pelos aciculares, glandulares anaranjados presentes en la cara abaxial e indusios

T. decurtata subsp. decurtata

40. Soros desnudos. Ejes y lámina abaxial con pelos uncinulados, pelos glandulares ausentes

41. Pinnas sésiles o subsésiles, con la base truncada; plantas de 0,40-1 m de altura; yemas a menudo presentes T. amambayensis

41. Pinnas pecioluladas, base cuneada o subcuneado-auriculada. Plantas de 0,10$0,30 \mathrm{~m}$ de altura; yemas ausentes

42. Pinnas de contorno elíptico, pinnatífidas, con la base cuneada; láminas herbáceas T. gymnosora

42. Pinnas lineales, base subcuneada, auriculada acroscópicamente. Láminas cartáceas T. aspidioides

39. Soros circulares, con indusios reniformes, pilosos o a veces reducidos a un fascículo de pelos

43. Esporangios a menudo setosos, indusios reducidos a un fascículo de pelos; indumento foliar setiforme, corto ( 0,05-0,2 $\mathrm{mm})$ y uniforme

44. Plantas pequeñas, $10-30 \mathrm{~cm}$, rupestres; lámina herbácea; raquis delgado; pinnas cortamente ovadas, a veces con glándulas amarillentas abaxiales; soros marginales T. stierii

44. Plantas mayores hasta $80 \mathrm{~cm}$, palustres. Lámina cartácea; raquis robusto, pinnas oblongas; glándulas ausentes soros medianos a submarginales T. heineri

43. Esporangios siempre glabros. Indumento foliar de pelos aciculares y/o uncinulados de diferentes longitudes (entre 0,3-2 $\mathrm{mm}$ ) o ausentes; pelos glandulares a menudo presentes

45. Pelos uncinulados presentes (a veces inconspicuos)

46. Pelos pluriceluares (hasta $2 \mathrm{~mm}$ long.) presentes en el pecíolo y raquis en alta densidad, pelos uncinulados muy escasos T. retusa

46. Pelos pluricelulares ausentes o presentes sólo en porción basal del pecíolo 47. Pelos uncinulados inconspicuos y pelos glandulares en la cara abaxial de la lámina y margen del indusio 
48. Rizomas largamente rastreros, casi desnudos y ennegrecidos; pecíolos con porción basal densamente pilosa y escamosa, glabrescentes en la porción media y distal; pinnas basales por lo común gradualmente reducidas T. rivularioides

48. Rizomas erectos; pecíolos esparcidamente pilosos y escamosos en toda su extensión; pinnas basales abruptamente reducidas ..... T. neglecta

47. Pelos uncinulados conspicuos y densos en ejes y láminas, pelos glandulares ausentes. Pinnas basales abrupta o subabruptamente reducidas

49. Yemas presentes. Pecíolos y raquis (al menos en el surco adaxial) con pelos uncinulados cortísimos, de 0,05-0,2 mm long. Indusios uncinulado-pilosos T. recumbens

49. Yemas ausentes; pecíolos y raquis con pelos setiformes y aciculares, o con pelos uncinulados de mayor longitud, hasta 0,5 mm, en ambos casos densísimos y 1-paucicelulares; indusios setosos, rara vez con pelos uncinulados, o indusios ausentes

50. Ejes con una mezcla de pelos uncinulados y aciculares de distintas longitudes o sólo pelos uncinulados

51. Cara abaxial de los segmentos totalmente cubierta con pelos uncinulados, densos T. regnelliana

51. Cara abaxial de los segmentos con pelos uncinulados únicamente entre venas T. raddii

50. Ejes con pelos aciculares o uncinulados uniformemente cortos 52. Cara abaxial uniformemente setosa, indusios setosos T. oligocarpa var. crassistipitata

52. Cara abaxial uniformemente uncino-pilosa, indusios glandulosos T. rioverdensis

45. Pelos uncinulados ausentes; yemas ausentes

53. Plantas con pelos glandulares pedicelados, hialinos o amarillentos; ejes con pelos setiformes, a menudo mezclados con pelos aciculares; láminas abruptamente reducidas T. mosenii

53. Plantas con pelos glandulares sésiles, amarillos a anaranjados, resinosos, o ausentes; láminas gradual o subabruptamente reducidas

54. Pecíolos y raquis pilosos, pelos aciculares, sin escamas; segmentos cortamente ovados o triangulares, de 3-8 mm long., con 4-6(8) pares de venas; cara abaxial con pelos glandulares anaranjado-resinosos; aeróforos ausentes o muy poco desarrollados T. opposita

54. Pecíolos glabros, raquis únicamente pilosos en el surco adaxial, pelos cortos arqueados, antrorsos; o ejes con pelos aciculares pluriceluares; a menudo escamas amorfas, adpresas, inconspicuas presentes sobre los ejes; segmentos largamente ovado-triangulares o lineartriangulares, de 6-15(18) mm long., oblicuos a subfalcados, con 615(20) pares de venas; con escamas pequeñísimas en las costas abaxiales; aeróforos mameliformes a liguliformes presentes

55. Soros marginales parcialmente cubiertos por el margen fuertemente revoluto; glándulas sésiles o cortamente pediceladas, color crema o amarillas; aeróforos en la base de las pinnas y segmentos en la cara abaxial T. cheilanthoides

55. Soros medianos o submarginales, margen plano o reflexo no cubriendo los soros; glándulas sésiles, anaranjadas; aeróforos en la base de las pinnas en la cara abaxial 
56. Láminas con 3-4 pares de pinnas basales abruptamente reducidas; indusios reniformes y "subathyrioides", densamente pilosos, pelos largos, 1-3-celulares, a veces con glándulas anaranjadas; segmentos oblicuos con el ápice fuertemente curvado T. metteniana

56. Láminas con 4-10 pares de pinnas basales subabrupta- a gradualmente reducidas; Indusios reniformes u orbiculares, con glándulas anaranjadas y/o pelos 1-celulares, muy cortos y encrespados. Segmentos rectos u oblicuos T. pachyrhachis var. pachyrhachis

\section{Macrothelypteris (H. Ito) Ching}

Género paleotropical con unas 10 especies, una asilvestrada en el Neotrópico. Se caracteriza por sus amplias frondes 3-pinnadas que lo asemejan a géneros dryopterioides como Megalastrum y Lastreopsis.

1. Macrothelypteris torresiana (Gaudich.) Ching, Acta Phytotax. Sin. 8: 310. 1963. Polystichum torresianum Gaudich., Acta Phytotax. Sin. 8(4): 310. 1963.

Descripción e iconografía: Smith (1992: 4), PeñaChocarro et al. (1999: 111).

Distribución y ecología: Esta es una especie paleotropical, descripta originariamente para el SE de Asia; adventicia y naturalizada en América. Se distribuye ampliamente desde el sur de Estados Unidos y Antillas hasta Bolivia, Brasil, Paraguay y Argentina, probable en Uruguay. Es un elemento ruderal, frecuente en orillas de arroyos y sitios pantanosos.

Materiales examinados: BRASIL. GoIÁs: Ipameri, ca. $48^{\circ} 08^{\prime} \mathrm{W}, 17^{\circ} 43^{\prime} \mathrm{S}, 700 \mathrm{~m}$, Rod.GO-213, Ipameri Caldas Novas, ca. $30 \mathrm{~km}$ de Ipameri, cerrado con mata ciliar, margem do riacho, 23-I-1996, M.R. Pietrobom-Silva 2622 (CTES). Minas Gerais: Viçosa, road to São Miguel, Immediately outside Agricultural College, $700 \mathrm{~m}$, steep grazed hillside among brush, occasional, 24-XII-1929, Y. Mexia 4161 (MO); road to Sao Miguel, $685 \mathrm{~m}$, small gulch, fronds up to 2,5 m, 18-III-1930, Y. Mexia 4476 (MO); Agricultural College, disused road Cha-Cha Valley, $680 \mathrm{~m}$, under steep bank at edge of woods, fronds up to $1,75 \mathrm{~m}$, in colony, 27-V-1930, Y. Mexia 4754 (MO); Agricultural College, foot of horticultural hill, $667 \mathrm{~m}$ bank of marsh, fronds up to $2.38 \mathrm{~m}$, abundant locally, 16-VII-1930, $Y$. Mexia 4861 (MO); Corrigo Riberró, $675 \mathrm{~m}$ streamside, in shady ravine, frequent, 19-VII-1930, $Y$. Mexia 4873 (MO); Fazenda de Aguada, 695 m streamside, partially wooded ravine, fern up to $1,5 \mathrm{~m}$ high, frequent, 29-VII-1930, Y. Mexia 4920 (MO). PARAGUAY. CANINDEYÚ: Ballinoti cue, en matas aisladas, rizoma corto superficial, 3-VII-1996, $B$. Jiménez \& G. Marín 1288 (BM). Cordillera: Caacupé, semideciduous forest to $20 \mathrm{~m}$ tall, $25^{\circ} 20^{\prime} \mathrm{S}$, 57010'W, 9-II-1984, W. Hahn 2039 (G). GuAiRÁ: Col. Independencia, ayo. Guazú, ca. S. Gervasio, 2557'S, 56 ${ }^{\circ} 17^{\prime} \mathrm{W}, 250 \mathrm{~m}, 27-\mathrm{III}-1993$, A. Schinini et al. 28040 (G); Cord. Ybytyruzú, base Co. Mymy, ca. Co. Polilla, 255' 'S, 56 ${ }^{\circ} 10^{\prime} \mathrm{W}, 400$ m, 23-VII-1989, E.E. Zardini 13716 (G); Cord. Ybytyruzú, road to Cantera Jhú, $25^{\circ} 48^{\prime} \mathrm{S}, 56^{\circ} 20^{\prime} \mathrm{W}, 2 \mathrm{~km} \mathrm{~S}$ route to Cnel. Oviedo, 27-IX-1989, E.E. Zardini \& Velásquez 14573 (G). PARAguarí: Acahay Massif, Acahay Massif, 265'ㅇ' $57^{\circ} 09^{\prime} \mathrm{W}, 500 \mathrm{~m}$, E peak, 21-VIII-1988, E.E. Zardini

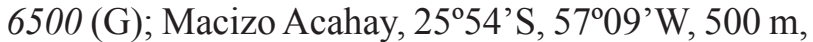
5-XII-1988, E.E. Zardini \& Florentín 7031, 7033 (G); Macizo Acahay, 26 $54^{\circ} \mathrm{S}, 5^{\circ} 09^{\prime} \mathrm{W}, 500 \mathrm{~m}$, central peak, 14-VII-1988, E.E. Zardini 5803 (G); on E peak, 11-VI-1989, E. Zardin et al. 12719 (G); along road to Athena, 25⒌'S, 5709'W, 11-VI-1989, E.E. Zardini \& Velásquez 12987 (G); Cerro Palacios, 2525'S, 57010'W, 250 m, 8-IX-1988, E.E. Zardini 7157 (G).

\section{Thelypteris Schmidel}

Thelypteris comprende alrededor de 300 especies en el Neotrópico, normalmente divididas en subgéneros. En la región estudiada que abarca centro de Brasil y Paraguay se encuentran 54 taxones.

Thelypteris subg. Amauropelta (Kunze) A.R. Sm.

Amauropleta es el subgénero más numeroso comprendiendo unas 200 especies, la mayoría de ellas de América tropical y subtropical, unas pocas habitan en Africa, Madagascar e Islas Mascarene. La región andina es la de mayor diversidad (Smith 1983, 1992). La mayoría de sus especies crecen en bosques y selvas 
montanas, por lo que en la región estudiada, mayormente de tierras bajas y pantanosas, se encuentran 16 especies exclusivas del área y regiones adyacentes, ecológicamente adaptadas. Sólo 3 especies neotropicales de amplia distribución crecen en el chaco-cerrado.

1. Thelypteris amambayensis (H. Christ) Ponce, Candollea 55(2): 310. 2000. Dryopteris amambayensis H. Christ, Repert. Spec. Nov. Regni Veg. 7: 374. 1909.

Thelypteris dutrae (C. Chr. ex Dutra) Ponce, Darwiniana 33: 263. 1995. Dryopteris dutrai C. Chr. ex Dutra, Ann. Prim. Reun. Sul-Amer. Bot. 2: 42.1940.

Figura 1

Descripción e iconografía: Ponce (1995: 263).

Distribución y ecología: Se encuentra en el sur de Brasil, Paraguay y el NE de la Argentina. Es un helecho terrestre endémico de la región Paranaense, creciendo en bosques de Araucaria y comunidades secundarias, próximo a arroyos o en suelos húmedos o pantanosos. No se encontró en Brasil central.

Materiales estudiados: PARAGUAY. AmambaY: Cerro Corá, en curso de agua en selva, 22-VIII-1980, $A$. Schinini \& E. Bordas 20340 (CTES). CANINDEYú: Jejui-mí sendero Jaku-apetí, terrestre, 2-VII-1996, G. Marín \& B. Jiménez 300 (BM). Cordillera: Valenzuela, 17-XII-1950, Schwarz 11092 (LIL). GuAIRÁ: Road Melgarejo-Antena, 6 km de Melgarejo, $25^{\circ} 55^{\prime} \mathrm{S}, 56^{\circ} 15^{\prime} \mathrm{W}, 5-\mathrm{III}-1989$, E.E. Zardini \& A. Aguayo 11138 (G, MO). Paraguarí: Nat. Park Ybicuí, trail from administration to La Rosada, $26^{\circ} 06^{\prime} \mathrm{S}$, 46ํㄱ' W, 31-X-1989, E.E. Zardini \& A. Aguayo 15794 (MO, PY, UC).

Se diferencia de la muy cercana Thelypteris linkiana (C. Presl) R.M. Tryon, principalmente por sus soros muchos más cortos a circulares.

Thelypteris amambayensis (H. Christ) Ponce fue citada para Minas Gerais por Salino \& Semir (2004) sin más datos; en esta revisión no se ha visto material de esta especie proveniente de ese territorio.

2. Thelypteris aspidioides (Willd.) R.M. Tryon, Rhodora 69: 5. 1967. Ceterach aspidioides Willd., Sp. pl., ed. 4, 5(1): 137. 1810.

Polypodium saxicola Sw., Kongl. Vetensk. Acad. Handl. 1817(1): 59, tab. 3, fig. 5. 1817. Thelypteris saxicola (Sw.) C.F. Reed, Phytologia 17: 312. 1968. Tipo: BRASIL, sin localidad, Freyreis s.n. (holotipo S; imagen vista), syn. nov.

Dryopteris aspidioides (Willd.) R.M. Tryon var. subhastata. Kongel. Danske Vidensk. Selsk. Skr. Naturvidensk. Afd. 7(4): 287. 1907. Lectotipo (Elegido por Smith, en Tryon \& Stolze 1992): PERÚ, Dpto. SAN MARTín: Tarapoto, Spruce 3964 (isolectotipo NY, imagen vista).

Figura 2A-B

Descripción e iconografía: Smith (1992: 13)

Distribución y ecología: Desde Costa Rica y Panamá hasta Bolivia y Brasil central. Es un elemento epipétrico, comúnmente sobre los lechos rocosos de arroyos.

El material original de Polypodium saxicola Sw. proveniente de Brasil central (Freyreis coleccionó en esta región) es idéntico al de Dryopteris aspidioides var. hastata del Perú amazónico. Sin embargo no se ha encontrado en el área estudiada material actual de esta entidad. Tal vez se halle confundido en los herbarios con Thelypteris gymnosora (sub T. ptarmica var. asplenioides), ya que presenta el mismo indumento piloso-uncinulado y soros oblongos, desnudos; pero a diferencia de $T$. gymnosora que posee lámina herbácea y pinnas pinnatífidas, de base cuneada y largamente pecioluladas (figura 2), en $P$. saxicola la lámina es coriácea y las pinnas enteras a pinnatisectas basal- y acroscópicamente auriculadas.

3. Thelypteris cheilanthoides (Kunze) Proctor, Bull. Inst. Jamaica, Sci. Ser. 5: 58. 1953. Aspidium cheilanthoides Kunze, Linnaea 22: 578. 1849.

Figura 3A

Descripción e iconografía: Smith (1992: 34); Ponce (1995: 276, fig. 5 I-J).

Distribución y ecología: Este taxón se encuentra en las Antillas Mayores y en el continente americano desde México a Bolivia y Brasil. En Brasil crece en el centro-sudeste hasta el estado de Santa Catarina más al sur, en barrancos y al costado de caminos y picadas en la selva.

Material examinado: BRASIL. MAto Grosso: Jaurú, distrito de Taquaruzú, Rio Jaurú, $15^{\circ} 15^{\prime}$ 'S, $58^{\circ} 45^{\prime} \mathrm{W}$, ca. 350 m, 9-XII-1991, P.G. Windisch \& J. Pires 6700 (SI, SJRP).

4. Thelypteris decurtata (Link) de la Sota subsp. decurtata, Lilloa 36(1): 65. 1983. Asplenium decurtatum Link, Fil. spec. 94. 1841.

Descripción e iconografía: Ponce (1995: 273). 

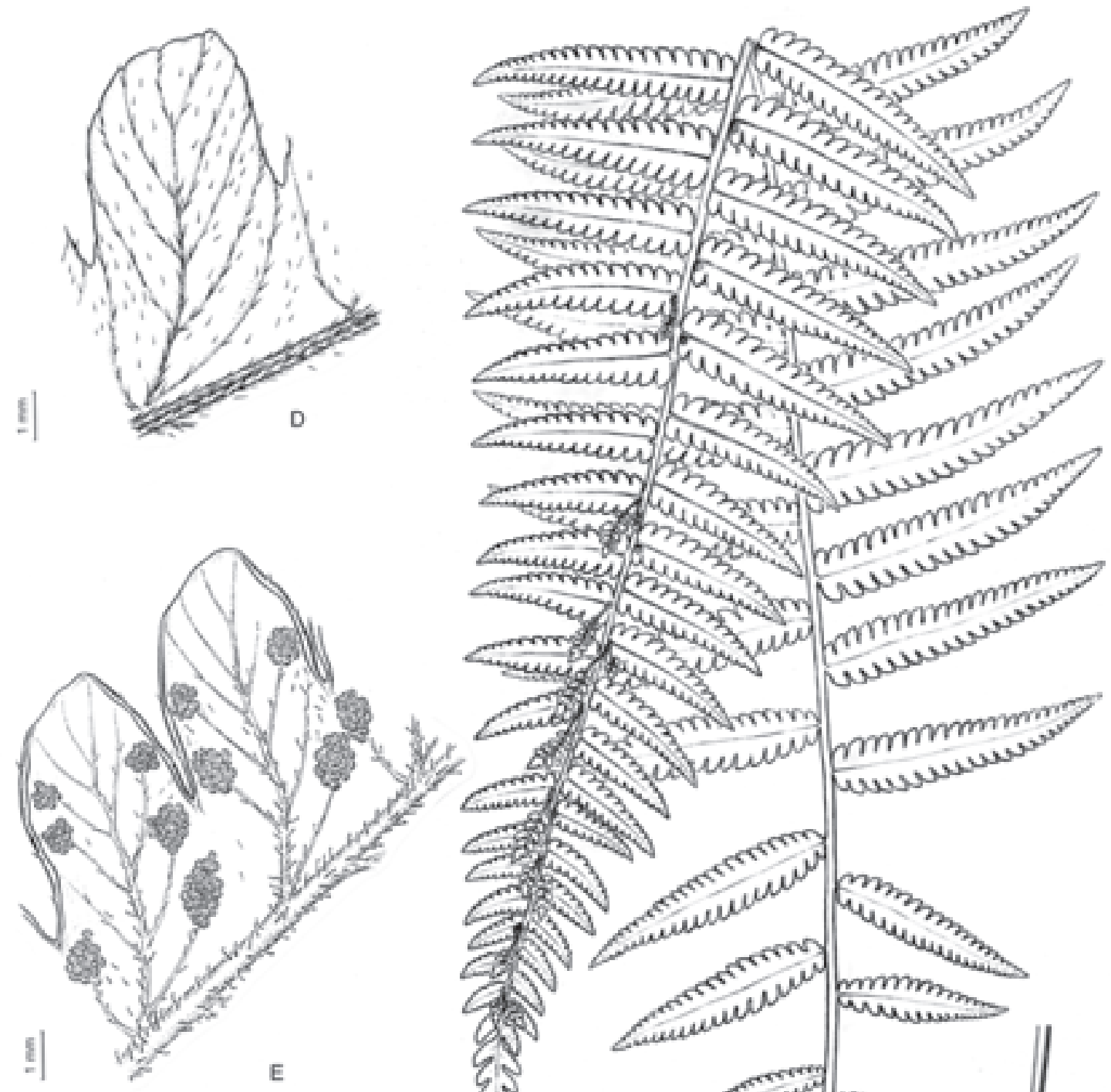
(m)
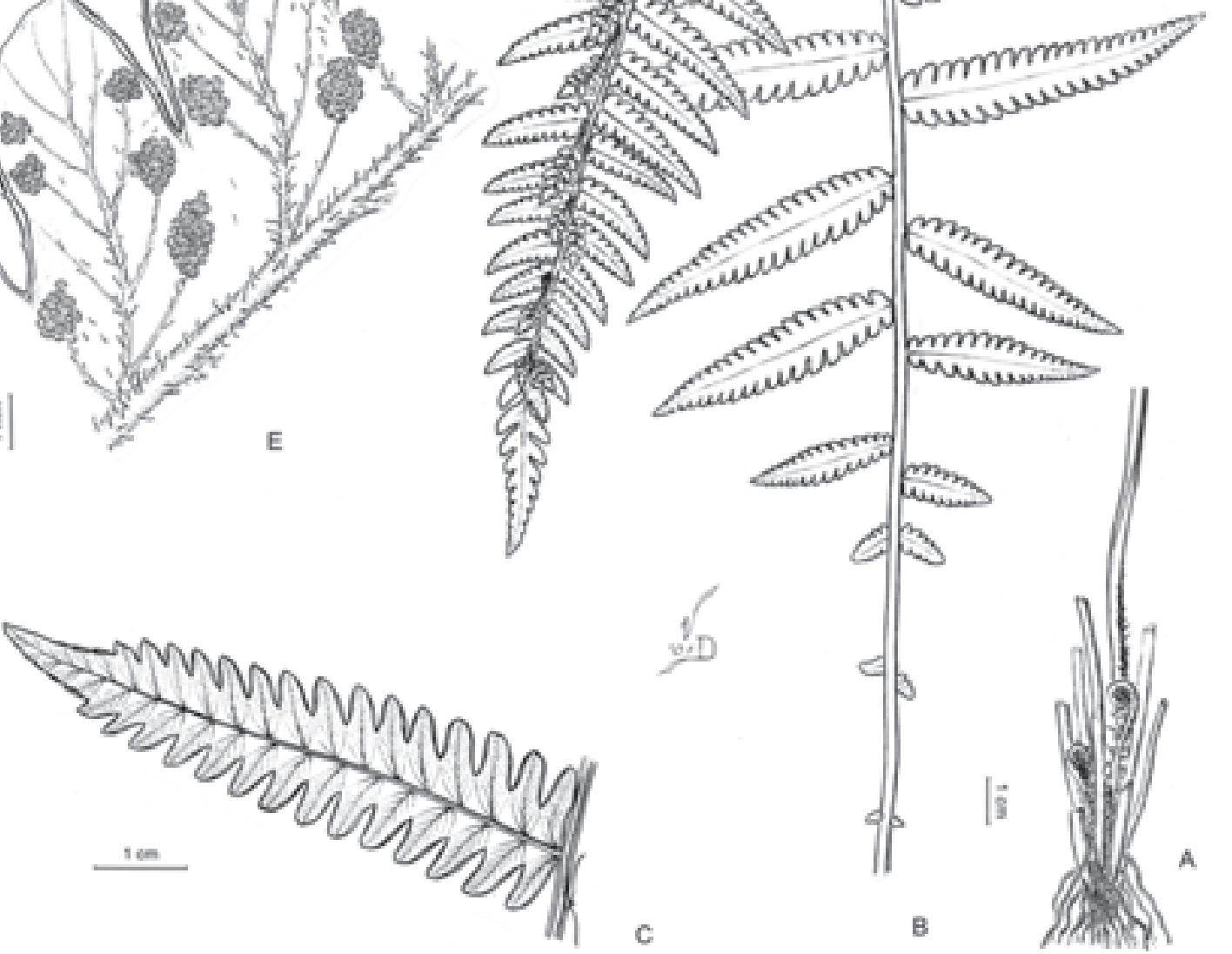

C
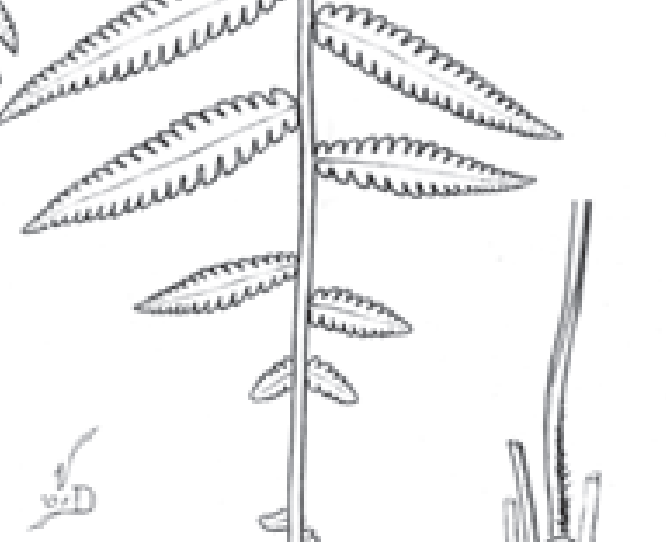

Figura 1. Thelypteris amambayensis. A. Rizoma. B. Lámina. C. pinna. D. Segmento cara adaxial. E. Segmentos cara abaxial (Schinini \& Bordas 20340). 
Distribución y ecología: Se encuentra en el centro y sudeste de Brasil, Paraguay, Bolivia, norte de Argentina y Uruguay. Este helecho vegeta en la orilla de cursos de agua en las selvas en galería.

Material examinado: PARAGUAY. CoRdILLERA: Curso sup. Río Y-acá, XI-1900, E. Hassler 6702 (G).

La densidad de los pelos aciculares, la presencia y coloración de los pelos glandulares y la forma "athyrioide" de sus indusios es muy variable.

5. Thelypteris gymnosora Ponce, nom. nov. para Gymnogramma asplenioides Sw., Vet. Akad. Hand1. 1817: 56, tab. 3, fig. 4. 1817, non Thelypteris asplenioides (Sw.) Proctor. Tipo: BRASIL, sin localidad, Freyreis s.n. (holotipo S, imagen vista).

Dryopteris ptarmica (Kunze ex Mett.) Kuntze f. asplenioides (Sw.) C. Chr., Kongel. Danske Vidensk. Selsk. Skr., Naturvidensk. Math. Afd., ser. 7, 4: 287. 1907. Thelypteris ptarmica (Kunze ex Mett.) C.F. Reed var. asplenioides (Sw.) Ponce, Darwiniana 33: 262. 1995.

Figura 2C

Descripción e iconografía: Ponce (1995: 262).

Distribución y ecología: Esta especie se encuentra desde el centro-este de Brasil hasta Santa Catarina. Es un helecho terrestre o epipétrico que crece en orillas o lechos de arroyos y ríos.

Materiales examinados: BRASIL. Minas Gerais: Ouro Preto, mata próxima à Passagem (camino para Mariana), 18-XII-1989, R. Simão-Bianchini 190 (SI). Mato Grosso: Chapada dos Guimarães, Véu da Noiva, 480 m, 16-II-1988, A. Salino 385 (SJRP).

Thelypteris gymnosora ha sido tratada como una variedad de T. ptarmica (Kunze ex Mett.) C.F. Reed pero posee suficientes diferencias como para ser considerada en el rango especie. Así en T. gymnosora los raquis son uncinulado-pilosos y los soros son mayormente elongados y desnudos, en T. ptarmica la pilosisdad es simple y los soros son cortamente elípticos con indusios espatulados. Ambas especies requieren condicionaes ambientales similares y son cercanas morfológica y ecológicamente a Thelypteris aspidioides.

6. Thelypteris heineri (C. Chr.) C.F. Reed, Phytologia 17: 282. 1969. Dryopteris heineri C. Chr., Repert. Spec. Nov. Regni Veg. 6: 380. 1909.

Descripción e iconografía: Ponce (1997: 278).
Distribución y ecología: Especie endémica, hasta ahora se la ha encontrado en los estados de Goiás, Minas Gerais y São Paulo. Habita en la región del cerrado, en sitios pantanosos en "capões" o en el interior de bosques semidecíduos o en galería ("ciliares")

Materiales examinados: BRASIL. GoIÁs: ca. $12 \mathrm{~km}$ Sa. do Ciapó, 840 m, gallery forest, 2-V-1973, Anderson $9639 a \& b$ (UC); Itajá-Povoado da Lagoa Santa, Córrego Coqueiro, 21-XII-1992, Rodríguez \& M.R. Pietrobom-Silva 406, 664 (SJRP); Marzagão, ca. $17^{\circ} 57^{\prime} \mathrm{S}, 48^{\circ} 37^{\prime} \mathrm{W}$, Rodovia GO-413, Caldas Novas-Marzagão, ca. $10 \mathrm{~km}$ de Marzagão, 2 km do Rio Bagé, 23-I-1996, M.R. Pietrobom-Silva 2657 (SI); Quirinópolis, ca. 18³0'S, 50³2'W, Rodovia G-206, Inaciolândia-Quirinópolis, 4 km de Quirinópolis, 24-I-1996, M.R. Pietrobom-Silva 2740 (SI). MINAS Gerais: Frutal, ca. $20^{\circ} 02^{\prime}$ S, $48^{\circ} 56^{\prime} \mathrm{W}$, região do Triângulo Mineiro, BR-153 Serra do Marimbondo, Fazenda Chapadão, ca. $22 \mathrm{~km}$ de Frutal, $650 \mathrm{~m}$, 22-I-1996, M.R. Pietrobom-Silva 2509 (SI).

Se caracteriza por ser un helecho de gran porte, de lámina abruptamente reducida en la base, raquis y costas con pelos setosos, presentes también en la lámina en forma esparcida, aeróforos pequeños y esporangios a menudo setosos.

7. Thelypteris metteniana Ching, Bull. Fan. Mem. Inst. Biol 10: 252. 1941.

Nephrodium palustre Mett. ex Baker, Syn. Fil. 270. 1827.

Descripción e iconografía: Ponce (1995: 278).

Distribución y ecología: Centro-sudeste y sur de Brasil, Argentina y Uruguay (Ponce 1987) muy probable en Paraguay. En bosques y bosques en galerías.

Material examinado: BRASIL. MinAS GERAIS: Caldas, 5-IX-1873?, C.W.H. Mosén 2151 (R).

8. Thelypteris mosenii (C. Chr.) C.F. Reed, Phytologia 17 (4): 294. 1968. Dryopteris mosenii C. Chr., Kongel. Danske Vidensk. Selsk. Skr., Naturvidensk. Math. Afd., ser. 7, 4: 300, fig. 27. 1907.

Dryopteris hassleri H. Christ, Bull. Herb. Boissier, sèr. 2, 7: 922.1907.

Dryopteris rojasii H. Christ, Repert. Spec. Nov. Regni Veg. 6: 349. 1909.

Figura 4 


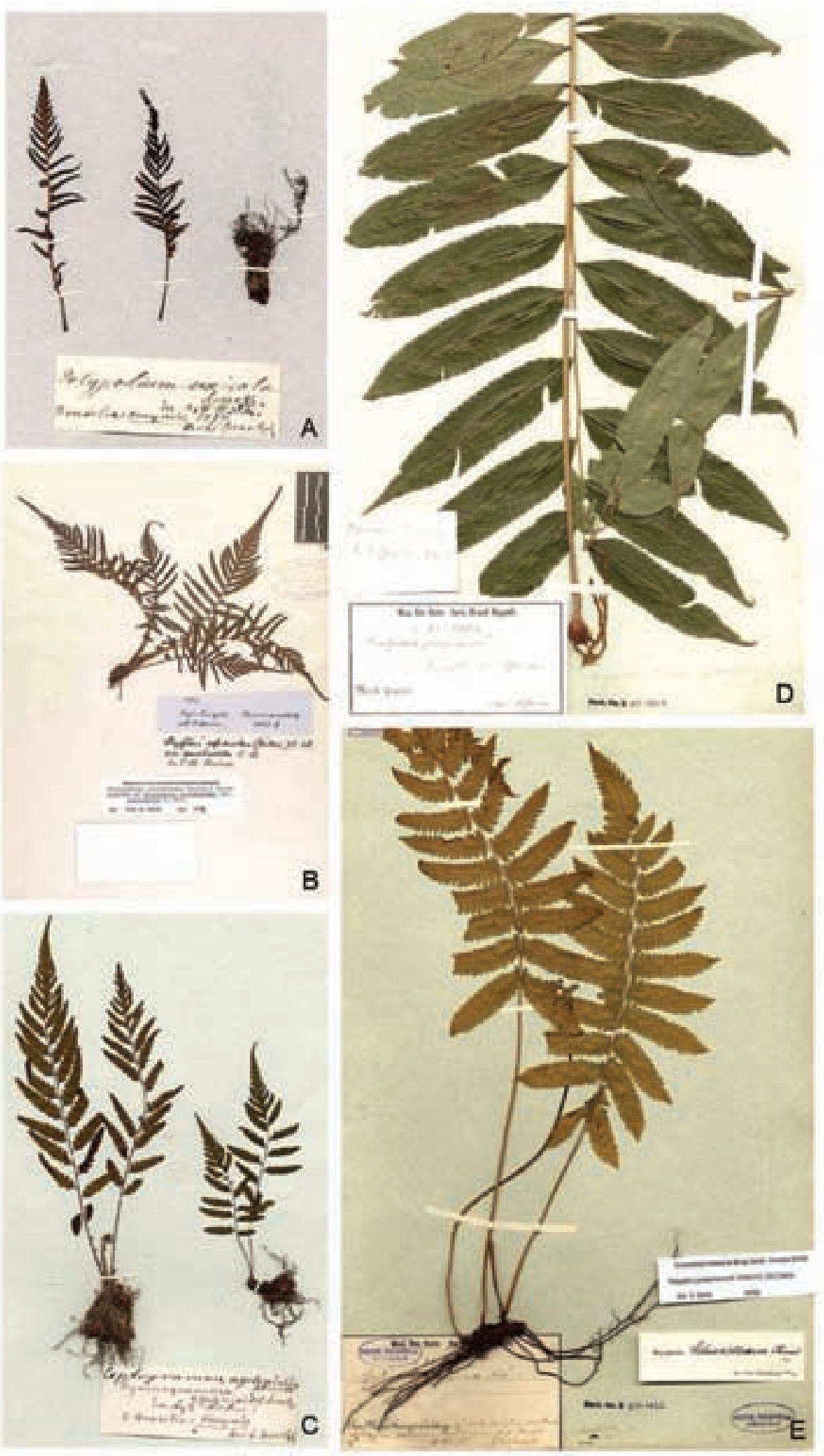

Figura 2. A. Polypodium saxicola Sw. (holototipo S). B. Dryopteris aspidiodes var. subhastata (isolectotipo NY), A y B = Thelypteris aspidioides. C. Gymnogramma asplenioides Sw. (holotipos). D. Goniopteris platypes Fée (isotipos). E. Thelypteris schwackeana (Mosén 4616, SI). 
Descripción e iconografía: Ponce (1998: 277)

Distribución y ecología: Especie endémica, crece en el este de Paraguay y centro y sudeste de Brasil. Habita en selvas en galería, cerrados y pastizales, en suelos pantanosos.

Materiales examinados: BRASIL. Minas Gerais: Uberlândia, Estação Ecológica de Panga, campo úmido, terrestre, s.d., M. Ranal 571 (HUFU, SI). Distrito Federal: Brasília, Bacia do Rio São Bartolomeu, local encharcado em pleno cerrado, "samambaia", 15 até $80 \mathrm{~cm}$ alt., 4-II-1981, E.P. Heringer et al. 6135 (MO). PARAGUAY. AMAMBAY: Sierra de Amambay, pr. Estrella, E. Hassler \& Rojas $10154 a$ (G, holotipo de Dryopteris rojasii H. Christ); Capiibary, 15-III-1951, Schwarz 12159 (LIL). Alto PARANÁ: Reserva Biológica Itabó, 35 km W Rio Paraná, $25^{\circ} 05^{\prime} \mathrm{S}, 54^{\circ} 05^{\prime} \mathrm{W}$, en pantano, 10-X-1990, A. Schinini \& G.C. Marmori 27098 (CTES, G). CaAguazú: In veciniis Caaguazú, 1905, E. Hassler $9056 a$ (BM isotipo de Dryopteris hassleri H. Christ).

Especie muy distintiva por su rizoma rastrero, negruzco, varias pinnas proximales abruptamente reducidas y pubescencia glanduloso-pilosa, blanquecina.

9. Thelypteris neglecta (Brade \& Rosenst.) Ching, Bull. Fan Mem. Inst. Biol. Bot. Ser. 10: 253. 1941. Dryopteris neglecta Brade \& Rosenst., Bol. Mus. Nac. Rio de Janeiro 7: 142, tab. 1, fig. III, tab. 7. 1931. Lastrea neglecta (Brade \& Rosenst.) Brade, Bradea 1: 222. 1972. Tipo: BRASIL. Rio DE JANEIRO: Teresópolis, Soberbo, 28-IX-1929, A.C. Brade 9492 (holotipo R!; isotipo HB!).

\section{Figura 5}

Descripción e iconografía: Brade \& Rosenstock (1931: 142).

Distribución y ecología: Especie endémica del centrosudeste de Brasil, en bosques montanos.

Material examinado: BRASIL. MinAs GeraIs: Alto Caparaó, Parque Nacional do Caparaó, Vale Verde, ca. $1.400 \mathrm{~m}$, terrestre, a margem de rio, 29-IX-1995, A. Salino 2289 (BHCB, SI).

Esta rara especie se caracteriza por el rizoma erecto, escamas castañas, pilosas, presentes también en las partes basal y media del pecíolo; pecíolo pajizo; lámina subabruptamente reducida, pinnas remotas arqueadas; raquis y cara abaxial de la lámina con diminutos pelos capitados, hialinos, presentes también en el margen del indusio.

Thelypteris neglecta se conocía sólo para la localidad del Tipo y aquí se la cita por primera vez para otra región, el material de Minas Gerais varía de aquel en que presenta pelos aciculares, pluricelulares en el pecíolo y raquis. Sin embargo la presencia o ausencia de pelos de cualquier tipo no es por sí solo un caracter determinante en las de especies Thelypteris.

10. Thelypteris oligocarpa (Humb. \& Bonpl. ex Willd.) Ching var. crassistipitata (Hieron.) C.F. Reed, Phytologia 17: 298. 1969. Aspidium oligocarpum Humb. \& Bonpl. ex Willd. var. crassistipitatum Hieron., Bot. Jahrb. Syst. 22: 367. 1897.

Descripción e iconografía: de la Sota (1977: 208); Ponce (1988: 325).

Distribución y ecología: Esta variedad conocida para las selvas subtropicales del noroeste de Argentina, se encuentra también en Brasil central y sudeste, en las selvas y bosques en galería. Su presencia en Bolivia es probable.

Materiales examinados: BRASIL. GoIÁs: Aporé, Rodovia 184 Aporé-Serranópolis, ca. 58 km de Aporé, $19^{\circ} 03^{\prime} \mathrm{S}, 52^{\circ} 01^{\prime} \mathrm{W}, 620 \mathrm{~m}$, Fazenda da Cachoeira do Corrente (Antigo Cemitério de Escravos), 10-VI-1993, M.R. Pietrabom-Silva 870 (SJRP); AporéSerranópolis, ca. $19^{\circ} 57^{\prime} \mathrm{S}, 52^{\circ} 01^{\prime} \mathrm{W}$, ca. $70 \mathrm{~km}$ de Aporé, ca. 700 m, Rio Correntes, 2-VIII-1995, M.R. Pietrobom-Silva et al. 2372 (SI).

Se diferencia de la variedad típica por su pecíolo castaño-verdoso, 3-4(6) mm diam., sus frondes de 80-150 cm long., la consistencia de la lámina herbácea, segmentos con margen crenado y las venas oscurecidas.

11. Thelypteris opposita (Vahl) Ching, Bull. Fan Mem. Inst. Biol. 10: 251. 1941. Polypodium oppositum Vahl, Eclog. Amer. 3: 53. 1807.

Figura 3

Descripción e iconografía: Smith (1992: 32); Ponce (1995: 274).

Distribución y ecología: Es una especie ampliamente distribuida, desde Antillas Mayores hasta Bolivia y centro-oeste y sur de Brasil (hasta Santa Catarina) y Paraguay. Helecho terrestre, común en campos pedregosos, en la selva primaria o en galería. También se lo encuentra en sitios encharcados, pantanos, orillas de arroyos o en barrancos del camino o vías férreas. 


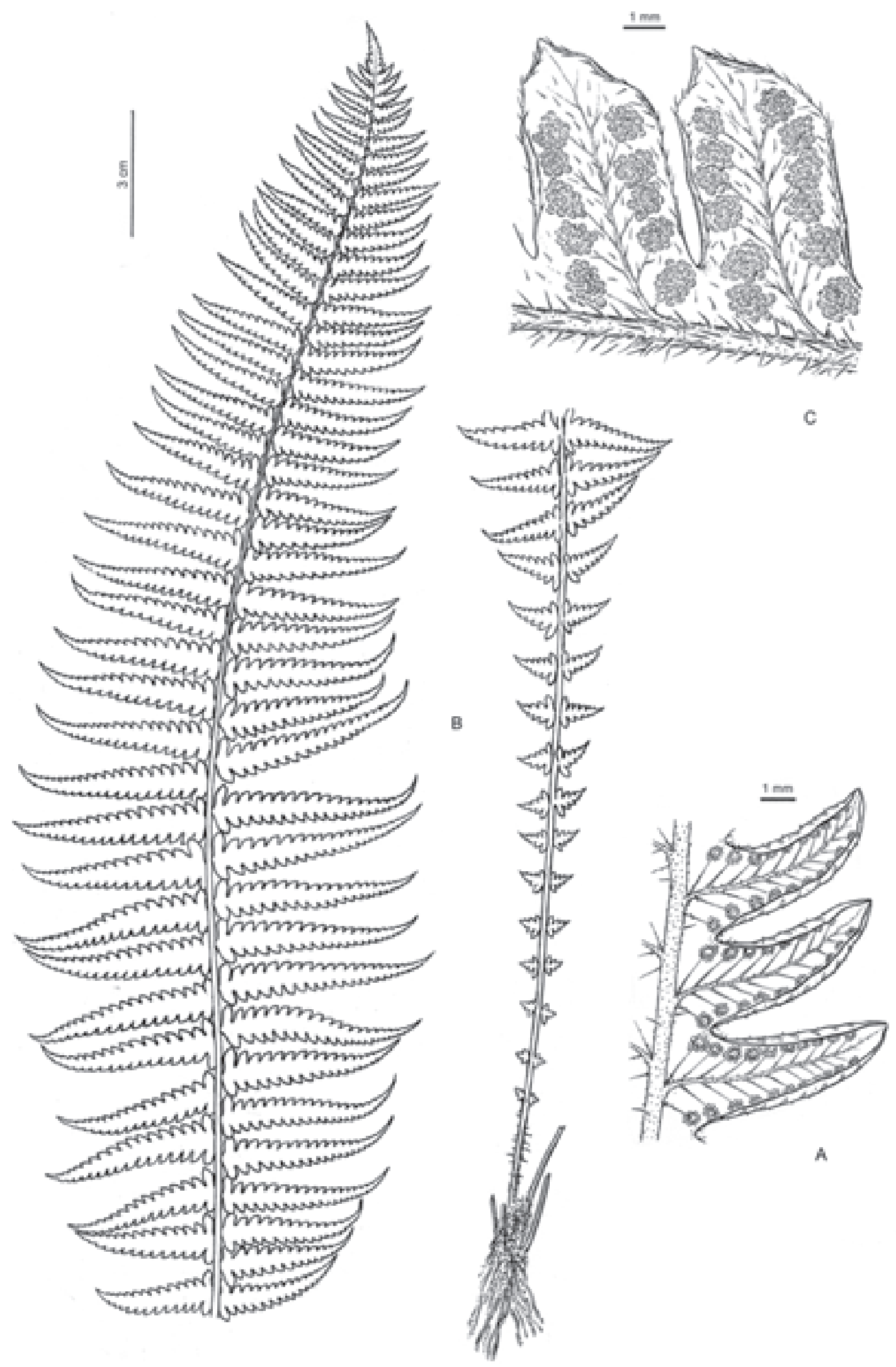

Figura 3A-C. A. Thelypteris cheilanthoides, segmentos cara abaxial (Hatschbach 8095). B-C. T. opposita, aspecto general. C. Segmentos cara abaxial (P.G. Windisch 8339). 


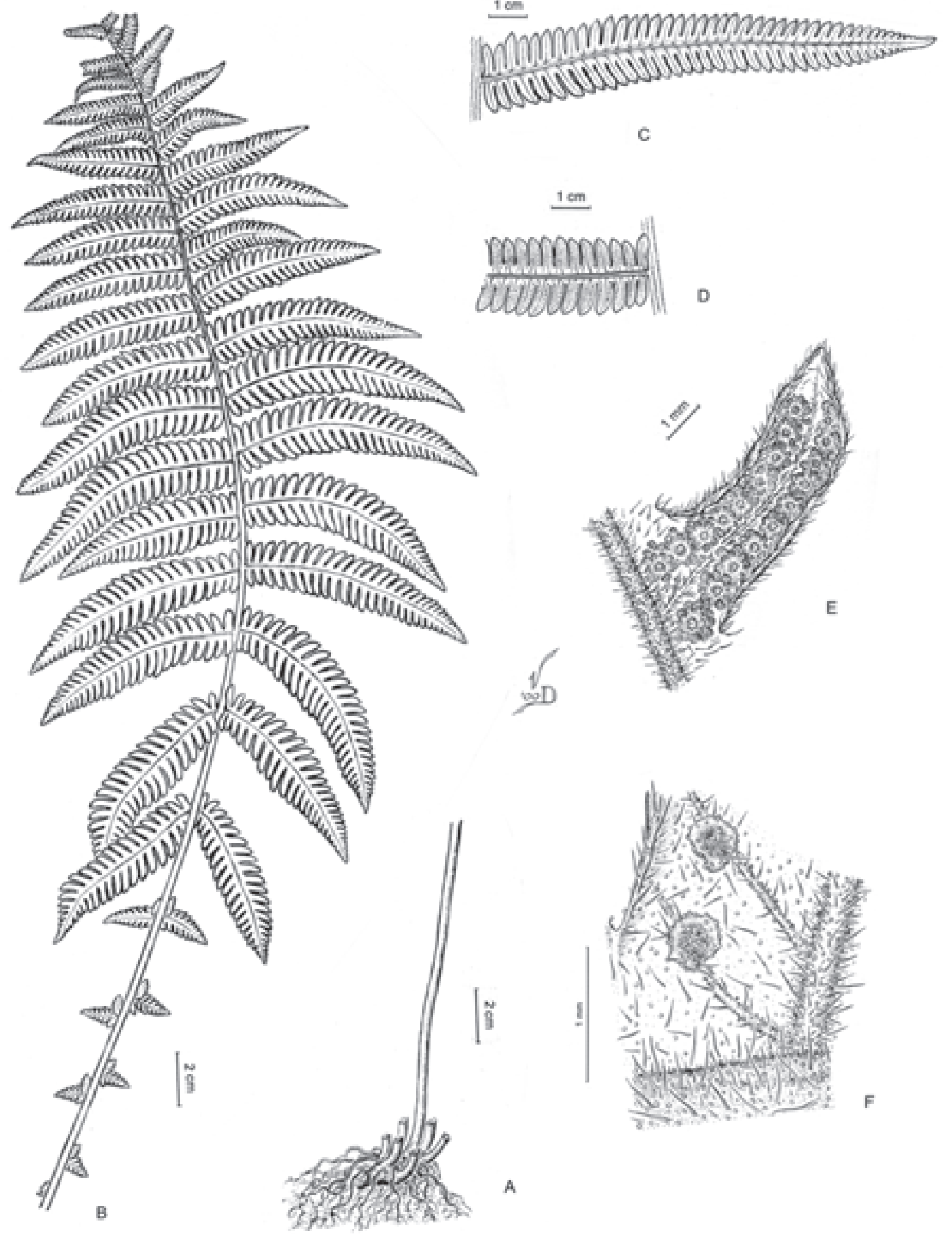

Figura 4A-F. Thelypteris mosenii. A. Rizoma. B. Lámina. C. Pinna media. D. Pinna basal. E-F. Segmento y detalle cara abaxial (Hassler 10154). 


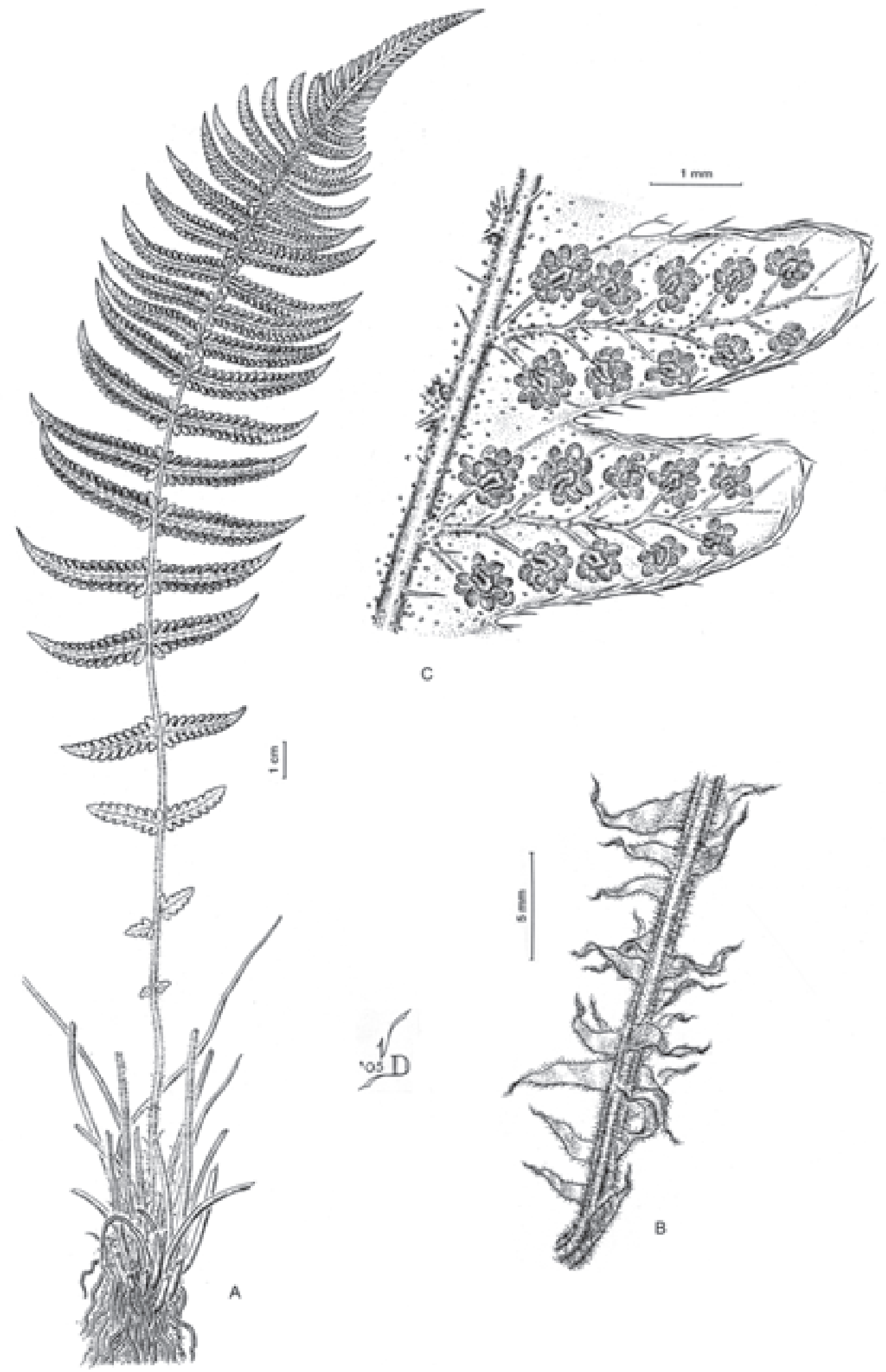

Figura 5A-C. Thelypteris neglecta. A. Aspecto general. B. Base del pecíolo. C. Segmentos cara abaxial (Salino 2289). 
Materiales examinados: BRASIL. GoiÁs: Chapada dos Veadeiros, ca. $8 \mathrm{~km} \mathrm{~S}$ of Cavalcante, $1.000 \mathrm{~m}$, 10-III-1969, H.S. Irwin et al. 24200 (MO); Serra Dourada, ca. $30 \mathrm{~km}$ SE of Goiás Velho, $14^{\circ} \mathrm{S}, 50^{\circ} \mathrm{W}$, $650 \mathrm{~m}$, lower slopes of Serra Dourada, 21-I-1966, H.S. Irwin et al. 11942 (MO); Marzagao, ca. 17²57'S, $48^{\circ} 37^{\prime} \mathrm{W}$, Rodovia GO-53, Marzagão-Água Limpa, ca. 9 km de Marzagão, região de cerrado com mata ciliar em vale entre morros, 24-I-1996, M.R. PietrobomSilva 2685 (SI); Aporé, ca. 1957'S, 5201'W, Rodovia Aporé-Serranópolis, ca. $23 \mathrm{~km}$ de Aporé, $580 \mathrm{~m}$, 1-VIII-1995, M.R. Pietrobom-Silva et al. 2292 (MBM, SI); Ipameri, $17^{\circ} 43^{\prime} \mathrm{S}, 48^{\circ} 08^{\prime} \mathrm{W}$, ca. $700 \mathrm{~m}$, Rodovia GO-213, Ipameri-Caldas Novas, 23-I-1996, M.R. Pietrobom-Silva 2619 (MBM). Minas Gerais: Juiz de Fora - São Pedro, 90 m encosta pedregosa, úmido frequente 5-IV -1984, R.N. Camargo \& Krieger 20676 (SJRP); Viçosa, Agricultural College land. Flood plain behind Director's house, $660 \mathrm{~m}$, 11-III-1930, Y. Mexia 4454 (MO), idem, 9-VII-1930, Y. Mexia 4852 (MO); idem, 21-VII-1930, Y. Mexia 4885 (MO). Mato Grosso: ca. $78 \mathrm{~km} \mathrm{~S}$ of Xavantina, 500 m, 16-VI-1966, H.S. Irwin et al. 17281 (MO); Nortelândia, P.G. Windisch 8339 (SI). Mato Grosso DO Sul: Selvíria, Estrada Selvíria-São Pedro, ca. 41 km; $300 \mathrm{~m} \mathrm{20} 23^{\prime} \mathrm{S}, 5^{\circ} 25^{\prime} \mathrm{W}, 11-\mathrm{XI}-1995$, M. Lucca Júnior et al. 84 (SI). PARAGUAY. AMAMBAY: Parque Nacional Cerro Corá, 2239'S, 56 03'W, 300 m, Arroyo Aquidaban Nigui, 13-II-1982, J. Solomon et al. 6908 (MO, PY). CANINDEYÚ: Carapá, en arroyito en bosque ribereño, 6-X-1997, M. Peña-Chocarro 296 (CTES).

Se puede confundir con Thelypteris pachyrhachis var. pachyrhachis, taxón que se diferencia de $T$. opposita por presentar escamitas sobre las costas abaxiales, aeróforos medianos y la cara abaxial glabra o sólo con glandulas sésiles.

12. Thelypteris pachyrhachis (Kunze ex Mett.) Ching var. pachyrhachis, Bull. Fan Mem. Inst. Biol.10: 253. 1941. Aspidium pachyrhachis Kunze ex Mett., Abh. Senckenberg. Naturf. Ges. 2: 367. 1858.

Dryopteris riopardensis Rosenst., Hedwigia 46: 121. 1906.

Dryopteris opposita (Vahl) Ching f. major Rosenst., Hedwigia 46: 120. 1906.

Descripción e iconografía: Smith (1992: 31); Ponce (1988: 279).

Distribución y ecología: Antillas Mayores y Menores, Colombia, Venezuela, Bolivia hasta el centro-E y S de
Brasil, Paraguay y NW de Argentina. Crece en barrancas, a lo largo de caminos y picadas, en "capoeiras" y bosques primarios.

Materiales examinados: BRASIL. MinAs GERAIS: Viçosa Agricultural College lands, Corrigo Riberro, 675 m, 19-VII-1930, Y. Mexia 4875 (MO); Viçosa Agricultural College, Corrigo Riberro, $675 \mathrm{~m}$, 22-VII-1930, Y. Mexia 4894 (MO); Viçosa, road to São Miguel, about km 3, 685 m, 18-III-1930, Y. Mexia $4478 b$ (MO). PARAGUAY. Amambay: Sierra de Amambay, Punta Pará, 1907-1908, E. Hassler \& T. Rojas 10411 (BM, G); Sierra de Amambay, Cerro Tovúi, Río Araguay-guazú, VIII-1921, Rojas 3895 (BM); Cordillera de Altos, 1885-1895, E. Hassler 661 (G). CAnindeyú: Reserva N at. Bosque Mbaracayú, Carapa, sendero Uruí después del Ycuá Sarakí, 14-IX-1996, G. Marín \& B. Jiménez 349 (CTES); transición, suelo húmedo, 7-X-1991, G.C. Marmori 2540 (CTES); en arroyito camino a Carapá, 6-X-1997, M. Peña-Chocarro 296 (BM).

Thelypteris pachyrhachis es un especie de amplia distribución geográfica, con otras dos restringidas variedades de los Andes tropicales, var. bogotensis (C. Chr.) Alston y var. sprucei (Baker) A.R. Sm. En consecuencia la var. pachyrhachis es la que presenta la variabilidad morfológica más importante.

13. Thelypteris raddii (Rosenst.) Ponce, Darwiniana 33: 266. 1995. Polypodium pubescens Raddi, Pl. Bras. 1: 23 t. 34. 1825, non L. 1759. Dryopteris raddii Rosenst., Hedwigia 56: 367. 1915.

Thelypteris minensis Abbiatti, Darwiniana 13: 563, fig. 8, tab. 6. 1964. Tipo: BRASIL. MinAs GERAIS: São Thomaz de Aquino, Fazenda Fortaleza do Dr. Luiz Pimenta Neves, 14-XII-1944, Irmão Teodoro 1 A-908 (holotipo LP!), syn. nov.

Descripción e iconografía: Ponce (1995: 266). Distribución y ecología: Se distribuye ampliamente desde el centro-sudeste hasta el sur de Brasil. Es un helecho terrestre, frecuente en barrancos al lado de caminos o lo largo de picadas en selvas y bosques en galería.

Materiales examinados: BRASIL. MinAs GerAIs: Alto Caparaó, descida para o Vale Verde, $1.600 \mathrm{~m}$, 29-IX-1995, A. Salino 2268 (SI); Serra da Moeda, na estrada vicinal que liga o Município de Moeda, BR-040, 12-IV-1996, A. Salino 2727 (SI).

Esta especie es muy cercana a Thelypteris oligocarpa, de la que se diferencia por su rizoma 
suberecto a rastrero, por la mayor longitud y alta densidad del indumento foliar uncinulado y por la posición submediana de los soros.

14. Thelypteris recumbens (Rosenst.) C.F. Reed, Phytologia 17: 308. 1968. Dryopteris recumbens Rosenst., Hedwigia 46: 123. 1906.

Figura 6

Descripción e iconografía: Ponce (1995: 264).

Distribución y ecología: Se encuentra en el sur de Brasil, Paraguay y NE de Argentina. Terrestre, en selvas y bosques de araucaria, cercano a los cursos de agua o sitios inundados. Elemento característico del bosque paranaense, no se ha hallado en Brasil central.

Material estudiado: PARAGUAY. Alto Paraná: Reserva Biológica Itabó, $35 \mathrm{~km} \mathrm{~W}$, Rio Paraná, $25^{\circ} 05^{\prime} \mathrm{S}, 5^{\circ} 05^{\prime} \mathrm{W}, 10-\mathrm{X}-1990$, A. Schinini \& G. Caballero Marmori 27046 (CTES, G); 20-X-1990, A. Schinini \& G.C. Marmori s.n. (CTES).

Esta especie se distingue por la presencia de yemas en el raquis, pilosidad cortamente uncinulada en los ejes, e indusios reniformes uncino-pilosos y a diferencia de otras especies de la sección Uncinella A.R. Sm. por su rizoma suberecto a rastrero.

15. Thelypteris regnelliana (C. Chr.) Ponce, Darwiniana 33: 264. 1995. Dryopteris regnelliana C. Chr., Kongel. Danske Vidensk. Selsk. Skr., Naturvidensk. Math. Afd., ser. 7, 4: 284, fig. 12. 1907.

Descripción e iconografía: Ponce (1995: 264).

Distribución y ecología: Su área abarca el centrosudeste y sur de Brasil, y nordeste de Argentina. Es una especie terrestre que vegeta a lo largo de caminos o picadas en bosques húmedos o mesofíticos, en suelos húmedos y pantanosos.

Materiales estudiados: BRASIL. Minas Gerais: Caldas, 30-X-1873, C.W.H. Mosén 2167 (Lectotipo S); idem, A.F. Regnell III.1446a (S); id., C.W.H. Mosén 2165 (S).

Thelypteris regnelliana se distingue por la pubescencia de sus frondes totalmente uncinuladopilosas, excepto en la cara adaxial de los segmentos, con pelos antrorso-setosos y en los indusios setosos. Es afín a $T$. raddii, que difiere principalmente en que no presenta pelos uncinulados en los pecíolos, raquis y costas. También se acerca a $T$. recumbens, pero en esta especie la longitud de los pelos uncinulados es mucho más corta, presenta yemas foliares e indusios reniformes, uncinulado-pilosos.

16. Thelypteris retusa (Sw.) C.F. Reed, Phytologia 17: 309. 1968. Polypodium retusum Sw., Kongl. Vetensk. Acad. Handl. 1817(1): 61.1817.

Descripción e iconografía: Ponce (1995: 272).

Distribución y ecología: Esta entidad se encuentra en el sudeste y sur de Brasil, es un helecho terrestre que crece tanto en la "mata atlántica" como en bosques semidecíduos o en el interior de "capoeiras".

Materiales estudiados: BRASIL. MinAs GeRAIS: Serra da Moeda, estrada que liga BR-040 a Moeda, próximo a Belo Horizonte, terrestre, beira de riacho, no interior de mata ciliar, 7-VI-1995, A. Salino 2108 (UC); idem, 8-XI-1995, A. Salino 2256 (SI).

Esta especie puede confundirse con Thelypteris araucariensis Ponce, la que se diferencia porque posee yemas foliares, rizomas decumbentes o rastreros y pinnas proximales de menor tamaño y no reflexas.

17. Thelypteris rioverdensis (C. Chr.) Ponce, Novon 8: 277. 1998. Dryopteris rioverdensis C. Chr., Kongel. Danske Vidensk. Selsk. Skr., Naturvidensk. Math. Afd., ser. 7, 4: 284, fig. 12. 1907. Lastrea rioverdensis (C. Chr.) Brade, Bradea 1: 223. 1972.

Descripción e iconografía: Ponce (1998: 277).

Distribución y ecología: Especie de Brasil central, presente en Bolivia. En orillas y lechos pedregosos de arroyos en bosques.

Materiales estudiados: BRASIL. Minas Gerais: Caldas, "In ripa ammis Rio Verde ad rupes umbrosas", 15-X-1873, C.W.H. Mosén 2171 (holotipo S); Nova Lima, corrégo do Capitão do Mato Bacia, 24-IX-1995, A. Salino 2235 (SI).

Se caracteriza por una pilosidad uncinulada muy corta y uniforme y por los indusios reniformes con diminutas glándulas marginales.

18. Thelypteris rivularioides (Fée) Abbiatti, Revista Mus. La Plata, Secc. Bot. 9: 19. 1958. Aspidium rivularioides Fée, Crypt. vasc. Brés. 1: 145, tab. 50, fig.1. 1869.

Dryopteris sinuata Sehnem in Reitz, Fl. Ilustrada Catarinense I, ASPI: 242. 1979.

Figura 7A-C 


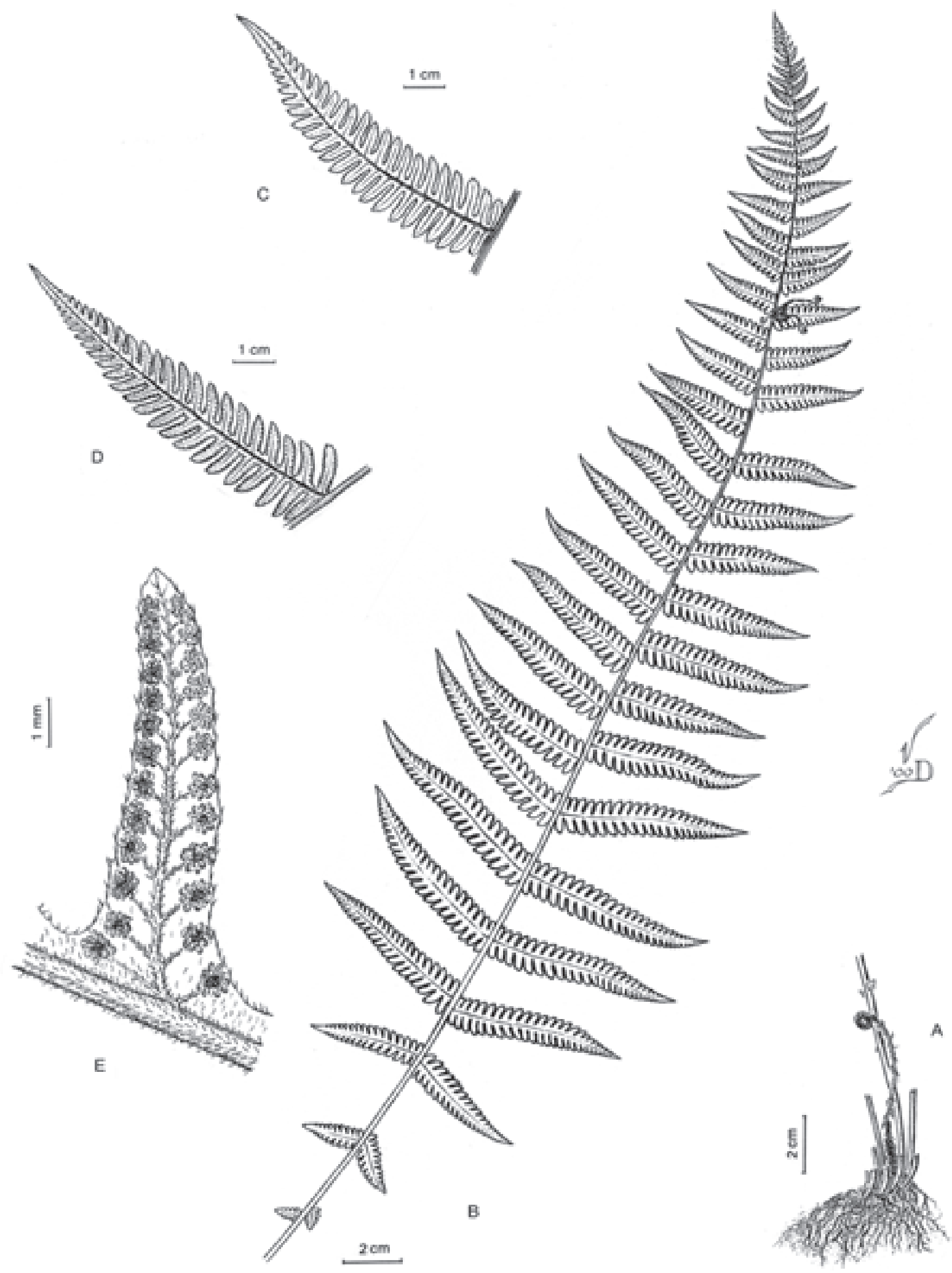

Figura 6A-E. Thelypteris recumbens. A. Rizoma. B. Lámina. C. Pinna basal. D. Pinna media. E. Segmento cara abaxial (Schinini \& Marmori s.n.). 
Descripción e iconografía: Ponce (1995: 267).

Distribución y ecología: Se distribuye desde el centrosudeste y sur de Brasil hasta Paraguay, Argentina y Uruguay (Ponce 1988). Es un helecho terrestre y palustre que crece en márgenes de arroyos, lagunas y suelos pantanosos, en formaciones vegetales primarias, y también en "capoeiras".

Materiales estudiados: BRASIL. Minas Gerais: Santana do Riacho, Serra do Cipó, km 126 antiga da Rodovia Belo Horizonte-Conceição, 9-III-1989, R.F. Novelino 617 (SI); Serra do Cipó, Campo, junto a riacho, no campo, 7-12-1992, A. Salino 1544 (UC); at intersection of highways 383 and $135 \mathrm{ca} .20 \mathrm{~km} \mathrm{~N}$ of Lafaiete, 870 m, 28-II-1976, G. Davidse \& T.P. Ramamoorthy 10777 (MO). Distrito Federal: Brasília, Jardim Zoológico, 975 m, 18-V-1966, H.S. Irwin et al. 15894 (MO). PARAGUAY. AMAMBAY: San Luis, 4-IV-1951, Schwarz 12275, 12277 (LIL); Sierra de Amambay, in altaplanitie et declivibus, 1907/1908, E. Hassler \& T. Rojas 10307 (BM, LIL). CANINDEYÚ: Ballinoti-cue, pastizal sobre suelo saturado, 11-X-1997, M. Peña-Chocarro 335 (BM); Jejui-mí, pastizal después del bosque de Puente Corona, 29-VI-1996, G. Marín \& B. Jiménez 277 (CTES); Paraguaria centralis, 1885/1895, E. Hassler 1830 (BM). Cordillera: San Bernardino, esteros, II-1916, T. Rojas 1630 (LIL); Valenzuela, 16-XII-1950, $B$. Sparre \& F. Vervoorst 973 (BM, LIL); Tobatí, "Ybytú Silla”, 2512'S, 5707'W, 297 m, 23-II-1991, E.E. Zardini \& Velázquez 26629 (MO, UC). CAAGUazú: 1905, E. Hassler 9042 (BM, LIL, MO, UC); L'Assomption, dans les forets, IV-1876, Balansa 318 (BM); Yhú, 24-I-1951, B. Sparre \& F. Vervoorst 2053, 2144 (BM, LIL). CAAZAPÁ: Tavaí, bog 1 km N of Hospital, $26^{\circ} 10^{\prime} \mathrm{S}, 55^{\circ} 27^{\prime} \mathrm{W}, 250 \mathrm{~m}, 28-\mathrm{X}-1988$, E.E. Zardini 7674 (FCQ, MO, UC); estero a la entrada del pueblo, $26^{\circ} 10^{\prime} \mathrm{S}, 5^{\circ} 20^{\prime} \mathrm{W}, 20-\mathrm{XII}-1988$, F. Mereles 2343 (G, MO). Alto PARANÁ: Reserva Biológica ItaibúItabó, 9-IV-1991, G.C. Marmori s.n. (CTES); Reserva Tati Yupi, 4-5 km NE de Hernandarias, $24^{\circ} 22^{\prime} \mathrm{S}$, $54^{\circ} 35^{\prime} \mathrm{W}$, A. Schinini \& G.C. Marmoni 26956 (CTES). Paraguarí. $15 \mathrm{~km}$ de Paraguarí, 1-X-1967, A. Krapovickas \& C. Cristóbal 13456 (CTES); Parque Nac. Ybycu'í, $5 \mathrm{~km}$ N of administración, Mina Basin, 260'ㅇ, 56 50'W, 18-III-1989, E.E. Zardini 12638 (G, MO, PY). Misiones. Santiago, Estancia La Soledad, 24-XII-1965, T.M. Pedersen 7647 (MO).

Los caracteres cuantitativos de esta especie presentan un amplio rango de variación y el indumento se encuentra en diferentes combinaciones de tipos de pelos.

19. Thelypteris stierii (Rosenst.) C.F. Reed, Phytologia 17(4): 316. 1968. Gymnogramma stierii Rosenst., Festschr. A. v. Bamberg: 64. 1905. Figura 7D-E

Descripción e iconografía: Ponce (1995: 272).

Distribución y ecología: Se encuentra en Brasil, Paraguay, Argentina y Uruguay. En cerrado con bosque xerófilo semidecíduo o bosques pantanoso o ciliares. Es un helecho terrestre y epilítico que habita en las orillas y lechos de arroyos pedregosos y cascadas en selvas.

Materiales estudiados: BRASIL. MinAS GERAIS: Frutal, região do triângulo Mineiro, ca. 22 km de Frutal, BR-153, Sa. do Marimbondo 2002'S, 4856'W, 650 m, 22-I-1996, M.R. Pietrobom-Silva 2498 (SI); Gurinhata, região do Triângulo Mineiro, Rodovia BR-364, S. do Lajeado, $19^{\circ} 12^{\prime} \mathrm{S}, 49^{\circ} 47^{\prime} \mathrm{W}$, ca. $620 \mathrm{~m}$, 25-II-1996, M.R. Pietrobom-Silva 2787 (SI). PARAGUAY. CONCEPCIÓN: "In regione calcarea cursus superioris fluminis Apa”, III-1912, E. Hassler \& Rojas 11071 (G).

Para Paraguay fue citada como Dryopteris melanopus Rosenst. nom. nud. (Hassler 1928). Se trata de la misma especie, con la particularidad de presentar glándulas amarillo-resinosas. Es común en materiales de Paraguay y de Brasil la presencia de esas glándulas en la cara abaxial, este caracter no se ha encontrado en especímenes de Argentina, sur de Brasil y Uruguay. No se considera una diferencia significativa, ya que este tipo de glándulas se encuentran también en materiales de la especie muy cercana Thelypteris concinna (Willd.) Ching, y es común su presencia en otras entidades del grupo, como T. loretensis A.R. Sm.

Como se ha dicho Thelypetris stierii se relaciona estrechamente con T. concinna (Willd.) Ching, que también presenta esporangios pilosos en la cápsula. Esta última especie se distingue por el color castaño oscuro a violáceo y el mayor diámetro de los pecíolos, y las dimensiones de la hoja en general mayores.

Especies citadas - Thelypteris araucariensis Ponce fue citada para Minas Gerais (A. Salino 6922, BHCB) por Salino \& Semir (2004), aunque no se ha visto el material se considera que la determinación sería correcta. Sin embargo no se podría asegurar la identificación y presencia de $T$. concinna en Brasil 

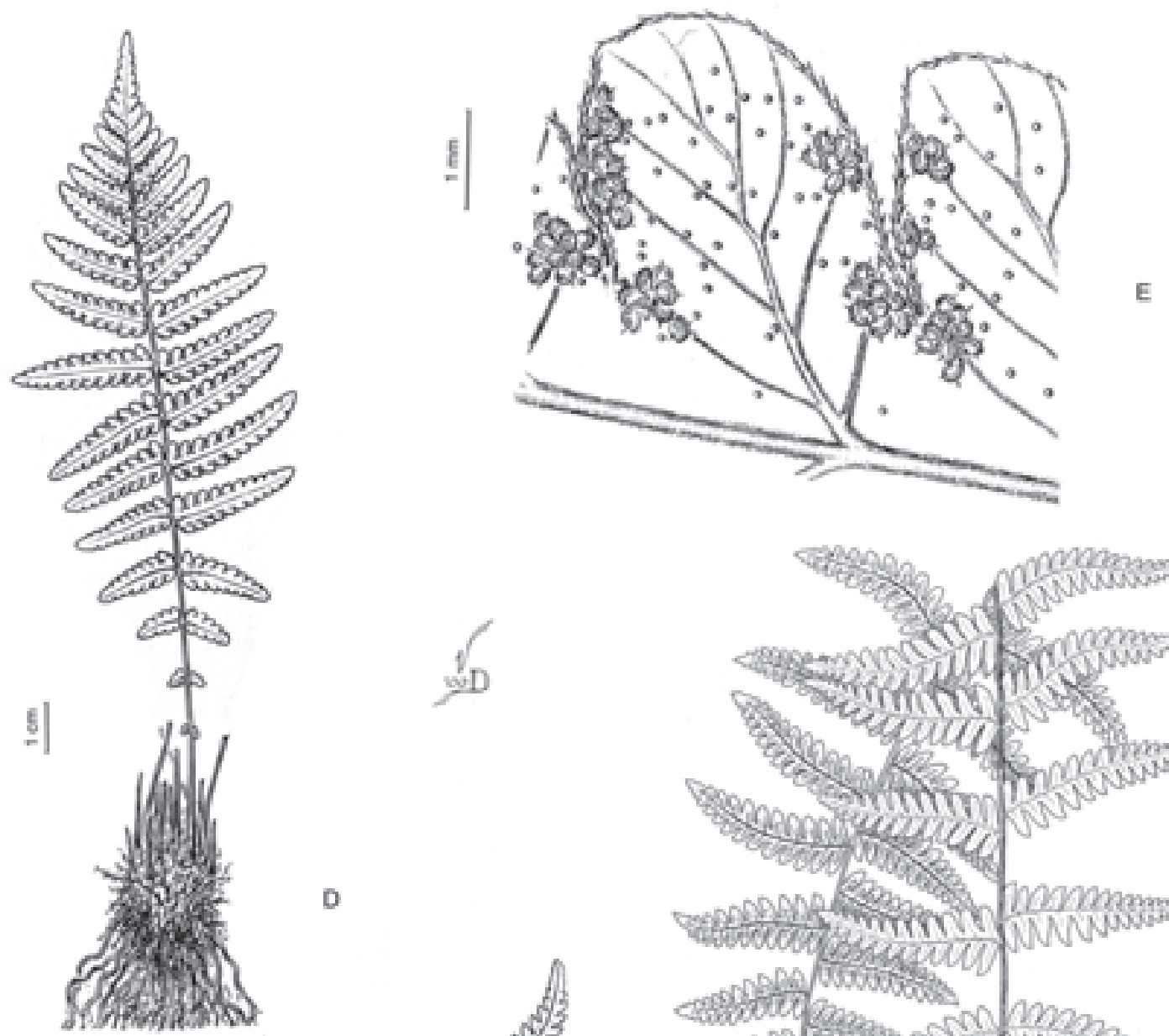

D

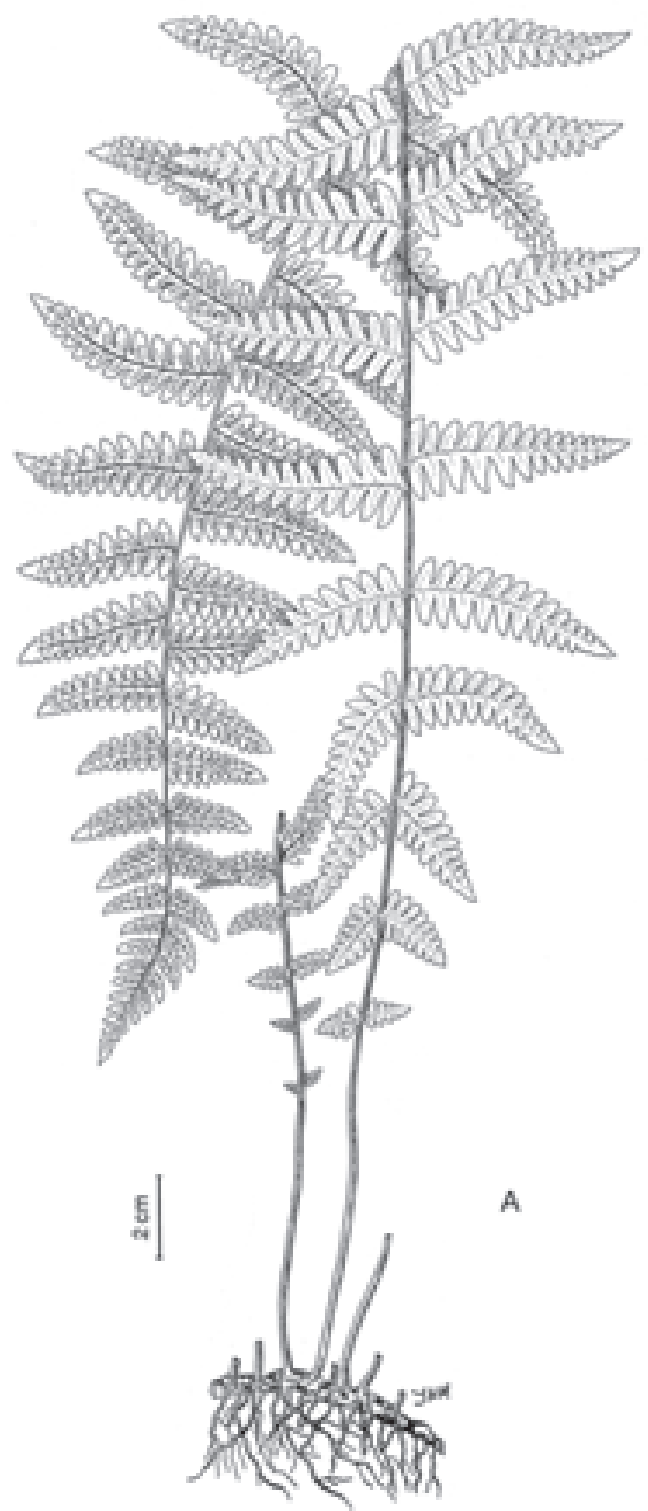

Figura 7A-C. Thelypteris rivularioides. A. Aspecto general. B. Pinna. C. Segmento cara abaxial. [adaptado de de la Sota (1977)]. D-E. T. stierii. D. Aspecto general. E. Segmento cara abaxial (Hassler \& Rojas 11071). 
(Salino \& Semir 2004), ya que esta es una especie andina.

\section{Thelypteris subg. Cyclosorus (Link) C.V. Morton}

Subgénero pantropical, se hallan presentes en el área 10 especies, cuatro de ellas de distribución restrigida al sur de Sudamérica.

20. Thelypteris berroi (C. Chr.) C.F. Reed, Phytologia 17: 263. 1968. Dryopteris berroi C. Chr., Kongel. Danske Vidensk. Selsk. Skr. Naturvidensk. Math. Afd., ser. 7, 10: 185. 1913.

Figura 8A-C

Descripción e iconografía: Smith (1971: 93); Ponce (1988: 364).

Distribución y ecología: Especie del Paraguay, sur de Brasil, Uruguay y NE y litoral de Argentina. Habita en los lechos de inundación de ríos y arroyos, y en campos pantanosos.

Materiales examinados: BRASIL. GoIÁs: Serra do Morcego, Córrego Estrema, ca. NE of Formosa, 800 m, 20-IV-1966, Irwin et al. 15115 (RB). МАто Grosso do Sul: Miranda, São Simão, Guaicurus, 20-VI-2006, E. Barbosa \& M. Pietrobom-Silva 1593 (UC). Minas Gerais: Coração de Jesus, Fazenda Felicidade, nas margens do córrego, 4-VIII-1979, S. Rita 16384 (UC); Ceres, Rio Piraputanga, ca. $180 \mathrm{~m}, 30-\mathrm{V}-1988$, A. Salino 453 (UC). PARAGUAY. Paraguarí: in silva pr. Sapucay, 18851895, E. Hassler 1678 (BM, G). Amambay: Parque Nac. Cerro Corá, along road through forest, 30-X-4-XI-1983, Foster 83-2-30 (UC), Sierra de Amambay, 1912-1913, T. Rojas 11231 (G); Colonia Santa Clara, ca. de Cerro Corá, arroyo Pindó, 18-XII-1999, M.S. Ferrucci et al. 1693 (CTES). Concepción: Ea. San Luis, ayo. La Paz, $22^{\circ}-23^{\circ} \mathrm{S}$, región de los Ríos Apa - Aquidabam, K. Fiebrig s.n. (G); Río Apa, in regione calcarea cursus superioris rio, 1912-13, E. Hassler 11686 (G).

Especie de área restringida y morfológicamente muy característica por sus ejes pajizos y lámina verde claro, pinnas lineal-elípticas, 1,3-3 cm lat. por $15-25 \mathrm{~cm}$ long., indumento hialino de pelos glandulares y aciculares, cara abaxial de los segmentos con pelos glandulares, a veces con escasos pelos aciculares o glabra, indusios glabros o glanduloso-pilosos. Se acerca a especies como Thelypteris browniana Ponce del Norte de Argentina y Bolivia, taxón de ejes castaño-pajizos y lámina verde oscuro, levemente discolor, pinnas lineales, 1-1,5 cm lat por 20-28 cm long., cara abaxial de los segmentos densamente pilosa, indusios pilosos. Asímismo ambas cercanas al grupo de T. ovata R.P. St. John de México y Florida (USA).

21. Thelypteris conspersa (Schrad.) A.R. Sm., Univ. Calif. Publ. Bot. 59: 60. 1971. Nephrodium conspersum Schrad., Gott. Gel. Anz. 1824: 869. 1824. Figura 9A-C

Descripción e iconografía: Smith (1971: 61); Ponce (1988: 366).

Distribución y ecología: Thelypteris conspersa se distribuye en Bolivia, Paraguay, centro-este y sur de Brasil, norte y mesopotamia de Argentina y Uruguay. Crece en vegetación primaria o secundaria, en bosques o bosques en galería, a orillas de arroyos, pastizales pantanosos y bordes de caminos anegados.

Materiales examinados: BRASIL. Mato Grosso: Canarana, bacia do Rio Xingú, $13^{\circ} 30^{\prime} \mathrm{S}, 52^{\circ} 20^{\prime} \mathrm{W}$, 400 m; estrada para Paranatinga, 14-X-1990, P.G. Windisch 5867 (SJRP); Nortelândia, P.G. Windisch 8325,8334 (SI); $26 \mathrm{~km} \mathrm{~N}$ of Xavantina on the road Xavantina-Cachimbo road, near the João Lopez bridge, 31-VII-1967, J.A. Ratter \& J. Ramos 238 (MO); Cuiabá, Serra de São Vicente, estrada de acesso ao Hotel Aguas Quentes; $15^{\circ} 55^{\prime} \mathrm{S}, 5^{\circ} 40^{\prime} \mathrm{W}, 450-500 \mathrm{~m}$, 18-VII-1991, P.G. Windisch \& W. Oliveira 6528 (SI). Minas Gerais: Marliéria, Parque Forestal do Rio Doce, Salão Dourado, 15-VI-1995, A. Salino 2150 (BHCB, SI); Viçosa, Agricultural College land, Horticultural Hill, 670 m, 3-VII-1930, Y. Mexia 4833 (MO). GoIÁs: Rio Santo Antônio, ca. $2 \mathrm{~km}$ da GO-70, $15^{\circ} 55^{\prime} \mathrm{S}, 50^{\circ} 08^{\prime} \mathrm{W}$, 510 m, 18-XII-1992, C.E. Rodrigues Júnior \& M.R. Pietrobom-Silva 288 (SJRP); Aporé, ca. 1957'S, $52^{\circ} 01^{\prime} \mathrm{W}$, Rodovia Aporé-Serranópolis, ca. $23 \mathrm{~km}$ de Aporé, ca. 580 m, 1-VIII-1995, M.R. Pietrobom-Silva 2294 (CTES); Quirinópolis, ca. 18³0'S, 50³2'W, Rodovia GO-206, Inaciolandia-Quirinópolis, ca. 4 km de Quirinópolis, 24-I-1996, M.R. Pietrobom 2739 (MBM). PARAGUAY. SAn PEdro: Colonia Guayabí, $20 \mathrm{~km}$ N de San Estanislao, 26-I-1968, A. Krapovickas et al. 14276 (CTES). CordILlERA. Cerro Zanja Yhú, $1 \mathrm{~km}$ E of road from route 1 to $3 \mathrm{~km}$ before Atyra, $25^{\circ} 13^{\prime} \mathrm{S}, 5^{\circ} 09^{\prime} \mathrm{W}, 30-\mathrm{VII}-1988$, E.E. Zardini 6304 (MO, PY); San Bernandino, VII-1915, T. Rojas 1276 (LIL). GuaIRÁ: Cordillera de Ybytyruzú, W del Co. Peró, 2 km E del Destacamento de Tororó, 2-IX-1988, E.E. Zardini 7961 (FCQ, G, MO). CaAguazú: Dans les bosquets, marecageux, 
10-IV-1876, B. Balansa 312b (G). CAAZAPÁ: Tavai, Rio Tebicuary-mi, XII-1988, F. Mereles 2291 (G, MO). ITAPÚA: Isla Yacyreta, costa S, 1-IV-1991, $A$. Pin et al. 597 (PY). Paraguarí: Arroyo Yuguyty, 7

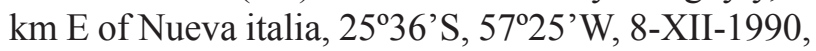
E.E. Zardini \& Velázquez 25131 (MO, UC); ca. 5 km NE de Paraguarí, camino a Chololo, balneario del Cdo. de Artillería, 25-XI-93, M.M. Arbo et al. 6106 (CTES). Alto Paraná: represa del Río Itabó, 24-V-1989, J. Prado 264 (FCQ). CENTRAL: Yaguarón, orilla de arroyo Yaguarón, 1-II-1966, A. Krapovickas et al. 12313 (CTES). Amambay: San Luis, Río Apa \& Río Aquidaban, 1908-1909, K. Fiebrig 4416 (BM).

22. Thelypteris dentata (Forssk.) E.P. St. John, Amer. Fern J. 26: 44. 1936. Polypodium dentatum Forssk., Fl. Aegypt.-arab. 185. 1775.

Figura 9D-E

Descripción e iconografía: Smith (1971: 58); Ponce (1995: 367).

Distribución y ecología: Esta especie originaria del paleotrópico, se ha naturalizado en América. Se

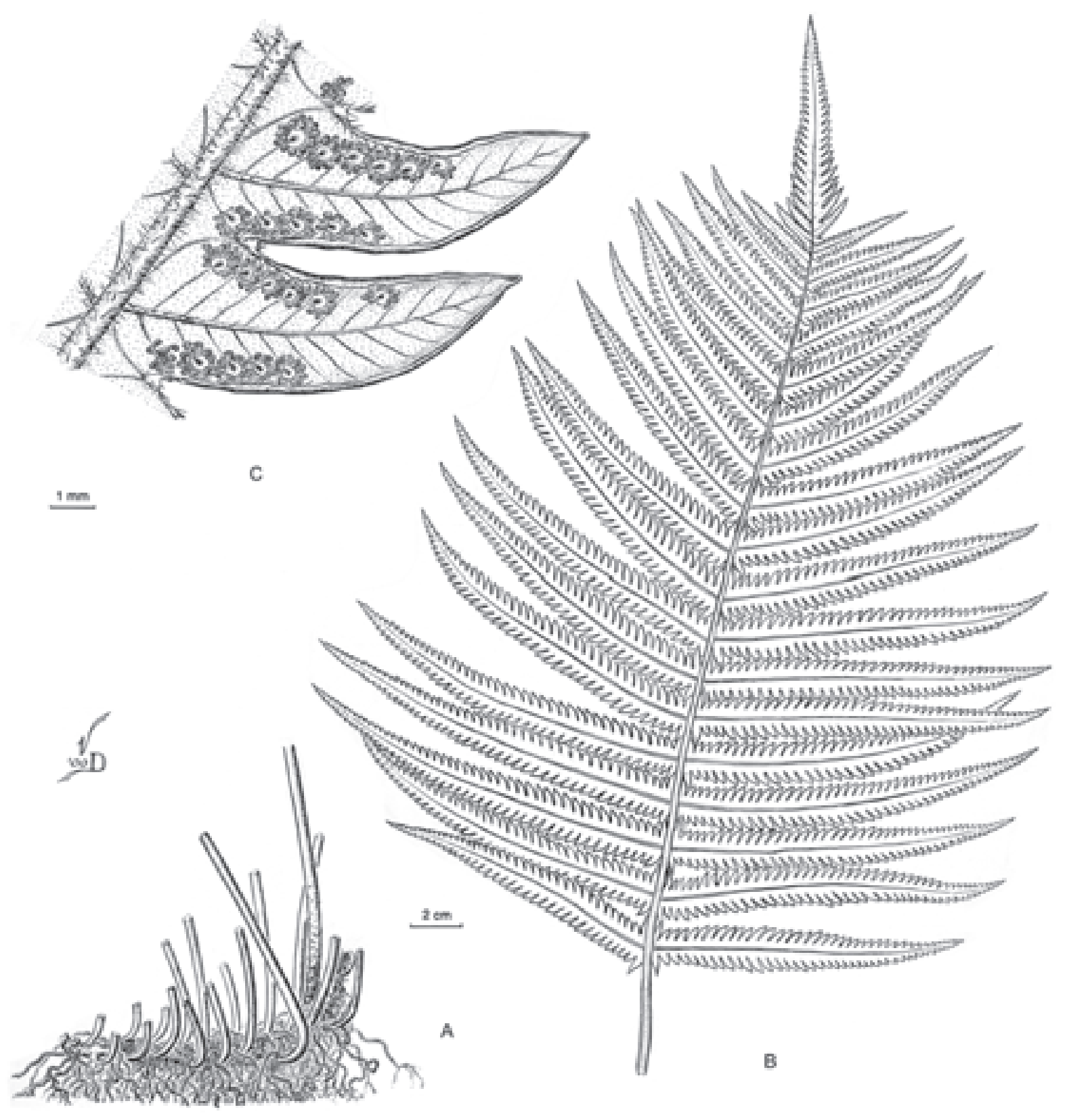

Figura 8A-C. Thelypteris berroi. A. Rizoma. B. Lámina. C. Segmento cara abaxial (Hassler 1678). 
encuentra desde el sudeste de Estados Unidos hasta Brasil, Paraguay, Chile, Argentina, y Uruguay. Este helecho con características de maleza, crece a los costados de los caminos, en los campos de cultivo abandonados, en el sotobosque de araucarias y las plantaciones de pinos. En el cerrado en márgenes de arroyos y picadas de bosques mesofíticos y en galería.

Materiales examinados: BRASIL. Mato Grosso: Selvíria, $5 \mathrm{~km}$ de Selvíria, margen do regato; úmido e sombreado, 10-X-1992, C.E. Rodrígues Júnior \& M.R. Pietrobom-Silva 254 (SJRP); Alto Taquarí, ca. 1750'S, $53^{\circ} 17^{\prime} \mathrm{W}$, ca. $25 \mathrm{~km}$ a Sudeste da Cidade, estrada de acesso a Fazendas, Córrego da Laje, 21-II-1996, M.R. Pietrobom-Silva et al. 3004 (SI). Minas Gerais: Jaboticatubas, Serra do Cipó, 7-VIII-1972, G. Hatschbach 30049 (MBM); Furnas, 8-VII-1995, A. Salino $2218 a$ (SI); Ituiutaba, S. Terezinha, 5-IX-1948, A. Macedo 1200 (MO); Cidade Ipatinga, Usiminas iron works, 12-II-1981, K. Mizoguchi 1497 (MO). PARAGUAY. Cordillera: Cerro Zanja Ihú, $1 \mathrm{~km} \mathrm{E}$ of road from route 1 to Atyra, $3 \mathrm{~km}$ before Atyra, 2513'S, 57³9'W, 25-VI-1988, E.E. Zardini 5151 (FCQ); Caacupé, ruta 2 (Mcal. López) km 47, 21-VII-1995, Pietrobom-Silva et al. 2088 (CTES, MO). Guairá: Cord. Ybytyruzú, Co. Peró, 1 km de Tororó, 255' $\mathrm{S}, 5^{\circ} 15^{\prime} \mathrm{W}$, E slopes, 17-II-1989, E.E. Zardini \& Velázquez 10868 (G, FCQ); Colonia Independencia, I-1967, A. Schinini 1087 (CTES). CAAZAPÁ: Pacurí, comunidad Mbya, 26² $10^{\prime} \mathrm{S}, 55^{\circ} 20^{\prime} \mathrm{W}$, 22-XII-1988, I. Basualdo 2129 (FCQ). PARAguarí: Nat. Park Ybycuí, gallery forest along tributary of Arroyo Minas, $4 \mathrm{~km} \mathrm{~N}$ of Administration, 26 $4^{\circ} \mathrm{S}, 56^{\circ} 48^{\prime} \mathrm{W}$, 31-X-1989, E.E. Zardini \& Velázquez 15595 (PY, UC); Estero Ypoá, $10 \mathrm{~km}$ of SW Nva. Italia, 2520'S, 57²8’W, 23-VI-1990, E.E. Zardini \& Velásquez 21356 (G). Alto Paraná: $4 \mathrm{~km}$ de Hernandarias, a represa Acaray, $25^{\circ} 17^{\prime}$ S, 54³5'W, 3-VII-1991, A. Schinini \& G.C. Marmori 27420 (CTES, G). CENTRAL: Estero de Ypoá, $5 \mathrm{~km} \mathrm{~S}$ of Pindoty, $25^{\circ} 20^{\prime} \mathrm{S}, 57^{\circ} 28^{\prime} \mathrm{W}, 2 \mathrm{~km}$ E of lake, 1-IX-1990, E.E. Zardini \& Velásquez 23222 (G). AмамвAY: Nat. Park Cerro Corá, Ayo. Aquidabán Nigui, 22³9'S, 56³'W, 300 m, 13-II-1982, J. Solomon et al. 6898 (PY, UC), 6907 (PY). CANINDEYÚ: Reserva Nacional Bosque Mbaracayú, Jejui-mí, 2 km sendero principal, 12-III-1997, M. Peña-Chocarro et al. 199 (BM, CTES), 7 km, 3-X-1998, M. Peña-Chocarro et al. 260 (CTES).

Esta especie se distingue por sus pecíolos robustos, castaño-verdosos o castaño-purpúreos, pinnas triangulares atenuadas en el ápice, par de venillas basales unidas formando una vena excurrente de hasta $4 \mathrm{~mm}$ long., y por su pilosidad corta y uniforme en la superficie abaxial de la lámina incluyendo indusios.

23. Thelypteris grandis A.R. Sm. var. kunzeana (Hook.) A.R. Sm., Univ. Calif. Publ. Bot. 59: 99. 1971. Nephrodium kunzeanum Hook., Sp. Fil. 4: 102. 1862.

Figura 10A-D

Descripción e iconografía: Smith (1971: 99); Ponce (1988: 369).

Distribución y ecología: Crece desde Ecuador a Argentina y Brasil central y sudeste. En la región del cerrado se encuentra en el interior de bosques semidecíduos y bosques en galerías, en barrancas de los ríos o cascadas.

Materiales examinados: BRASIL. Mato Grosso: Cáceres, junto ao Rio Piraputanga; $16^{\circ} 05^{\prime}$ 'S, 57 $40^{\circ}$ 'W, 150 m, 2-XI-1987, A. Salino 188 a (SJRP); Alto Araguaia, Rio Claro, 22-IX-1974, G. Hatschbach \& R. Kummrow 35081 (UC); Inocência, ca. 19²46'S, $51^{\circ} 48^{\prime} \mathrm{W}$, ca. $400 \mathrm{~m}$ alt., Rodovia MS São PedroInocência, ca. 17 km de Inocência, 11-XI-1995, M.R. Pietrobom-Silva \& de Lucca 2472 (SI); Cassilândia, ca. $19^{\circ} 07^{\prime} \mathrm{S}, 51^{\circ} 44^{\prime} \mathrm{W}$, ca. $500 \mathrm{~m}$, Rodovia InocênciaCassilândia, 11-XI-1995, M.R. Pietrobom-Silva \& M. de Lucca Júnior 2487 (MBM). Minas Gerais: Frutal, ca. $20^{\circ} 02^{\prime}$ 'S , $48^{\circ} 56^{\prime} \mathrm{W}$, região do Triângulo Mineiro, ca. $650 \mathrm{~m}$, ca. $22 \mathrm{~km}$ de Frutal, BR-153 Serra do Marimbondo, Fazenda Chapadão, 22-I-1996, M.R. Pietrobom-Silva 2505 (CTES, SI); Gurinhata, ca. 19¹2'S, 4947'W, ca. 620 m, Rodovia BR-364, São Paulo-Cuiabá/Rancho Alegre-Bastos, Serra do Lajeado, 25-I-1996, M.R. Pietrobom-Silva 2791 (MBM).

23. Thelypteris grandis A.R. Sm. var. pallescens (C. Chr.) A.R. Sm., Univ. Calif. Publ. Bot. 59: 99. 1971. Dryopteris oligophylla Maxon var. pallescens C. Chr., Kongel. Danske Vidensk. Selsk. Skr., Naturvidensk. Math. Afd., ser. 7, 10: 188. 1913.

Dryopteris oligophylla Maxon var. lutescens C. Chr., Kongel. Danske Vidensk. Selsk. Skr., Naturvidensk. Math. Afd., ser. 7, 10: 188. 1913.

Descripción e iconografía: Smith (1977: 99).

Distribución y ecología: Se distribuye en las Antillas, en Costa Rica y en Sudamérica hasta Bolivia y Brasil central. En campos rupestres cercanos a cursos de agua. 
Material estudiado: BRASIL. Minas Gerais: Patos de Minas, cascata, 750 m, 27-VIII-1950, A. Duarte 2948 (MO); Itutati, São Vicente, em campo, 31-V-1950, A. Macedo 2417 (UC).

24. Thelypteris hispidula (Decne.) C.F. Reed, Phytologia 17: 283. 1968. Aspidium hispidulum Decne. Nouv. Ann. Mus. Hist. Nat. 3: 346. 1834. Figura 9F-G

Descripción e iconografía: Smith (1971: 64); Ponce (1988: 370).

Distribución y ecología: Pantropical, en América se encuentra desde el sudeste de Estados Unidos, México y Antillas hasta Bolivia, Paraguay, Brasil, Argentina y Uruguay. En selvas en galería, en las orillas de cursos de agua y cascadas, bañados o pastizales pantanosos.

Materiales examinados: BRASIL. Mato Grosso: Matupá, P.G. Windisch 8961 (SI); Chapada dos Guimarães, santuário do Jamaca, 14-II-1988, A. Salino 348 (SJRP); Água Boa, bacia do Rio Araguaia, ca. $120 \mathrm{~km}$ do rio Araguaia, ca. $18 \mathrm{~km}$ após rio das Mortes, $13^{\circ} 55^{\prime} \mathrm{S}, 51^{\circ} 45^{\prime} \mathrm{W}, 300 \mathrm{~m}$, Rod. MT 326, direção BR-158, ca. 40 km de Água Boa, 23-X-1992, P.G. Windisch et al. 7160 (SI); Salto do Céu, junto à cachoeira do Rio Branco (Salto do Céu), $15^{\circ} 15^{\prime} \mathrm{S}$, $58^{\circ} 10^{\prime} \mathrm{W}, 400 \mathrm{~m}, 28-\mathrm{XII}-1994$, P.G. Windisch et al. 7809 (SI). Minas Gerais: Viçosa, Agricultural College land, Horticultural Hill, 670 m, 4-VII-1930, Y. Mexia 4840 (MO, isotipo de T. quadrangularis var. repens); Viçosa, road to São Miguel, just outside Agricultural College, 700 m, 26-XII-1929, Y. Mexia 4171 (MO); Viçosa, Agricultural College, Horticultural Hill, 670 m, 16-VII-1930, Y. Mexia 4863 (MO); Viçosa, Agricultural College lands, road to São Miguel, $675 \mathrm{~m}$, 19-III-1930, Y. Mexia 4487-a (MO); Caldas, ca. $21^{\circ} 56^{\prime} \mathrm{S}, 46^{\circ} 23^{\prime} \mathrm{W}$, Pocinhos do Rio Verde, ca. $5 \mathrm{~km}$ de Caldas, ca. 1.150-1.200 m, Complexo da Serra da Mantiqueira, 16-VI-1995, M.R. Pietrobom-Silva 1930 (MBM). Distrito Federal: Brasília, bacia do Rio São Bartolomeu, barranco de córrego, 21-I-1981, E.P. Heringer et al. 6004 (MO). PARAGUAY. Cordillera: Co. Tobatí, 6-V-1979, G. Schmeda 613 (G); prope Tobatí, E. Hassler 3998 (G, UC); Valenzuela, Mbocaya-guazú-ty, 26-XII-1950, B. Sparre \& F. Vervoorst 1304 (BM, LIL); Caacupé, 2520'S, 57010'W, 9-II-1984, W. Hahn 2024 (PY, UC); $10 \mathrm{~km}$ of Arroyos y Esteros, $25^{\circ} 8^{\prime} \mathrm{S}, 57^{\circ} 10^{\prime} \mathrm{W}$, 18-II-1989, E.E. Zardini \& Velázquez 16328 (UC);
Tobatí, “Ybytú Silla" mesa, 297 m, 2512'S, 5707'W, 23-II-1991, E.E. Zardini \& Velázquez 26626 (FCQ, UC). Guairá: Borja, 23-I-1953, J.E. Montes 16274 (BM); Acati, $25^{\circ} 55^{\prime} \mathrm{S}, 56^{\circ} 15^{\prime} \mathrm{W}, 12-\mathrm{XII}-1988$, N. Soria 2900 (MO, FCQ); Cordillera de Ybytyruzú, road to Cantera Jhú, $25^{\circ} 48^{\prime} \mathrm{S}, 56^{\circ} 20^{\prime} \mathrm{W}, 5 \mathrm{~km} \mathrm{~S}$ of route to Cnel. Oviedo, 27-IX-1989, E.E. Zardini \& C. Velázquez 14686 (G),16-X-1989, E.E. Zardini \& Velázquez 15235 (FCQ, G). CAAGUAzú: Caaguazú, 21-I-1951, B. Sparre \& F. Vervoorst 1740 (LIL), 1785 (BM, LIL). CAAZAPÁ: Tavai, $1 \mathrm{~km} \mathrm{~N}$ of Hospital, $26^{\circ} 10^{\prime} \mathrm{S}, 5^{\circ} 27^{\prime} \mathrm{W}, 29-\mathrm{X}-1988$, E.E. Zardini 7726

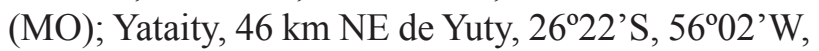
130 m, 23-III-1993, A. Schinini et al. 27765 (G); Castor cué desvío a Pacurí, $26^{\circ} 10^{\prime} \mathrm{S}, 55^{\circ} 17^{\prime} \mathrm{W}$, 22-XII-1988, N. Soria 3113 (G); Itapúa, El Tirol, $19,5 \mathrm{~km}$ by road NNE Encarnación, 6-X-1979, M.S. Foster 79-7 (UC); Guarapi, lieux humidis umbragés, I-1880, B. Balansa 2922 (BM, G). Paraguarí: Sapucay, in silva, 1885-1895, E. Hassler 1844b (BM,

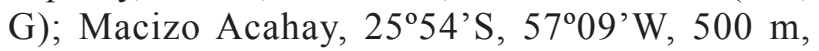
11-VI-1988, E.E. Zardini 4743 (G, PY) 4770 (PY); 16-VI-1988, E.E. Zardini 4824 (PY); Cord. de Ybytyruzú, $25^{\circ} 55^{\prime} \mathrm{S}, 56^{\circ} 15^{\prime} \mathrm{W}$, Valley Co. Peró, Acatí and Muy Muy, 13-I-1989, E.E. Zardini 9406 (CTES, FCQ), 9451 (FCQ, G); 1 km del Destacamento Tororó, on W side of cerro, $25^{\circ} 55^{\prime} \mathrm{S}, 56^{\circ} 15^{\prime} \mathrm{W}$, 13-II-1989, E.E. Zardini \& A. Aguayo 9520 (FCQ); Estero Ypoá, $20 \mathrm{~km} \mathrm{~W}$ of Carapeguá, $25^{\circ} 17^{\prime} \mathrm{S}$, 50²5’W, 7-I-1990, E.E. Zardini \& Velázquez 17538 (G); between Nva. Italia and Carapequá, 254's, 57016'W, 14-XII-1989, E.E. Zardini \& Velázquez 16737 (G); N part of Lake Ypoá basin 12,6 km SE of Nueva Italia. $\mathrm{S}$ border of bañado on Ayo. Cañabe

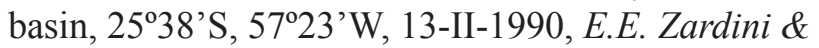
Velazquez 18039 (UC); Estero del Ypoá, 10 km SW of Nva. Italia S of Cañada, $25^{\circ} 20^{\prime} \mathrm{S}, 57^{\circ} 28^{\prime} \mathrm{W}$, 23-VI-1990, E.E. Zardini \& Velázquez 21356 (UC); $19 \mathrm{~km} \mathrm{~W}$ of Carapeguá, $\mathrm{N}$ of pacheco, $25^{\circ} 17^{\prime} \mathrm{S}$, 57²5'W, 7-XII-1990, E.E. Zardini \& Velázquez 17630 (UC); Parque Nacional Ybycu-í, bosque ca. Ayo. Mina, 26³'S, 56º50'W, 14-V-1989, A. Aguayo 160 (PY, UC). Alto Paraná: Puerto Stroessner, V-1983, L.C. Ortega 1806, 1810 (G). Central: Yaguarón, orilla del Ayo. Yaguarón, 1-II-1966, A. Krapovickas et al. 12313 (UC); Ypané, 15-VIII-1983, N. Soria 145

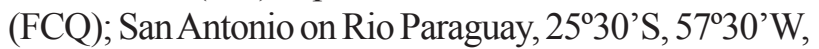
3-VIII-1990, E.E. Zardini \& Velázquez 22553 (UC); Asunción, III-1877, B. Balansa s.n. (G), B. Balansa 312 (BM); Neembucu. Pilar, frente a la 


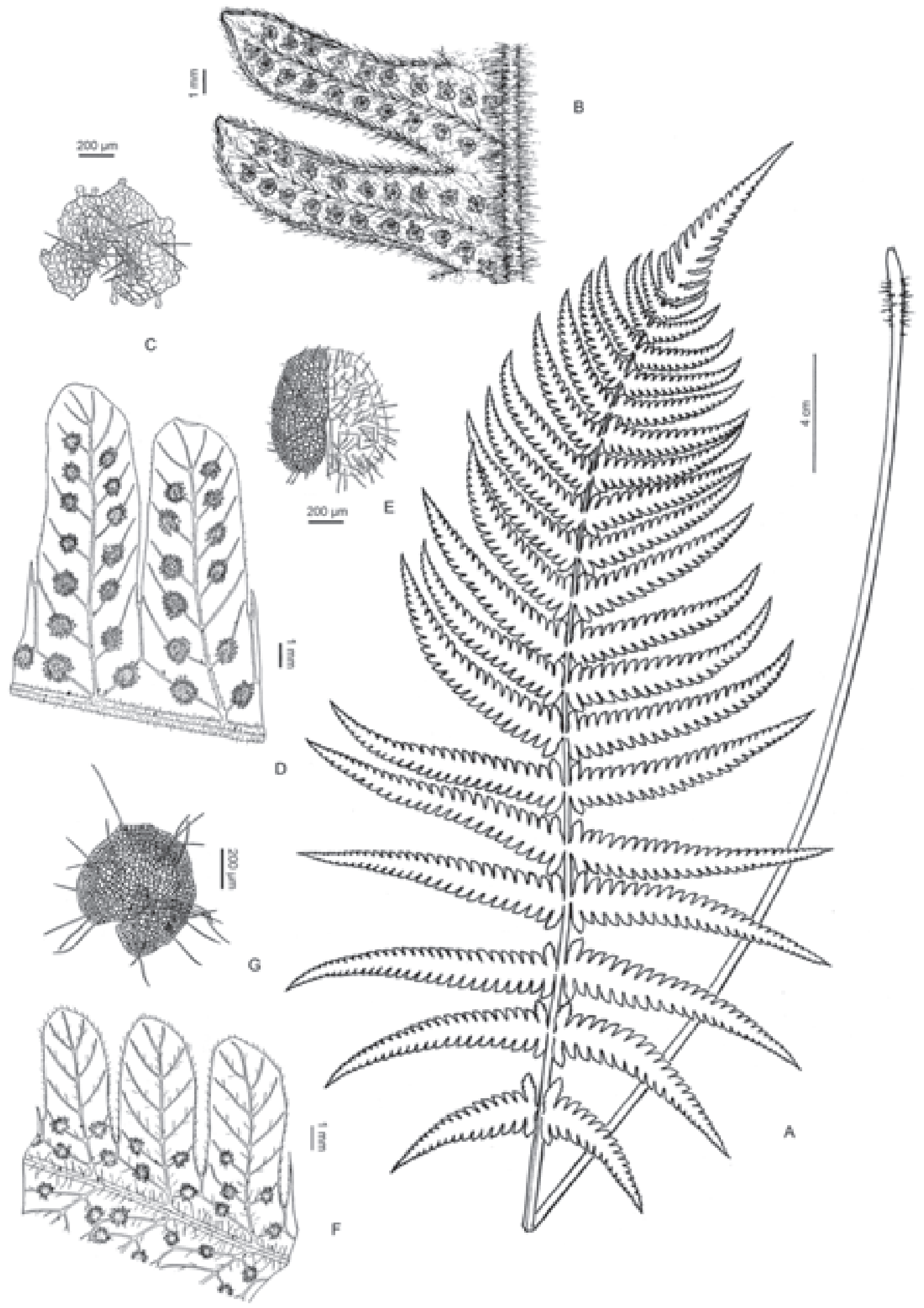

Figura 9A-C. Thelypteris conspersa. A. Fronde. B. Segmentos cara abaxial. C. Indusio. (Windisch 5867). D-E. T. dentata. D. Segmentos cara abaxial. E. Indusio.F-G. T. hispidula. F. segmentos cara abaxial. G. Indusio [D-G, adaptado de de la Sota (1977)]. 
desembocadura del Bermejo, 14-XII-1950, T. Meyer 16091 (LIL); Humaitá, 9-XII-1950, T. Meyer 16159 (LIL). Canindeyú: Reserva Natural Bosque Mbaracayú, Jejui-mi, sendero Aguara'i, 12-X-1997,
M. Peña-Chocarro 347 (BM), Ríacho Mbopí, afl. Rio Paraguay, 11-IX-1893, A.F. Regnell \& C.A.M. Lindman A1947 (BM), Paraguay central, 1888-1890, T. Morong 302 (BM).

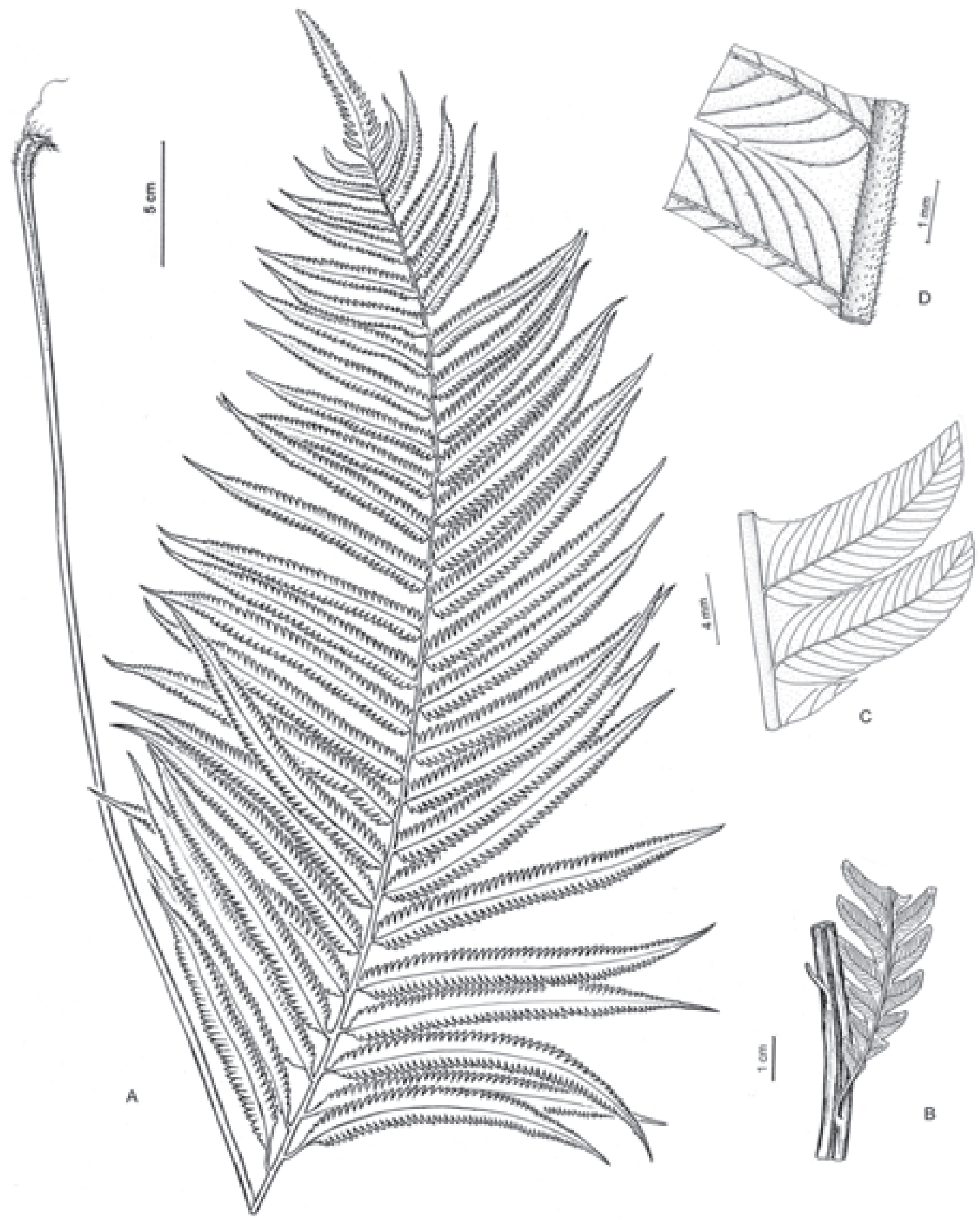

Figura 10A-D. Thelypteris grandis var. kunzeana. A. Fronde. B. Base pinna distal. C. Segmentos. D. Detalle venación. (Pietrobom-Silva \& de Lucca 2472). 
25. Thelypteris interrupta (Willd.) K. Iwats., J. Jap. Bot. 38: 314. 1963. Pteris interrupta Willd., Phytographia 13: tab. 10, fig. 1. 1794.

Figura 11A-C

Descripción e iconografía: Smith (1971: 54); Ponce (1988: 375).

Distribución y ecología: Especie cosmopolita, en América habita desde Florida (USA), México y Antillas hasta Bolivia, Paraguay, Argentina y Uruguay. Se encuentra en tierras bajas, en lagunas, esteros, pantanos, lechos de inundación de ríos y en canales artificiales. Forma extensas poblaciones debido a su rizoma rastrero flotante y es común que las plantas se encuentren estériles. En vegetación de cerrado, mata ciliar, orillas de arroyos y zanjas encharcadas.

Materiales estudiados: BRASIL. Minas Gerais: Agricultural College grounds, Corriga Bartholomeo, 670 m, 13-II-1930, Y. Mexia 4340 (MO); Patos de Minas, Mata da Corda, 700 m, 30-VIII-1950, A. Duarte 3021 (MO); Frutal, região do Triângulo Mineiro, 2002'S, 48 $56^{\circ} \mathrm{W}, 650 \mathrm{~m}, 22 \mathrm{~km}$ de frutal, BR-153 Serra do Marimbondo, Fazenda Chapadão, 22-II-1996, M.R. Pietrobom-Silva 2511 (CTES, SI); Ituiutaba, Santa Terezinha, 4-IV-1950, A. Macedo 2217 (MO); Jaíba, Rodovia Jaíba-Itacarambi, próximo de Moçambinho, 19-VI-2004, G. Hatschbach \& O.S. Ribas 78024 (MBM). Distrito Federal: Recreio dos Bandeirantes, Praia de Sernambetiba, $23^{\circ} 00^{\prime} \mathrm{S}, 43^{\circ} 20^{\prime} \mathrm{W}, 4-\mathrm{IV}-1952$, L.B. Smith et al. 6362 (MO). Mato Grosso do Sul: Paranaíba, ca. $19^{\circ} 37^{\prime} \mathrm{S}, 51^{\circ} 32^{\prime} \mathrm{W}$, Rodovia SelvíriaInocência, proximidades do Povoado de São Pedro, 11-XI-1995, M.R. Pietrobom-Silva \& M. de Lucca 2458 (SI); en route from Bataguaçu to Río Paraná, $350 \mathrm{~km}$ SE from Campo Grande, along BR-163, $300 \mathrm{~m}$, 5-IX-1987, S. Tsugaru \& H. Guinoza 2079 (MO). PARAGUAY. SAn Pedro: Estancia San Antonio, potrero 8 de Diciembre, XI-1992, N. Soria 5366 (FCQ); Cordillera, Cordillera de Altos, in silva, herba 0,5-0,8 m, 1898-1899, E. Hassler 3205 (BM, G); San Bernardino, in dumetis, 1885-1895, E. Hassler 232 (G), E. Hassler 89 (G), VI-1915, E. Hassler 1266 (G); camino a San Bernardino, 24-IX-1967, A.G. Schulz 16111 (CTES); Lago Ypacaraí, Esteros Kendall-Patino, 1-1,2 m, IV-1913, E. Hassler 12561 (BM, G); Caacupé a Piribebuy, $25^{\circ} 22^{\prime} \mathrm{S}, 56^{\circ} 15^{\prime} \mathrm{W}$, 22-IV-1992, O. Morrone \& J. Pensiero 84 (FCQ). Guairá. Villarrica, P. Jörgensen 4053 (LIL); Villarica, 1905, E. Hassler 8603 (BM, G); Santa Bárbara, prés Villa Rica, 27-II-1876, B. Balansa 314A
(BM); Colonia Independencia, I-1967, A. Schinini 1121 (CTES). ITAPÚA: Guarapi, XII-1881, B. Balansa 2913 (BM, G). Misiones: Estero del Puerto Turí, Isla Yacyretá, 8-IV-1988, S. Keel et al. 1352 (FCG). PARAguarí: Estero del Ypoá, 20 km W Carapeguá, N Pacheco, 25 ${ }^{\circ} 17^{\prime}$ S, $57^{\circ} 25^{\prime} \mathrm{W}, 13-\mathrm{I}-1990$, E.E. Zardini \& Velázquez $17874(\mathrm{G})$, Estero del Ypoá, $10 \mathrm{~km} \mathrm{SW}$ Nva. Italia, $25^{\circ} 20^{\prime} \mathrm{S}, 5^{\circ} 28^{\prime} \mathrm{W}, 10-\mathrm{II}-1990$, E.E. Zardini \& Velázquez 18978 (G). Alto Paraná: 1910, K. Fiebrig 6152 (G); Central, Asunsión, V-1874, B. Balansa 314 (G); Ñemby, Barrio Industrial, 13-III-1985, E. Bordas 3736 (CTES, G); Isla Valle, 10-VI-1987, R. Degen 214 (G). Ñeembucu: estero $600 \mathrm{~m}$ away from laguna Sirena, (SE corner), distrito

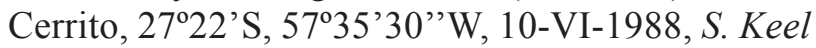
\& L. Spinzi 1478 (FCQ). Presidente Hayes: Ruta Trans-Chaco, km 75, 13-I-1989, F. Mereles 2453 (CTES, FCQ, G); Sin indicación del departamento. Paraguay septentrional, K. Fiebrig $5113 b(\mathrm{G})$; Puente Nacional, Riacho, Guaienru, Rojas 12081 (LIL).

26. Thelypteris patens (Sw.) Small var. patens, Ferns SE States: 243. 1938. Polypodium patens Sw., Prodr.: 133. 1788.

Descripción e iconografía: Smith (1971: 72); Ponce (1988: 371).

Distribución y ecología: Especie de amplia distribución en todo el Neotrópico, desde el sur de México y Antillas hasta la Argentina. La variedad patens es poco común en los subtrópicos de Sudamérica meridional. En bosques montanos primarios y bosques en galería, a las orillas de arroyos y en terrenos pantanosos.

Materiales estudiados: BRASIL. Minas Gerais: Agricultural College, foot of Horticultural Hill, $668 \mathrm{~m}$, 16-VII-1930, Y. Mexia 4862 (MO); Districto de Ilhéus, Fazenda da Tabunha, 300 m, 15-VIII-1930, $Y$. Mexia 4952 (MO). PARAGUAY. Alto Paraguay: 3-VIII-1956, A.L. Woolston 704 (UC).

Se diferencia de las variedades más frecuentes en el cono sur como smithiana y dissimilis por la escasa y corta pilosidad en la costa adaxial, la ausencia de pelos en el pie del esporangio y por las esporas crestado-foraminadas.

27. Thelypteris patens (Sw.) Small var. dissimilis (Schrad.) A.R. Sm., Univ. Calif. Publ. Bot. 59: 75. 1971. Nephrodium dissimile Schrad., Gött. Gel. Anz.: 869. 1824. 
Descripción e iconografía: Smith (1977: 75); Ponce (1988: 372).

Distribución y ecología: Esta variedad crece en el centro-sudeste de Brasil, Paraguay y en NE de Argentina. En bosques montanos y bosques en galería, a las orillas de arroyos y en terrenos pantanosos.

Materiales estudiados: BRASIL. Minas Gerais: Viçosa, road to Sao Miguel, near $9 \mathrm{~km}, 650 \mathrm{~m}$, 31-XII-1929, Y. Mexia 4190 (MO).Viçosa, road to

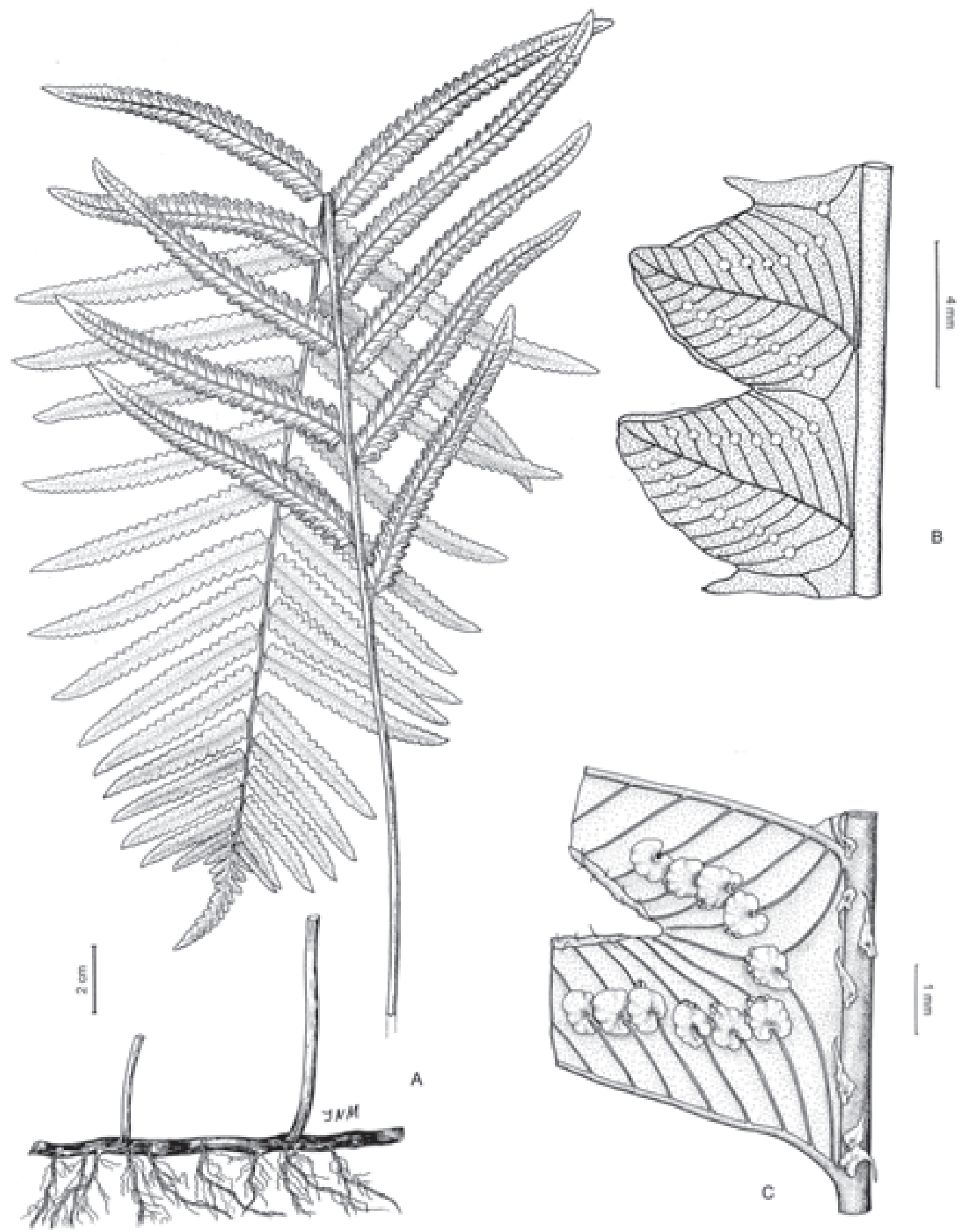

Figura 11A-C. Thelypteris interrupta. A. Planta. B. Segmentos. C. Detalle de segmento fértil [adaptado de de la Sota (1977)]. 
São Miguel, 685 m, 18-III-1930, Y. Mexia 4478 (MO). CEARÁ. Baturité, Serra de Baturité, 27-I-1990, M.F. Morel 106 (SJRP). PARAGUAY. CaAguazú: Carayao, 16-II-1968, A. Krapovickas et al. 13860 (CTES). Alto Paraná: Puerto Gibajas, a 4 km de Puerto Iguazú, Río Paraná, 28-III-1970, A. Krapovickas et al. 15746 (CTES, LP, MO). Amambay. Sierra de Amambay, Punta Porá, IV-1907/1908, E. Hassler \& Rojas 10411 (G).

La variedad dissimilis se separa fácilmente de las otras dos por sus indusios glabros y muy escasa pilosidad en la cara abaxial, no obstante sus esporas con perisporio reticulado-crestado con espinas entre las crestas presentan una morfología intermedia entre las var. patens y smithiana.

28. Thelypteris patens (Sw.) Small var. smithiana Ponce, Darwiniana 28: 373. 1988(1987).

Figura 12A-C

Descripción e iconografía: Smith (1977: 76); Ponce (1988: 373).

Distribución y ecología: Esta variedad es la más difundida en el centro-sudeste y sur de Brasil, Paraguay y norte de Argentina. En el área crece en bosques en galería y en ambientes degradados.

Materiales estudiados: BRASIL. GoIÁs: Serra Dourada, ca. $17 \mathrm{~km}$ S of Goiás Velho, ca. $6 \mathrm{~km}$ NE of Mossamedes, 750 m, E side of Serra, 9-V-1973, Anderson 9951 (UC). Minas Gerais: Tiradentes 19-II-1985, L. Krieger et al. 20379 (SJRP, UC); Furnas, 6-VII-1995, A. Salino 2188 (UC); Viçosa, Agricultural College lands. Base of Horticultural Hill, 670 m, 18-III-1930, Y. Mexia 4478 (MO); 16-VII-1930, Y. Mexia 4864 (MO). PARAGUAY. PARAGUARí: Macizo Acahay, 255'', 5709'W, 500 m, Eastern peak, 30-VI-1988, E.E. Zardini \& C. Cuevas (CTES, G, MO, PY); E peak, 14-VII-1988, E.E. Zardini 5690 (CTES, MO, PY); 5-IX-1988, E.E. Zardini \& T. Florentín 7029 (MO); E peak, $500 \mathrm{~m}$, 26-VII-1988, E.E. Zardini 6141 (G, MO, PY); 21-VIII-1988, E.E. Zardini 6568 (G, MO, PY); 3-IX-1988, E.E. Zardini \& T. Florentín 6876 (MO, PY), 500 m, 5-II-1989, E.E. Zardini \& C. Velázquez 9328 (CTES, G, MO, PY); E.E. Zardini \& C. Velázquez 9367 (MO); idem, $400 \mathrm{~m}$, on E side, 11-VI-1989, E.E. Zardini 12859 (G, MO); 2552'S, $57^{\circ} 08^{\prime} \mathrm{W}$, northern slope, 17-II-1992, E.E. Zardini \& T. Tillería 30530 (MO). GuarRÁ: Cord. Ybytyruzú, road to Cantera Jhú, $25^{\circ} 48^{\prime} \mathrm{S}, 56^{\circ} 20^{\prime} \mathrm{W}, 5 \mathrm{~km} \mathrm{~S}$ of route to Coronel Oviedo, along Chorro Creek, 4-XII-1988, E.E. Zardini \& A. Aguayo 8388 (G, MO); idem, 27-IX-1989, E.E. Zardini \& A. Aguayo 14798 (FCQ, G, MO, UC); Cordillera de Ybytyruzú, $15 \mathrm{~km} \mathrm{~N}$ Antena, $25^{\circ} 45^{\prime} \mathrm{S}, 56^{\circ} 15^{\prime} \mathrm{W}$, 14-VII-1989, E.E. Zardini \& R. Velázquez 13480 (FCQ, G, MO); A. Aguayo 585 (FCQ, G, MO); a $6 \mathrm{~km}$ de Melgarejo hacia cerro Acatí, arroyo Tacuara, 17-VI-1989, A. Aguayo 464 (MO).

La variedad smithiana se diferencia de la var. patens por la presencia de 1-3 pares de pinnas basales reducidos, su pilosidad más abundante y de mayor longitud en la costa y cóstulas del lado adaxial, por los esporangios con un pelo capitado que en la variedad típica son siempre glabros y por sus esporas equinadocrestadas. Probablemente se compruebe que esta variedad se trate de una buena especie por estas y otra evidencias, como que en las Antillas Menores, Walker \& Jermy (1985) encontraron que la var. scabriuscula sensu Smith es un tetraploide, mientras que la var. patens es diploide.

Especie probable

Thelypteris kunthii (Desv.) C.V. Morton, Contr. U.S. Natl. Herb. 38: 53. 1967.

Material de esta especie se cita para el nordeste de Brasil [sub T. normalis (C. Chr.) Moxley, Smith (1977)]

\section{Thelypteris subgen. Goniopteris}

Es un subgénero exclusivo del Neotrópico, con cerca de 90 especies, abundante en los bosques montanos lluviosos, en sitios sombreados y húmedos, a la orilla de ríos, encotrándose también en tierras bajas en pantanos y vegetación xerófila. En el territorio de Paraguay y Brasil central se encuentran 13 especies, ocho de ellas restringidas a la región.

29. Thelypteris abbiattiae C.F. Reed, Phytologia 17 : 257. 1968. Goniopteris burkartii C. Chr. ex Abbiatti, Darwiniana 13: 556. 1964, non T. burkartii Abbiatti (1964).

Nota: La ortografía abbiattii se corrigió de acuerdo a la Recomendación 60C.1(a) ya que la especie está dedicada a la botánica Delia Abbiatti (f).

Figura 13

Descripción e iconografía: Ponce (1988: 377).

Distribución y ecología: Crece en el sur de Brasil, Paraguay y Argentina hasta el Río de La Plata; en los 
lechos de inundación de los bosques en galería, en suelos arcillosos o arenosos.

Materiales examinados: PARAGUAY. CANINDEYÚ: Jejui-mi, ca. $1.500 \mathrm{~m}$ al $\mathrm{N}$ de la caseta, 8-V-1996, G. Marín \& B. Jiménez 189 (BM, MO); Jejui-mi, sendero Aguara'i, 12-X-1997, M. Peña-Chocarro
346 (BM); Jejeui-mi, sendero Aguarai, 17-I-1997, B. Jiménez 1783 (BM, CTES, MO); a unos $1.500 \mathrm{~m}$ al N de la caseta, 8-V-1996, G. Marín \& B. Jiménez 189 (MO).

Se caracteriza por sus plantas medianas, pinnas largamente triangulares crenadas y sus yemas axilares

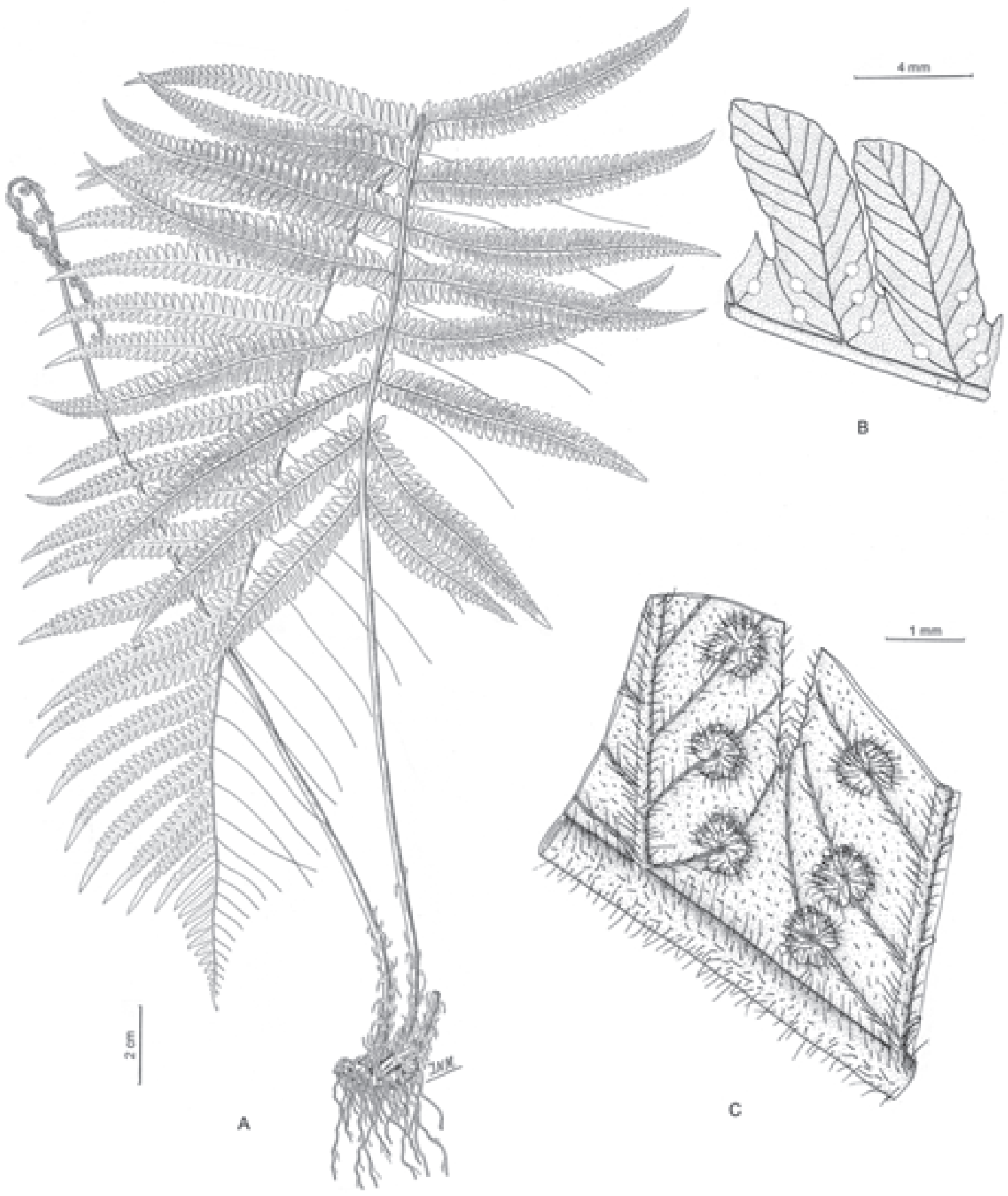

Figura 12A-C. patens var. smithiana. A. Aspecto general. B. Segmento. C. Detalle de segmento fértil [adaptado de de la Sota (1977)]. 

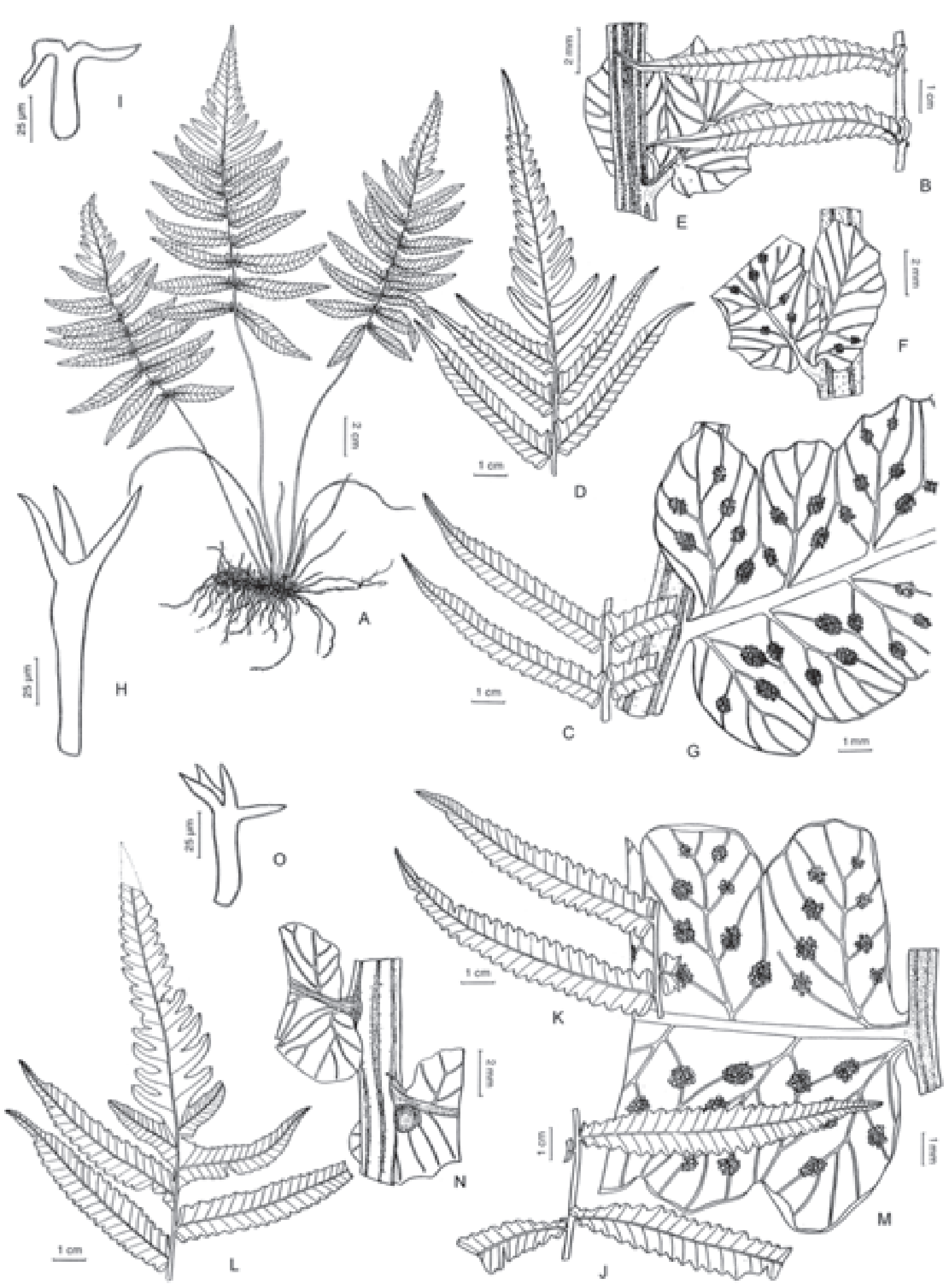

Figura 13A-H. Thelypteris riograndensis. A. Aspecto general B. Pinnas basales. C. Pinnas medias. D. Ápice. E-F. Lóbulos de segmento distales. I-H. Pelos ramificados. J-N. T. abbiattiae. J. Pinnas basales. K. Pinnas medias. L. Lámina apical. M. Base pinnas medias. N. Base pinnas proximales [adaptado de Abbiatti (1964)]. 
en en las pinnas proximales. Es una especie afín a T. riograndensis, de la que se separa por dichas yemas prolíferas entre otros caracteres.

30. Thelypteris abrupta (Desv.) Proctor, Rhodora 61: 306. 1959(1960). Polypodium abruptum Desv., Mem. Soc. Linn. Paris 6: 239. 1827.

Goniopteris pyramidata Fée, Hist. Foug. Antill. 11: 61, tab. 16, fig. 2. 1866.

Figura 14

Descripción e iconografía: Smith, (1992: 58, 1993: 81). Distribución y ecología: Este helecho crece en las Antillas Mayores y Menores, Guyanas, Brasil amazónico (Pará, Acre, Roraima, Amazonas, Mato Grosso), Perú y Bolivia. Se lo encuentra en márgenes de arroyos.

Materiales estudiados: BRASIL. MATo Grosso: Juína, Linhas, terra Erminio Mainardi, 4-XI-1987, Pivetta 1446 (HB). Mato Grosso do Sul: São Manoel, II-1912, F.C. Hoehne 5281 (R). Roraima: Boa Vista, Reserva Ecológica de Maracá, Ilha de Maracá, picada da Corredeira da Rapariga, $61^{\circ} 50^{\prime} \mathrm{W}, 3^{\circ} 35^{\prime} \mathrm{N}$, 24-III-1987, B.L. Stannard \& M.G.M. Arrais 829A (UC), $829 B$ (UC), 829 (UC).

31. Thelypteris biformata (Rosenst.) R.M. Tryon, Rhodora 69: 5. 1967. Dryopteris biformata Rosenst., Repert. Spec. Nov. Regni Veg. 7: 300. 1909.

Descripción e iconografía: Ponce (1988: 377); Smith (1992: 60).

Distribución y ecología: Crece en Colombia, Ecuador, Perú, Bolivia y Brasil amazónico a sudeste.

Materiales estudiados: BRASIL. Minas Gerais: Uberlândia, Reserva Ecológica do Panga, 8-V-1987, M. Ranal 478 (HUFU, UC); 7-II-1990, M. Ranal 542 (HUFU, UC); 18-VII-1991, M. Ranal 546 (HUFU, UC).

32. Thelypteris biolleyi (H. Christ) Proctor, Bull. Inst. Jamaica Sc. Ser. 5: 58. 1953. Aspidium biolleyi H. Christ in Pittier, Prim. Fl. Costaric. 3: 31. 1901. Goniopteris nephrodioides var. biolleyi (Christ) Brade, Bradea 1(22): 216. 1972

Descripción e iconografía: Smith (1992: 53, 62).

Distribución y ecología: Especie de amplia distribución, desde el sur de México, Jamaica, Centroamérica y norte de Sudamérica hasta Perú y norte de Brasil, citado para los estados de Amazonas y Bahia.
Materiales examinados: BRASIL. Mato Grosso: Fazenda Geo-Açu, Colider-MT, A. Salino 269 (UC); Fazenda da Gaúcha, $22 \mathrm{~km}$ antes de Colider-MT, 14-I-1998, A. Salino 3096 (UC). Pernambuco: São Vicente Ferrer, complexo da Serra do Mascarenhas, ca. 7³5'S, 3530'W, 600-650 m, 30-X-1998, M.R. Pietrobom-Silva 4456, 4458, 4459 (SI).

33. Thelypteris jamesonii (Hook.) R.M. Tryon, Rhodora 69(777): 6. 1967. Nephrodium jamesonii Hook., Sp. Fil. 4: 66. 1862. Dryopteris jamesonii (Hook.) C. Chr., Kongel. Danske Vidensk. Selsk. Skr., Naturvidensk. Math. Afd., ser. 7, 10: 227. 1913.

Dryopteris warmingii C. Chr., Kongel. Danske Vidensk. Selsk. Skr., Naturvidensk. Math. Afd., ser. 7, 10: 227. 1913. Thelypteris warmingii (C. Chr.) R.M. Tryon, Rhodora 69: 8. 1977.

Figura 15A-B

Descripción e iconografía: Smith (1992: 56).

Distribución y ecología: Se encuentra en Ecuador, Perú, Bolivia y Brasil central y sudeste (Goiás, Minas Gerais, São Paulo, Mato Grosso). Crece en ambiente de cerrado con mata semidecidua y mata ciliar.

Materiales estudiados: BRASIL. GoIÁs: Mineiros, Pedra Aparada, ca. $16^{\circ} 50^{\prime} \mathrm{S}, 52^{\circ} 40^{\prime} \mathrm{W}$, mata, margen de estrada, na base de rochedo, 4-VII-1996, P.G. Windisch 8191 (SI). Mato Grosso: Parque Estadual Serra Ricardo Franco, ca. 400 m, P.G. Windisch 1476 (UC). Localidad desconocida, 1881-1886, H. Smith s.n. (CM). Minas GERAIS. Gurinhatá, $19^{\circ} 12^{\prime}$ S, 4947'W, região do Triângulo Mineiro, ca. $620 \mathrm{~m}$, Rodovia BR-364, São Paulo-Cuiabá/Rancho Alegre-Bastos, Serra do Lajeado, ca. $10 \mathrm{~km}$ do Trevo de Gurinhatá, terrestre en barranco úmido, margem do regato interior da mata ciliar, 25-I-1996, M.R. Pietrobom-Silva 2790 (SI); Frutal, ca. $20^{\circ} 02^{\prime}$ 'S, 48 $56^{\circ}$ 'W, Região do Triângulo Mineiro, ca. 650 m, ca. 22 km de Frutal, BR-153 Serra do Marimbondo, Fazenda Chapadão, interior do mata ciliar, próximo a cachoeira, 22-I-1996, M.R. Pietrobom-Silva 2504 (SI).

En el material estudiado el rizoma varía de suberecto o decumbente a cortamente rastrero, del mismo modo se observa una variación continua de la densidad de pelos estrellados en las costas y cóstulas abaxiales. Esta especie es muy cercana a T. schwackeana, que se diferencia por su rizoma rastrero. 


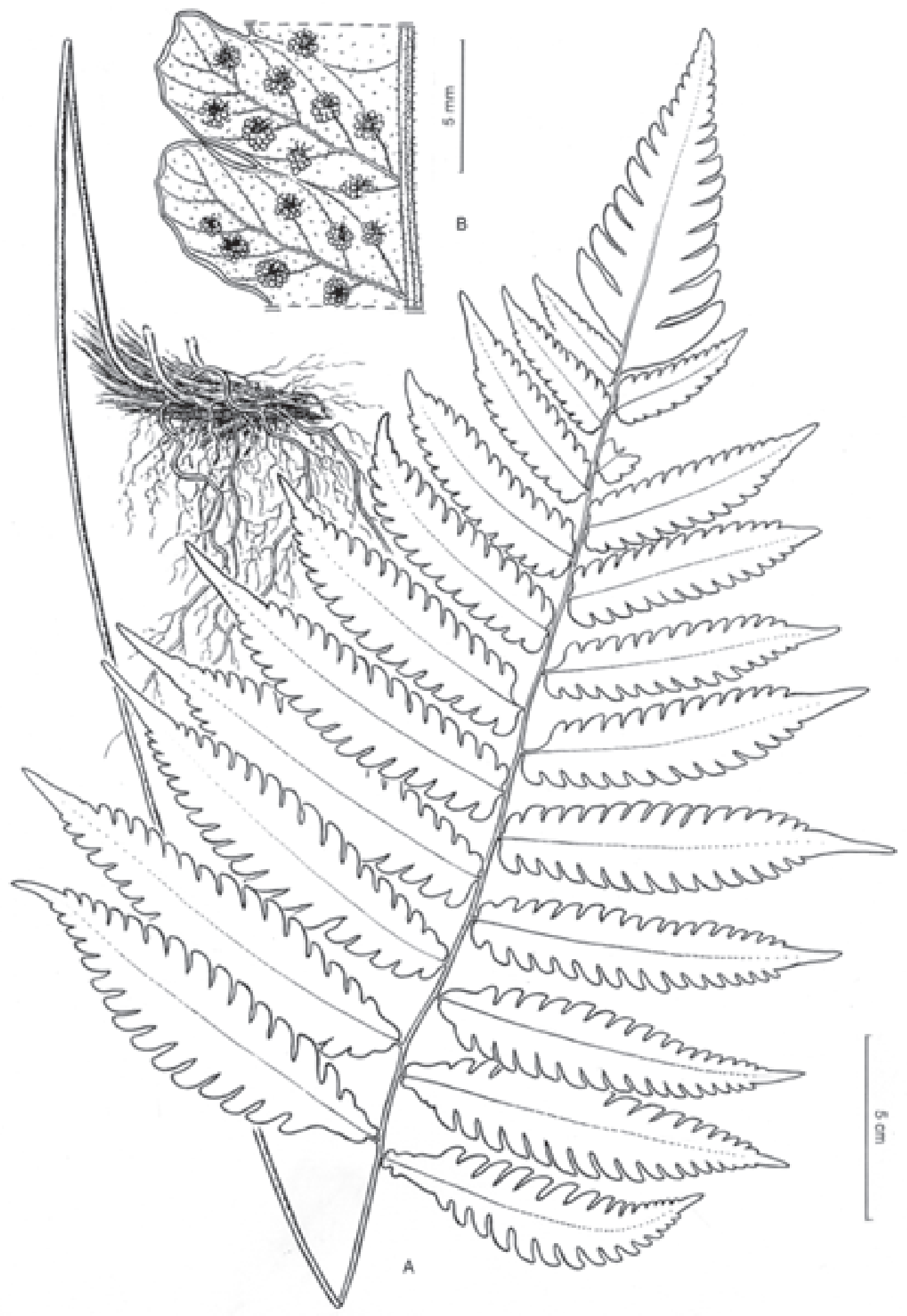

Figura 14A-B. Thelypteris abrupta. A. Aspecto general. B. Detalle segmento abaxial (Stannard \& Arrais 829). 


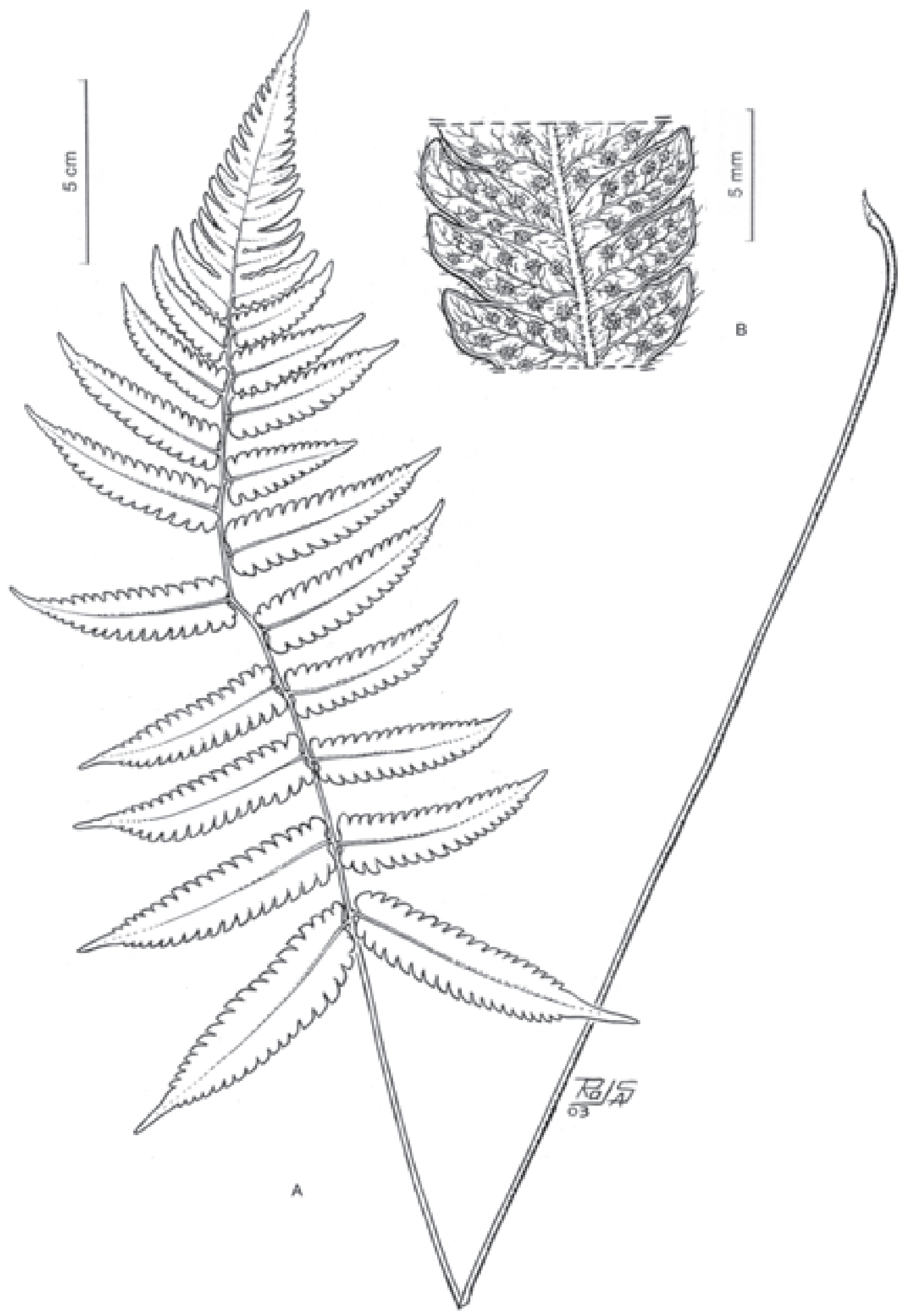

Figura 15A-B. Thelypteris jamesonii. A. Aspecto general. B. Detalle segmento abaxial (Windisch 8191). 
34. Thelypteris juruensis (C. Chr.) R.M. Tryon \& D.S. Conant, Acta Amazonica 5: 33. 1975. Dryopteris juruensis C. Chr., Kongel. Danske Vidensk. Selsk. Skr., Naturvidensk. Math. Afd., ser. 7, 10: 256. 1913.

Figura 16A-B

Descripción e iconografía: Smith (1992: 61).

Distribución y ecología: Esta especie crece desde Ecuador hasta Bolivia y Guyanas, Brasil amazónico (Amapá, Amazonas, Acre) y se la ha encontrado en Mato Grosso.

Materiales estudiados: BRASIL. Mato Grosso: Juina, Rio Tinta Larga, Carimpo Veronesi, 1-X-1987, Pivetta 1473 (HB). ACre: Caramí Amazonas, Rio Juruá,
Cigana Varzea, 7³7’'S; 72³6’ W, 150 m, 22-VIII-1986, T.B. Croat 62527 (MO). AmazonAs: Río Solimões and Río Javarí, Ilha Aramaça, almost opposite Tabatinga, 24-VII-1973, E. Lleras et al. P16802 (UC).

35. Thelypteris lugubris (Kunze ex Mett.) A.F. Tryon \& R.M. Tryon, Rhodora 84: 128. 1982. Aspidium lugubre Kunze ex Mett., Abh. Senckenb. Naturforsch. Ges. Frankfurt 2: 378 (Farngattungen IV: 94) 1858.

Figura 17A-D

Distribución y ecología: Centro y SE de Brasil y Paraguay. Terrestre, crece a orillas de arroyos, cascadas y en bosques húmedos o secos semidecíduos o bosques marginales.

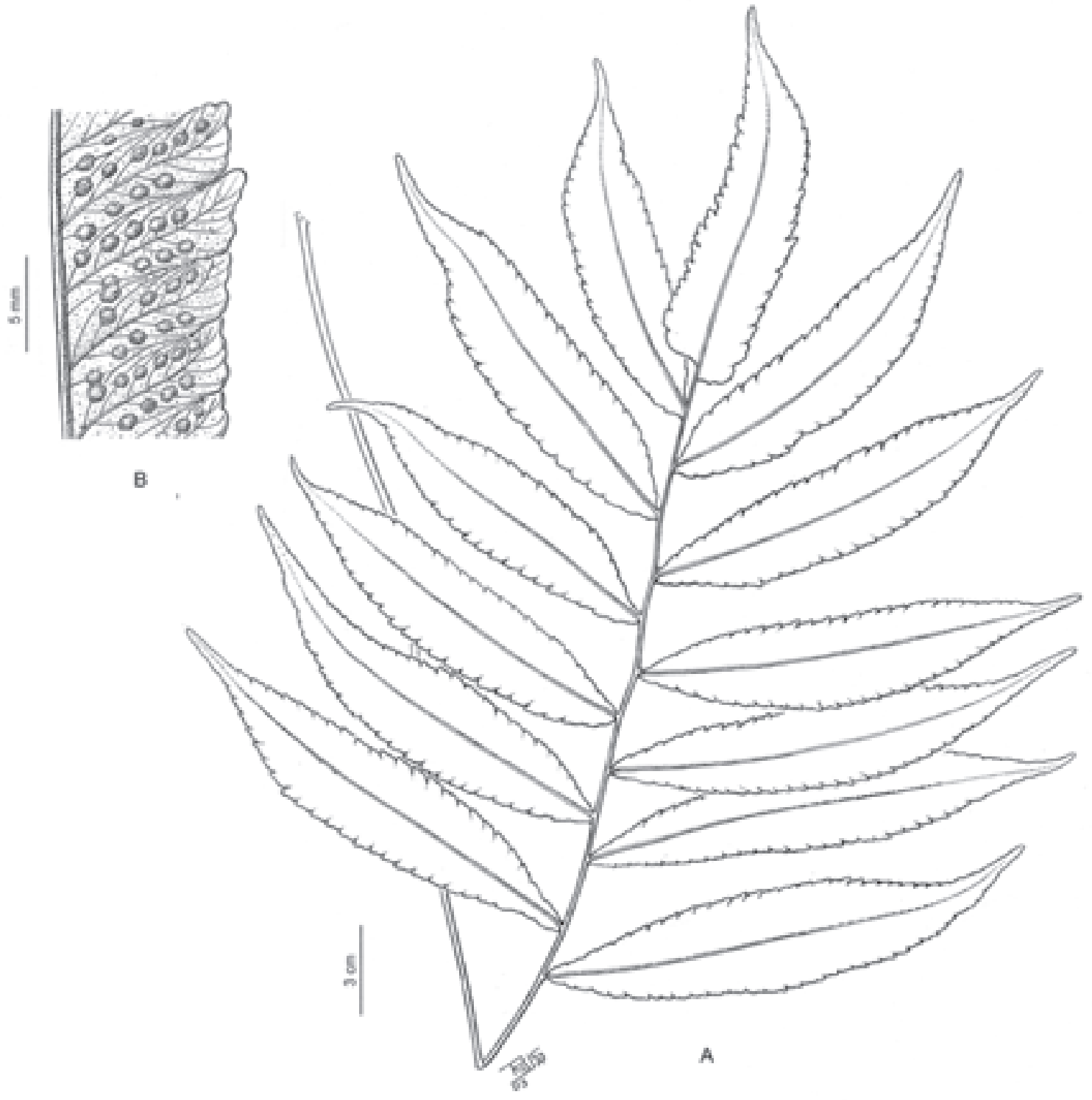

Figura 16A-B. Thelypteris juruensis. A. Fronde. B. Detalle segmento abaxial (Croat 62527). 
Materiales examinados: BRASIL. GoIÁs: Aporé, $52^{\circ} 01^{\prime} \mathrm{W} 19^{\circ} 57^{\prime} \mathrm{S}$, Rod. Aporé-Serranópolis, ca. 70 $\mathrm{km}$ de Aporé, ca. $700 \mathrm{~m}$, Rio Correntes, cachoeria, 2-VIII-1995, M.R. Pietrobom-Silva 2373 (MBM). Mato Grosso: Guarantá do Norte, Serra do Cachimbo, à esquerda do Rio Braço Norte; Serra com mata seca semidecídua de encosta, margen do Rio Braço Norte, 950'S, 5455'W, 16-VII-1995, A.P.N. Soares 38 (SI). Minas Gerais: S. Sebastião do Paraíso, Fazenda Fortaleza, 20-IV-1945, A. Brade \& Altamiro 204 (ICN); Furnas, 8-VII-1995, A. Salino 2213 (UC); A. Salino 2216 (SI, UC). PARAGUAY. SAN PEDro: al NE de S. Estanislao, camino a Luz Velha, bosque degradado en vega de arroyo, 18-III-1989, U. Eskuche \& Z. Ahumada 6162 (G). AмамваY: Sierra de Amambay, 1907-1908, E. Hassler \& T. Rojas 10455 (BM). Paraguarí: Cerro Choló, interior de selva, 8-IX-1976, A. Schinini 13370 (CTES, G).

Se caracteriza por rizoma rastrero, con escamas castañas, angostamente triangulares, con pocos pelos furcados, yemas presentes en el haz sobre raquis y costas; raquis con pelos 2-4-ramificados, a menudo mezclados con pelos simples, hialinos a rojizos, persistentes o glabrescentes en el envés; costas de las pinnas densamente pilosas, lado adaxial con pelos simples, lado abaxial con pelos simples y estrellados, a veces con pequeñas escamas inconspicuas; cara adaxial de los segmentos con pelos simples subadpresos, antrorsos, comúnmente en el área marginal, cara abaxial con una mezcla de pelos simples, aciculares y setiformes sobre cóstulas y venas, rara vez furcados; soros con indusios orbiculares, persistentes, castaño-rojizos, pilosos en el margen, pelos simples.

36. Thelypteris montana Salino, Brittonia 54: 334. 2002(2003). Aspidium quadrangulare Fée, Crypt. vasc. Brés. 1: 145, tab. 50, fig. 2. 1869, non Nephrodium quadrangulare Fée (1852).

Descripción e iconografía: Salino [2002(2003: 334)]. Distribución y ecología: Endémica del centro-sudeste de Brasil, en bosques húmedos, en zonas montanas o bajas.

Materiales examinados: BRASIL. Rio DE JANEIRo: Magé, $3^{\circ}$ Distrito, Paraíso, Centro de Primatología, 20-XI-1984, G. Martinelli et al. 10348 (SI). MinAS GeraIs: Juiz de Fora, 29-IX-1937, A.C. Brade 15910 (RB).
37. Thelypteris platypes (Fée) Ponce, comb. nov. Goniopteris platypes Fée, Crypt. vasc. Brés. 1: 106, tab. 33, fig.1 "f. 3". 1869. Dryopteris vivipara (Raddi) Brade var. platypes (Fée) C. Chr., Kongel. Danske Vidensk. Selsk. Skr., Naturvidensk. Math. Afd., ser. 7, 10: 255. 1913. Tipo: BRASIL. RIO DE JANEIro: A. Glaziou 2402 (holotipo, P no visto; isotipo, $\mathrm{S}$, imagen vista).

Nota: En Christensen (1913) el material C.W.H. Mosén 85 (S, imagen vista); Jelinek 140 (B, imagen vista) citado bajo Dryopteris vivipara var. platypes, corresponden a $T$. vivipara; del mismo modo Aspidium macropus Mett. [Tipo: Brasil, Bahía, Claussen 112, (B, imagen vista)] también coincide con esta especie.

Figura 2D y 18A-B

Distribución y ecología: Endémica de Brasil central y norte. Terrestre, en bosque semidecíduos estacionales y bosques húmedos al este de Minas Gerais

Materiales examinados: BRASIL. Minas Gerais: Marliéria, Parque Estadual do Vale do Rio Doce, 15-VI-1995, A. Salino 2133 (SI, UC); Trilha do Vinhático, 16-VI-1995, A. Salino 2161 (UC), Trilha da Campolina, 5-IX-1995, V.V. Scudeller \& D. Graçano 81 (UC); Viçosa, Fazenda da Aguada, 690 m, 28-VII-1930, Y. Mexia 4915 (MO).

Se caracteriza por el rizoma rastrero con escamas ferrugíneas, con pelos mayormente furcados, también 3-4 ramificados. Pecíolos castaño claro a pajizoverdosos, 1/2 de la longitud de la fronde, glabros o con dimintuos pelos estrellados, cortos, escasos. Frondes pinnadas de 1,20-2 m long., raquis cortamente piloso en el surco, pelos estrellados, pinnas 10-16 pares, oblongo-elípticas de 2,5-4 cm lat. $\times 15-25 \mathrm{~cm}$ long., cuneadas a largamente cuneadas, sésiles o subsésiles, margen levemente aserrado, 4-6 pares de pinnas unidas y excurrentes hacia el margen.

Thelypteris platypes se distingue de $T$. vivipara por sus frondes hasta de 1,8-2 m long., la consistencia papirácea, sus pinnas largamente oblongo-elípticas, de base cuneada y venas notables adaxialmente, con el extremo ensanchado en el margen aserrado.

38. Thelypteris riograndensis (Lindm.) C.F. Reed, Phytologia 17: 309. 1968. Polypodium riograndense Lindm., Ark. Bot. 1: 230, tab. 3, fig. 6. 1903. Figura 13A-H 

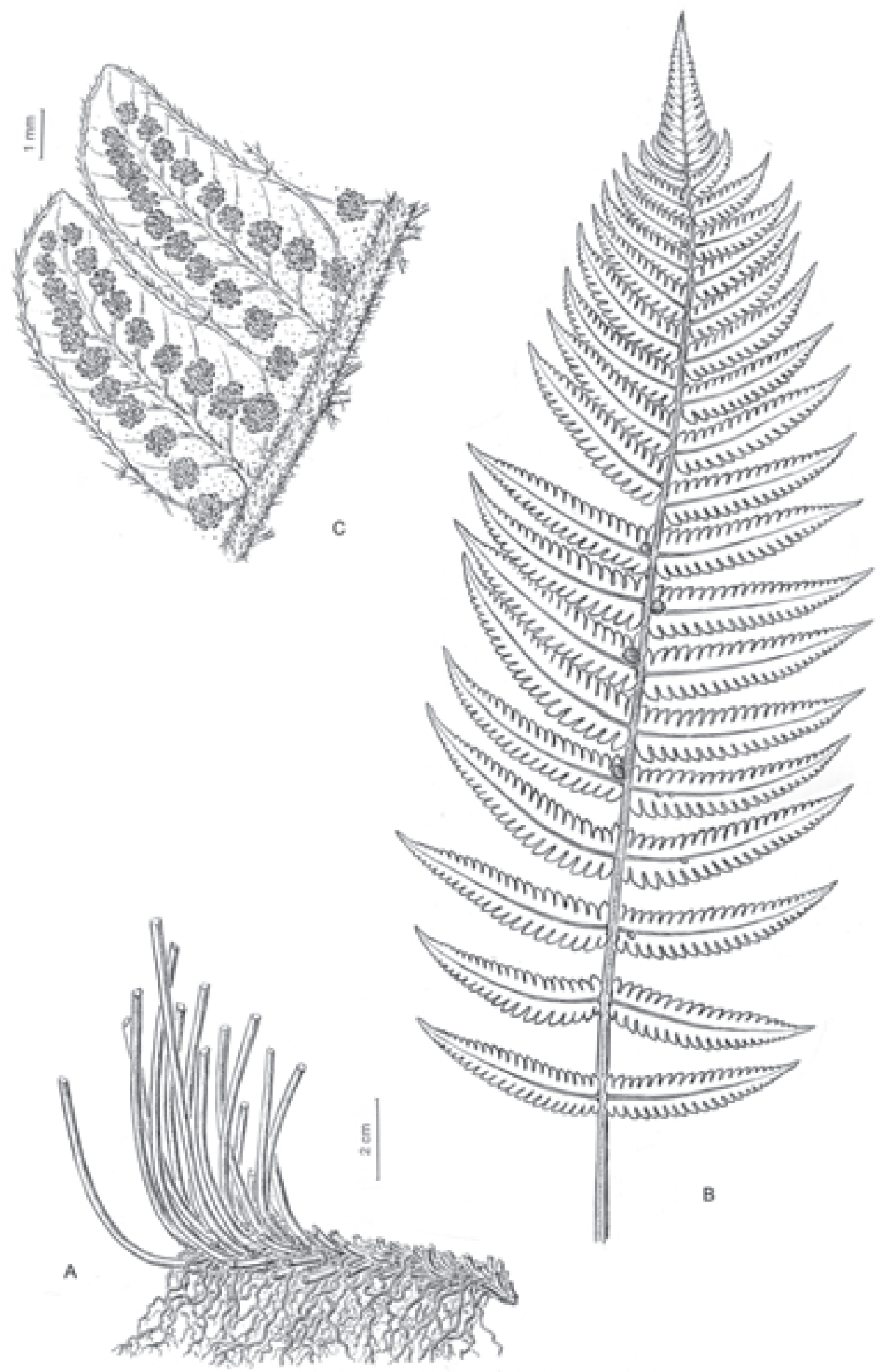

Figura 17A-C. Thelypteris lugubris. A. Aizoma. B. Lámina. C. Segmentos cara baxial (Schinini 13370). 

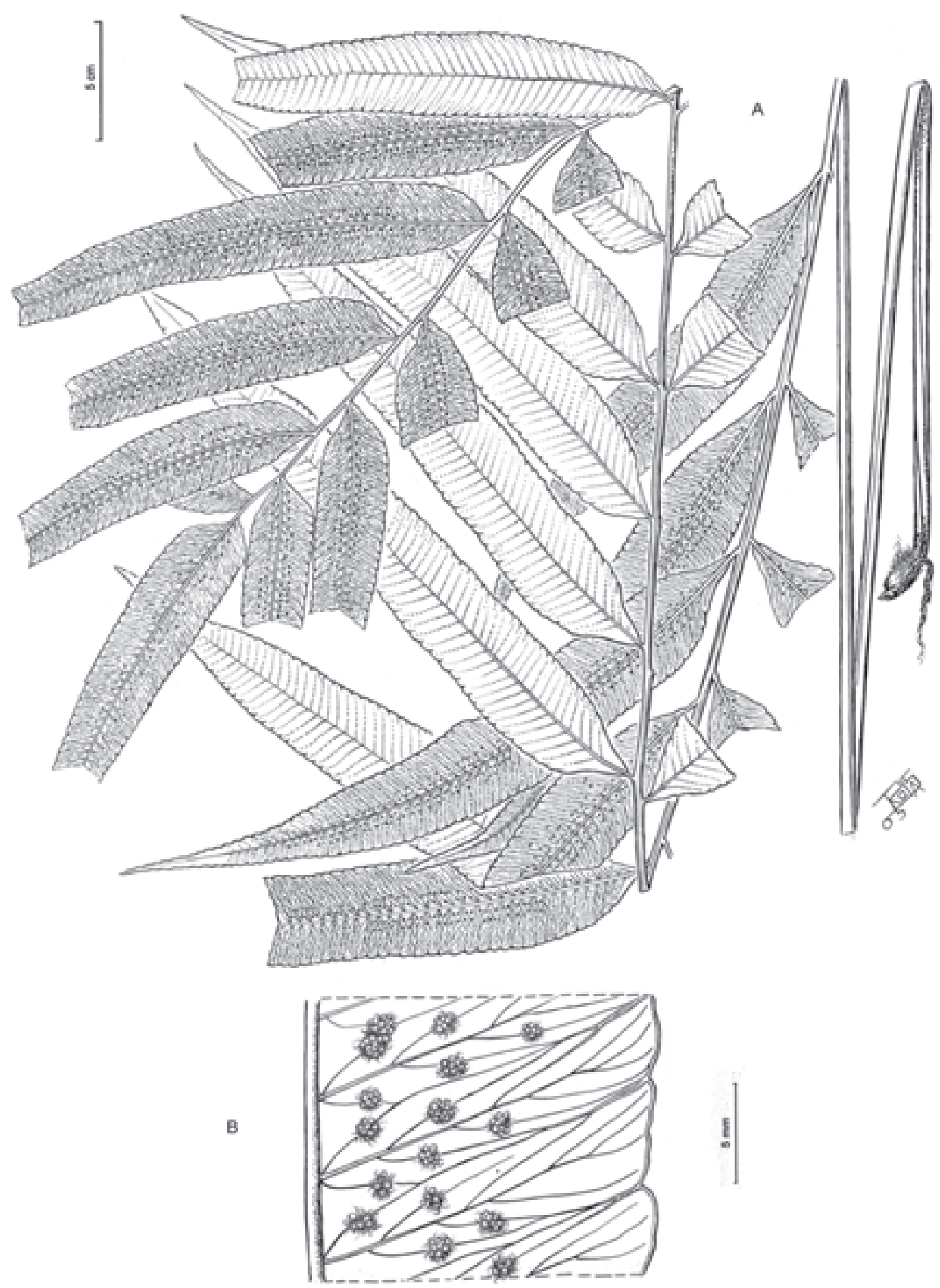

Figura 18A-B. Thelypteris platypes. A. Planta. B. Detalle segmento abaxial (Salino 2133). 
Descripción e iconografía: Ponce (1988: 378).

Distribución y ecología: Crece en el centro-sudeste y sur de Brasil, Paraguay, nordeste y mesopotamia de Argentina y Uruguay. Habita en bosque ribereños y es frecuente en los lechos de inundación de las selvas en galería.

Materiales estudiados: BRAZIL. Minas Gerais: Viçosa, road to São Miguel, km 8, Corrigo Sujo, $Y$. Mexia $4876 a$ (UC). PARAGUAY. Cordillera: Valenzuela, Río Yhacá, 18-XII-1950, B. Sparre \& F. Vervoorst 1101 (LIL). GuAIRÁ: região da Cascata Se Syî, mata, 23-24-V-1989, P.G. Windisch 5481 (FCQ, UC). CAAZAPÁ: Tavaí, camino a Estancia de Constancio Trociuk, $2 \mathrm{~km}$ al S de Destacamento, 26 $6^{\circ} 10^{\prime} \mathrm{S}, 55^{\circ} 27^{\prime} \mathrm{W}$, 30-X-1988, E.E. Zardini 7791 (FCQ, UC). PARAguARí: Parque Nacional Ybycui, gallery forest along Arroyo Minas, on trail to Salto Guaraní, 21-X-1988,E.E. Zardini 7455 (PY). Alto PARANÁ: Reserva Biológica de Itabó (Proyecto Itaipú) junto ao Rio Paraná, $240 \mathrm{~m}$, ca. $25^{\circ} 05^{\prime} \mathrm{S}$, 543'' $\mathrm{W}, 23-24-\mathrm{V}-1989$, P.G. Windisch 5469 (FCQ, UC).

Thelypteris riograndesis es una especie muy cercana a $T$. abbiattiae. En $T$. riograndensis las pinnas son fuertemente oblicuas, aserradas y auriculadas en la base, en T. abbiattiae las pinnas son horizontales o suboblicuas, crenadas o lobuladas y con yemas frecuentemente en el par de pinnas basales. Abarcan la misma área y no se han encontrado individuos intermedios.

39. Thelypteris scabra (C. Presl) Lellinger, Amer. Fern J. 74: 60. 1984. Polypodium scabrum C. Presl, Del. Prag. 1: 169. 1822.

Dryopteris oligophylloides Sehnem, Fl. Ilustrada Catarinense, I, ASPI: 124. 1979. Tipo: BRASIL. Rio Grande do Sul: Santa Maria, A. Dutra 115 (holotipo ICN!). syn. nov.

Figura 19A-D

Descripción e iconografía: Ponce (1988: 379).

Distribución y ecología: Se encuentra en Paraguay, S de Brasil, E de Argentina y Uruguay. Es una de las especies más comunes en bosques y formaciones en galería de los ríos, donde vegeta en sus orillas o en el sotobosque.

Materiales estudiados: BRASIL. Mato Grosso: Rio Sta. Luzia, Rio Brilhante, G. Hatschbach 25193 (UC). PARAGUAY. Amambay: Parque Nacional Cerro Corá, 30-X/4-XI-1983, M.S. Foster 83-2-32 (UC). Dpto. desconocido, Carapeguá, Rojas 3205
(SI); Flora Orientalis, 1914, Chodat s.n. (G); Chodat 49 (G). Canindeyú: Reserva Nacional Bosque Mbaracayú, Carapá, 6-X-1997, M. Peña-Chocarro 291 (CTES). Guairá: Cord. Ybytyruzú, road Melgarejo-Antena, on E slopes, $5 \mathrm{~km} \mathrm{~S}$ of Melgarejo, $25^{\circ} 48^{\prime} \mathrm{S}, 56^{\circ} 15^{\prime} \mathrm{W}, 13-\mathrm{III}-1989$, E.E. Zardini \& Velázquez 11463 (MO); 9-IX-1989, E.E. Zardini 14058 (G, UC); Cord. Ybytyruzú, road MelgarejoAntena, 2550'S, 56²10'W, 9-IX-1989, E.E. Zardini \& Velásquez 13974 (G, MO); Cord. de Ybytyruzú, road Melgarejo-Antena, $25^{\circ} 45^{\prime} \mathrm{S}, 56^{\circ} 15^{\prime} \mathrm{W}, 6 \mathrm{~km} \mathrm{~N}$ of Antena, 14-VII-1989, E.E. Zardini 13425 (G); road to Cantera Jhú, $8 \mathrm{~km} \mathrm{~S}$ of route to Coronel Oviedo, along Chorro Creek, 16-X-1989, E.E. Zardini 15003 (MO), a $3 \mathrm{~km}$ de Melgarejo, camino Co. Acatí, 24-VI-1989, A. Aguayo 560 (FCQ, G, MO, UC), Melgarejo-Cerro Acatí, $8 \mathrm{~km} \mathrm{~S}$ of Melgarejo, 25 $48^{\circ} \mathrm{S}$,

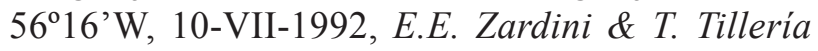
32638 (MO); Colonia Indepencia, $25^{\circ} 57^{\prime} \mathrm{S}, 56^{\circ} 17^{\prime} \mathrm{W}$, Arroyo Guazú, camino a San Gervasio, $250 \mathrm{~m}, A$. Schinini et al. 28047 (CTES); Syi, 24-V-1989, P.G. Windisch 5475 (UC). Paraguarí: Cerro Acahay, 28-VII-1988, S. Keel et al. 1552 (FCQ). Alto ParanÁ: Puerto Pampa, X-1901, Riemes 104, 115 (SI); in regione fluminis Alto Paraná, 1909-1910, K. Fiebrig 5634 (LIL, SI); Reserva Biológica Itabó, 1-X-1991, G. Caballero Marmori 2523 (CTES); sendero Carajá, junto ao Rio Paraná, ca. $240 \mathrm{~m}$, ca. 2505'S, 54³0'W, 24-V-1989, P.G. Windisch 5443, 5454 (FCQ, UC). CAAZAPÁ: Estancia Golondrina, Reserva Privada Ypeti, E.E. Zardini \& G. Hellman 48991 (UC).

Esta especie se caracteriza por el rizoma rastrero, láminas glabras o apenas pilosas sobre el raquis adaxial, gemíferas, e indusios espatulares inconspicuos.

40. Thelypteris schwackeana (H. Christ ex C. Chr.) Salino, Brittonia 54: 338. 2003. Dryopteris schwackeana C. Chr., Kongel. Danske Vidensk. Selsk. Skr., Naturvidensk. Math. Afd., ser. 7, 10: 243. 1913. Lectotipo: designado por Salino (2003): BRASIL. MinAs GERAIS: Ouro Preto, 22-VIII-1902, C.A.W. Schwacke 14892 (BM, no visto). Figura 2E

Descripción: Salino [2002 (2003: 338)].

Distribución y ecología: Endémica centro-sudeste de Brasil.

Materiales examinados: BRASIL. Minas Gerais: Caldas, 25-II-1876, C.W.H. Mosén 4616 (SI, imagen); Ouro Preto, locis humidis, 22-VIII-1902, 


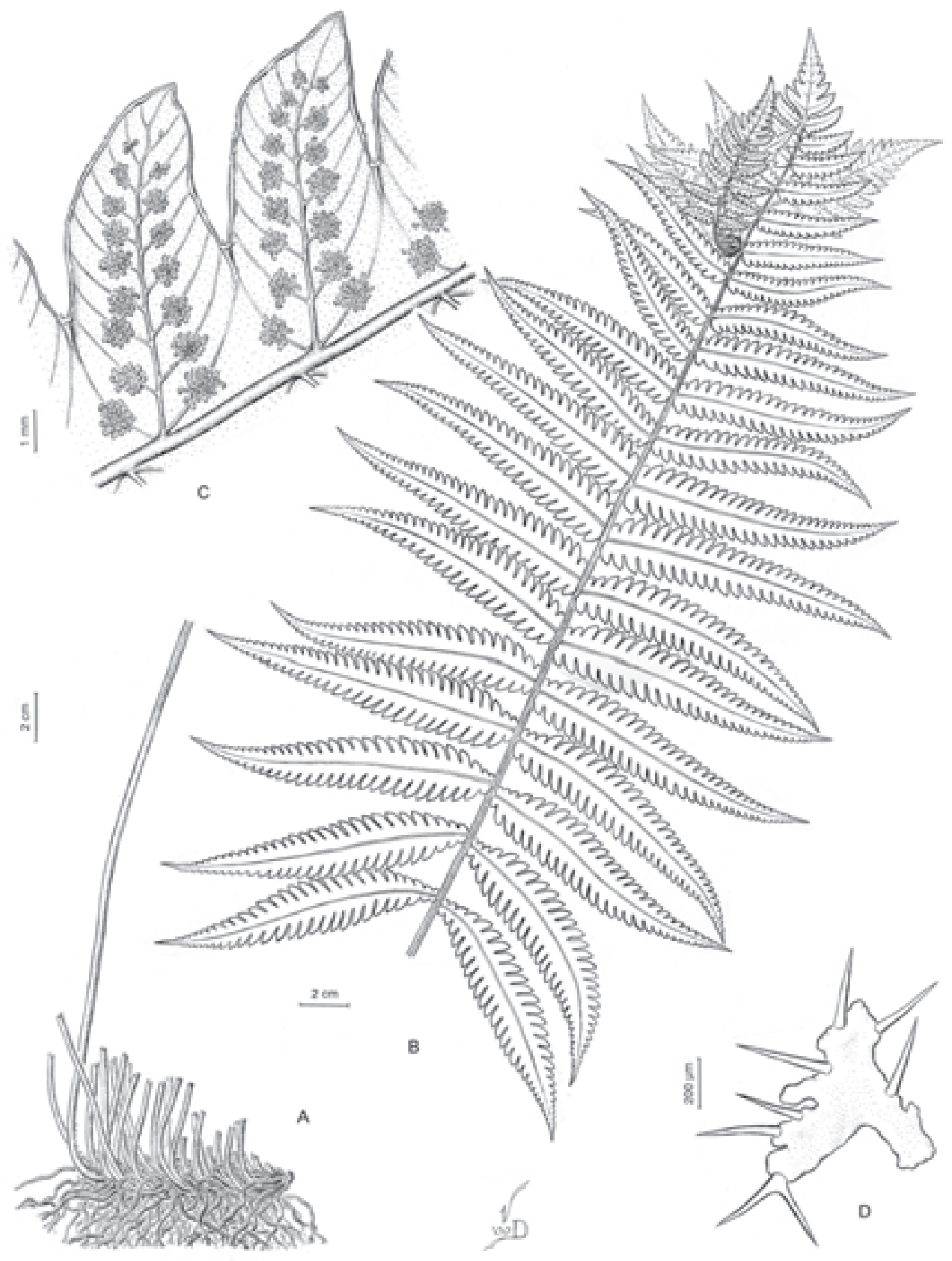

Figura 19A-D. Thelypteris scabra. A. Rizoma. B. Lámina. C. Segmentos cara abaxial. D. Indusio (Chodat 49). 
C.A.W. Schwacke 14892, 14893 (sintipos C).

Se caracteriza por el rizoma rastrero con escamas con pelos ramificados; raquis con pelos simples; pinnas inferiores reflexas, medias horizontales de base truncada, cara adaxial de los segmentos pilosa en costas y márgenes, cara abaxial con pelos simples y ramificados, 6-7 pares de venas, las 3 inferiores conniventes en el seno.

41. Thelypteris semirii Salino \& Melo, Novon 10: 74, fig. 1A-E. 2000.

Descripción e iconografía: Salino \& Melo (2000: 74). Distribución y ecología: En remanente del bosque atlántico y esporádicamente en bosques semidecíduos de la región. Terrestre en sitios sombríos y húmedos.

Materiales estudiados: BRASIL. MinAS GERAIS: Parque Florestal Estadual do Rio Doce, Trilha do Vinhático, 16-VI-1995, A. Salino 2167 (SI, UC); Viçosa, Agricultural College lands, road to São Miguel, 675 m, 19-III-1936, Y. Mexia 4487b (MO, UC); Carangola, Fazenda Santa Rita, 26-V-1989, A. Salino \& B. Cosenza 709 (UC); idem, s.d., A. Salino 2848 (UC).

42. Thelypteris tristis (Kunze) R.M. Tryon, Rhodora 69: 8. 1967. Polypodium triste Kunze, Linnaea 9: 47. 1834.

Figura 20D-E

Descripción e iconografía: Ponce (1988: 381); Smith (1993: 114).

Distribución y ecología: Presenta una distribución tropical-andina y amazónica, hallándose en Panamá, Colombia, Venezuela, Guayanas, Brasil amazónico, Ecuador, Perú, Bolivia y noroeste de Argentina. Terrestre en el interior del bosque.

Material estudiado: BRASIL. Mato Grosso: Juína, 29 $\mathrm{km} \mathrm{N}$ da cidade, P.G. Windisch 8512 A (SI).

Esta entidad se distingue por la base largamente cuneada de sus pinnas y la glabricie casi total de la lámina.

\section{Thelypteris subg. Meniscium}

Es un grupo exclusivo de América tropical y subtropical, con alrededor de 26 especies, estrechamente relacionado con el subg. Goniopteris. Sus especies habitan preferentemente ambientes bajos, húmedos o inundados. Sin endemismos en el área estudiada.

43. Thelypteris angustifolia (Willd.) Proctor, Bull. Inst. Jamaica, Sci. Ser. 5: 57. 1953. Meniscium angustifolium Willd., Sp. P1., ed. 4, 5(1): 133. 1810.
Polypodium salicifolium Vahl, Eclog. Amer. 3: 51. 1807. nom illeg., non Thelypteris salicifolium (Hook.) C.F. Reed.

Figura 20A-C

Descripción: Smith (1992: 93).

Distribución y ecología: Crece desde el sur de Mexico, América central y sur hasta Bolivia, centro-sudeste y sur de Brasil y Paraguay. Especie palustre, en bosques o pastizales, a la orilla de arroyos y en esteros.

Materiales estudiados: BRASIL. Goí́s: Serra Dourada, ca. $30 \mathrm{~km}$ SE of Goiás Velho, $650 \mathrm{~m}$, 21-I-1966, H.S. Irwin et al. 11943 (MO). MinAS GeraIs: Cascata, Patos de Minas, 700 m, 31-VIII-1950, A.P. Duarte 3041 (MO). Mato Grosso do Sul: Crassilândia, ca. 46 km de Cassilândia, 11-XI-1995, M.R. Pietrobom-Silva \& M. de Lucca Júnior 2482 (CTES). PARAGUAY. Amambay: Parque Nacional Cerro Corá, along banks of creek through forest, 18-IX-1980, M. Foster 80-2-41 (UC), 30-X-1983, M. Foster 83-2-15 (UC); Sierra de Amambay, "In altaplanitie et declivibus, 1907-1908”, Rojas 10500c (G); "r. Esperanza ad ripas, 1907-1908", Rojas $10508(\mathrm{G})$.

44. Thelypteris arborescens (Humb. \& Bonpl. ex Willd.) C.V. Morton, Contr. U.S. Natl. Herb. 38: 50. 1967. Meniscium arborescens Humb. \& Bonpl. ex Willd., Sp. Pl., ed. 4, 5(1): 133. 1810.

Descripción e iconografía: Smith (1992: 70, 1993: 82). Distribución y ecología: Crece de Honduras a Bolivia y Guayanas a Brasil central. En bosques a la orilla de ríos, arroyos o cascadas.

Materiales estudiados: BRASIL. CEARÁ: Pará-Gomes, Fr. Allemão \& M. de Cysneiros 1689 (R). Goiás. ca. $63 \mathrm{~km}$ da cidade, estrada Aporé-Serranópolis, Cachoeira do Rio Correntes $18^{\circ} 50^{\prime} \mathrm{S}, 52^{\circ} 05^{\prime} \mathrm{W}, 610 \mathrm{~m}$, 3-IV-1992, P.G. Windisch et al. 6983 (SJRP). MinAS Gerais: Minas, Sabará, I-1916, F.C. Hoehne 6771, $6774(\mathrm{R})$.

45. Thelypteris chrysodioides (Fée) C.V. Morton, Contr. U.S. Natl. Herb. 38: 51. 1967. Meniscium chrysodioides Fée, Gen. Fil.: 225. 1852.

Dryopteris chrysodioides (Fée) Maxon \& C.V. Morton var. goyazensis Maxon \& C.V. Morton, Bull. Torrey Bot. Club 65: 374. 1938. Thelypteris chrysodioides var. goyazensis (Maxon \& C.V. Morton) C.V. Morton, Contr. U. S. Natl. Herb. 38: 51. 1967.

Figura 20B-C 
Descripción e iconografía: Smith (1993: 86).

Distribución y ecología: Se encuentra en Ecuador, Bolivia, Guyanas y norte y centro de Brasil. Palustre en suelos inundados de bosques en galería o pantanos.

$\mathrm{Su}$ presencia en Paraguay es muy probable ya que en el herbario histórico de Asunción (AS) se encuentra material de esta especie, aunque no se puede citar por carecer de datos de colección.

Materiales examinados: BRASIL. GoIÁs: Vallee du Rio Corumbá, 23-VII-1894, M.A. Glaziou 22631
(UC, isotipo de la var. goyazensis, no visto); Gurupi, Gurupi, 1 km W of Belém-Brasília highway, $11^{\circ} 43^{\prime} \mathrm{S}$, 494'W, 350-400 m, 19-IX-1963, G. Eiten \& L.T. Eiten 5583 (MO). Mato Grosso: Guarantá do Norte, Serra do Cachimbo, à esquerda do Rio Braço Norte, ca. 545'' 'W, 950'S, 16-VII-1995, A.P.N. Soares 30 (HB, SJRP); Ribeirão da Cascalheira, Expedition Base Camp, near Base Camp, 12 $49^{\prime} \mathrm{S}, 51^{\circ} 46^{\prime} \mathrm{W}$, 7-VIII-1968, P.W. Richards 6622 (MO); Localidad desconocida, H. Smith 120 (R).

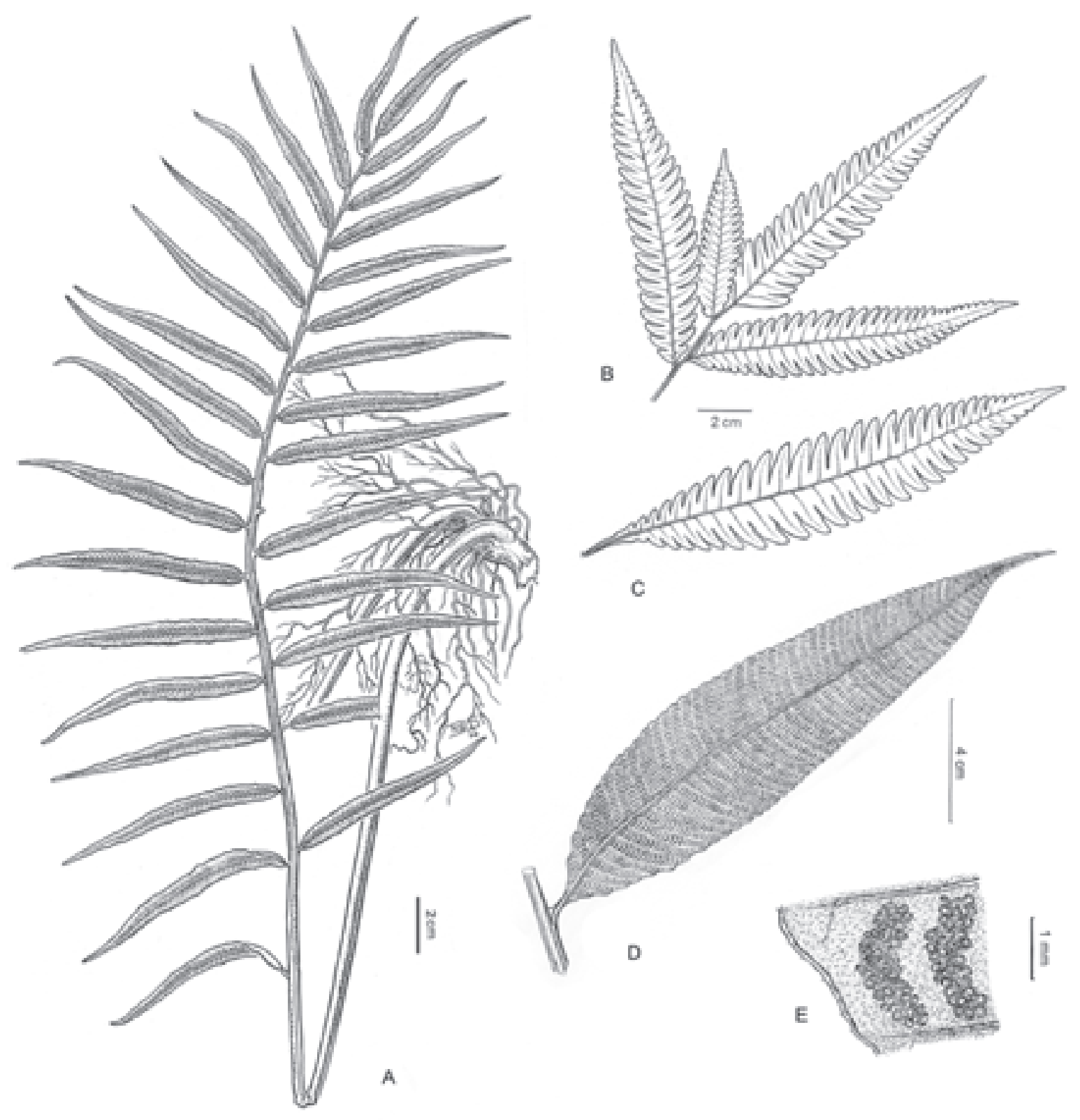

Figura 20. A. Thelypteris angustifolia, Aspecto general (Hassler 10500). B. T. tristis, Ápice de la lámina. C. Pinna media. (Windisch 8512). D-E. T. chrysodioides. D. Pinna. E. Detalle soros (Pietrobom-Silva 4416). 
Se caracteriza por sus pinnas elípticas $(3-7 \mathrm{~cm}$ lat.) de ápice acuminado, margen subrepando a crenado, por los soros lunulados, confluentes a la madurez, con esporangiáster y esporanfios con pelos(1-3) en el pie (inconspicuos).

46. Thelypteris longifolia (Desv.) R.M. Tryon, Rhodora 69: 7. 1967. Meniscium longifolium Desv., Mém. Soc. Linn. Paris 6: 223. 1827.

Dryopteris handroi Brade, Arq. Jard. Bot. Rio de Janeiro 18: 29. 1965. Meniscium handroi (Brade) Brade, Bradea 1: 229. 1972. Tipo: BRASIL. São Paulo: Moji Guaçu, Reserva Florestal, 19-IX-1956, Handro 629 (holotipo, SP!), syn. nov.

Figura 21

Descripción e iconografía: Smith (1983: 123).

Distribución y ecología: Se encuentra en Ecuador, Bolivia, Guyanas y norte y centro de Brasil y Paraguay. Terrestre o palustre en selva en galería o suelos pantanosos.

Crece en bosques primarios o degradados, a orillas de cursos de agua y en pantanos.

Material examinado: BRASIL. Distrito Federal: Reserva Águas Emendadas, 24-I-1978, A. Krapovickas \& C. Cristóbal 33228, 33233 (CTES). Goiás: Pirenópolis, Serra dos Pireneus, Fazenda Sola dos Pireneus, G. Hatschbach et al. 70263 (MBM, UC); idem, Anderson 8149 (UC). Mato Grosso: Serra do Roncador, ca. $86 \mathrm{~km} \mathrm{~N}$ of Xavantina, 550 m, 31-V-1966, H.S. Irwin et al. 16304 (MO); Bacia do Rio Xingú, estrada Barra do Garça a Canarana (BR 158) $13^{\circ} 35^{\prime} \mathrm{S}, 52^{\circ} 00^{\prime} \mathrm{W}, 400 \mathrm{~m}$, 15-X-1990, P.G. Windisch 5856 (SI, SJRP, UC). Minas Gerais: Conceição do Mato Dentro, Pito Aceso, 19-V-1989, G. Hatschbach \& M. Hatschbach 52933 (MBM, UC). PARAGUAY. Amambay: Sierra de Amambay, 8-IV-1907, E. Hassler \& Rojas 10443 (G, sub Dryopteris guaranitica).

Es una especie muy frecuente en Brasil, se caracteriza por sus pinnas largamente oblongoelípticas, leve a densamente pilosas o glandulosopilosas en la cara abaxial y por los esporangios con 1-2 pelos en el pie que terminan en 2 células aciculares y una capitada.

Para Paraguay se la citó como Dryopteris guaranitica Rosenst. en Hassler, Trab. Inst. Bot. Farmacol. 45: 24. 1928, nom. nud.

Thelypteris arborescens y T. maxoniana A.R. $\mathrm{Sm}$., presentes en la región andina y el centro-sudeste de Brasil, son entidades muy cercanas a T. longifolia.

47. Thelypteris maxoniana A.R. Sm., Fieldiana, Bot. 29: 71. 1992.

Doryopteris desvauxii Mett. f. glandulosa Maxon \& C.V. Morton, Bull. Torrey Bot. Club 65: 372. 1938.

Figura 21

Descripción e iconografía: Smith (1992: 71).

Distribución y ecología: Se encuentra en Colombia, Ecuador, Perú, Bolivia y centro de Brasil (Mato Grosso, Goiás, Distrito Federal y Minas Gerais), terrestre o palustre en bosques en galería inundables o en pantanos y lechos de arroyos.

Materiales examinados: BRASIL. Distrito FEDERAL: ca. $35 \mathrm{~km} \mathrm{SW}$ of Brasília on road to Anápolis, 700-1.000 m, 6-IX-1964, H.S. Irwin \& T.R. Soderstrom 6042 (MO). MinAs GerAIs: Chapada dos Guimarães, 17-II-1988, A. Salino 407 (SJRP); Conceição do Mato Dentro, Pito Aceso, 19-V-1989, G. Hatschbach et al. 52933 (CTES). Mato Grosso: Água Boa, estrada de Canarana a Paranatinga, $13^{\circ} 45^{\prime} \mathrm{S}, 52^{\circ} 45^{\prime} \mathrm{W}, 350-400 \mathrm{~m}$, Bacia do Rio Xingú, 15-X-1990, P.G. Windisch 5871 (HB, SJRP, SI, UC); Canarana, Bacia do Rio Xingú, estrada para Paranatinga, ca. $4 \mathrm{~km}$ de Canarana, $13^{\circ} 30^{\prime} \mathrm{S}, 52^{\circ} 20^{\prime} \mathrm{W}$, 400 m, 14-X-1990, P.G. Windisch 5864, 5869 (HB, SI, UC); Jaurú, distrito de Taquarucú, Rio Jaurú,15¹0'S, $58^{\circ} 45^{\prime} \mathrm{W}, 430$ m, 9-XII-1991, P.G. Windisch \& J. Pires 6709, 6710, 6718 (SI, SJRP).

48. Thelypteris salzmannii (Fée) C.V. Morton, Los Angeles County Mus. Contr. Sci. 35: 7. 1960. Meniscium salzmannii Fée, (Mém. foug. 5) Gen. fil.: 223. 1852.

Figura 22

Descripción e iconografía: Smith (1983: 129, 1992: 73). Distribución y ecología: Se encuentra desde Venezuela a Bolivia y centro-sudeste de Brasil y Paraguay. Helecho frecuente en cerrados arbustivos o bosques montanos, en la orilla de ríos, esteros o pantanos.

Materiales examinados: BRASIL. GoIÁs: Goiás Velho, the beaker beyond church of Santa Barbara, 8-XI-1976, J. Wilson $5 W$ (MO); $30 \mathrm{~km} \mathrm{~N}$ de Itumbiara, BR-153, 20-I-1978, A. Krapovickas et al. 33120 (CTES); Chapada dos Veadeiros, $18 \mathrm{~km} \mathrm{~N}$ of São João da Aliança. 14³0'S, 47³0'W, 20-IV-1956, Y. Dawson 14493 (MO); Aporé, estrada Aporé-Serranópolis, km 22, 500 m, 3-IV-1992, P.G. Windisch et al. 6900 
(SJRP), idem, Anderson 6300, 7232 (UC). Distrito FEDERAL: Sobradinho, ca. $20 \mathrm{~km}$ E de Brasília, 1.000 m, 6-VII-1966, H.S. Irwin et al. 18029 (MO). MinAS Gerais: Serra da Anta, Cerrado ca. $2 \mathrm{~km} \mathrm{NW}$ of Paracatú, 700 m, 7-II-1970, H.S. Irwin et al. 26282 (MO, UC); Diamantina, Trinta Reis, 13-III-1989, R.F. Novelino 652 (SI); Santa Barbara, 13-II-1934, A.J. de Sampaio 6980 (R); Belo Horizonte, Serra do Taquaril, 21-II-1934, A.J. de Sampaio 7183 (R);
Joaquim Felício, Rio da Onça, 14-IV-1996, G. Hatschbach et al. 64932 (CTES, MBM, UC); Buenópolis, Serra do Cabral, $7 \mathrm{~km}$ da cidade $17^{\circ} 53^{\prime} \mathrm{S}$,

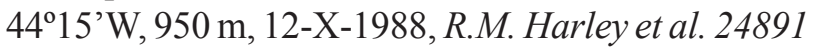
(SI); Serra do Espinhaço, $18 \mathrm{~km}$ W of Grão Mogol, 950 m, 17-II-1969, H.S. Irwin et al. 23441 (MO, UC); Diamantina, 8-XII-1992, estrada para Biribiri, $A$. Salino 1556 (SI, UC); Serra do Espinhaço, ca. $33 \mathrm{~km}$ $\mathrm{W}$ of Montes Claros, road to Água Boa, $1.000 \mathrm{~m}$,

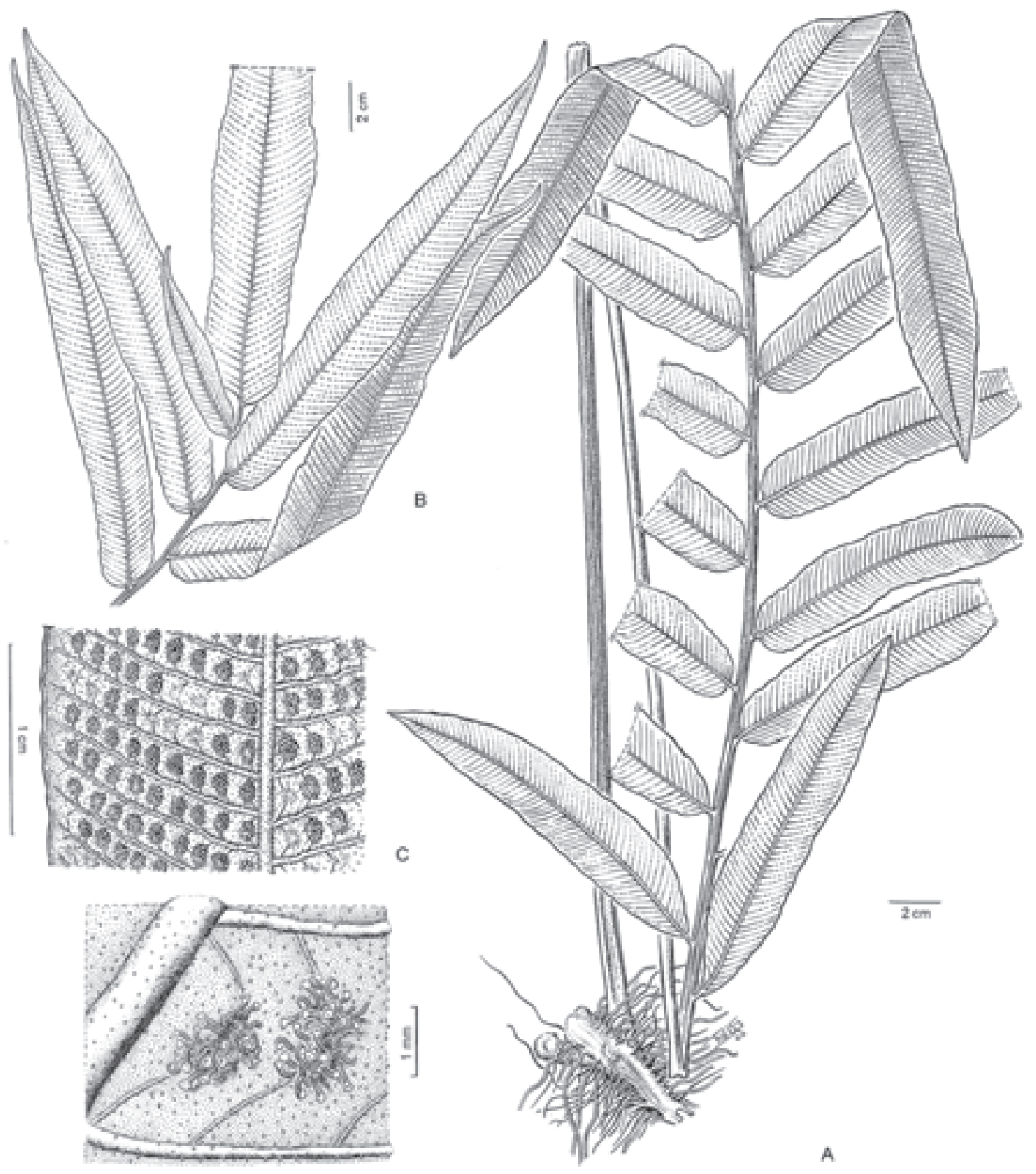

Figura 21A-C. Thelypteris longifolia. A. Aspecto general. B. Sector apical de la lámina. C. Detalle cara abaxial (Hassler \& Rojas 10443). D. T. maxoniana, Detalle cara abaxial de pinna fértil (Windisch 5871). 
23-II-1969, H.S. Irwin et al 23730 (MO); Buenópolis, Curimataí, 9-VI-2004, G. Hatschbach et al. 77656 (MBM). Mato Grosso: Chapada dos Guimarães, estrada para Campo Verde, $620 \mathrm{~m}$, Rio da Casca, 1-X-1990, P.G. Windisch et al. 5799 (HB, SJRP); Guarantã do Norte, Serra do Cachimbo, à esquerda do Rio Braço Norte, ca. 050'S, 545' 'W, 16-VII-1995, A.P.N. Soares 34 (SI). PARAGUAY. CoRDILLERA. Valenzuela, Mbocayá guazú, 26-XII-1950, G.J. Schwarz 11332 (LIL); Altos, camino a Loma Grande, $25^{\circ} 17^{\prime} \mathrm{S}, 5^{\circ} 15^{\prime} \mathrm{W}, 19-\mathrm{VII}-1989$, I. Basualdo
2605 (FCQ, G, MO); $1 \mathrm{~km}$ E of Nueva Colombia on road to Atyra, $25^{\circ} 17^{\prime} \mathrm{S}, 57^{\circ} 13^{\prime} \mathrm{W}, 26-\mathrm{V}-1990$, E.E. Zardini \& R. Velázquez 20506 (MO), on arroyo Mbaéy, 2511'S, 57¹7’W, 17-VI-1992, E.E. Zardini \& T. Tillería 32197 (MO); desvío de la Ruta para ramal Piribebuy-Paraguarí, ca. $3 \mathrm{~km}$ sobre la ruta, 21-VII-1995, M.R. Pietrobom-Silva et al. 2121 (MO). CAaguazú: desvío a Yhú, 19-IV-1990, I. Basualdo 2864 (FCQ, MO). CAAZAPÁ: Tavai, detrás del hospital, $26^{\circ} 10^{\prime} \mathrm{S}, 55^{\circ} 17^{\prime} \mathrm{W}, 19-\mathrm{V}-1989$, N. Soria 3932 (FCQ). Dpto. desconocido, Tucauqua, Chodat 40 (G).

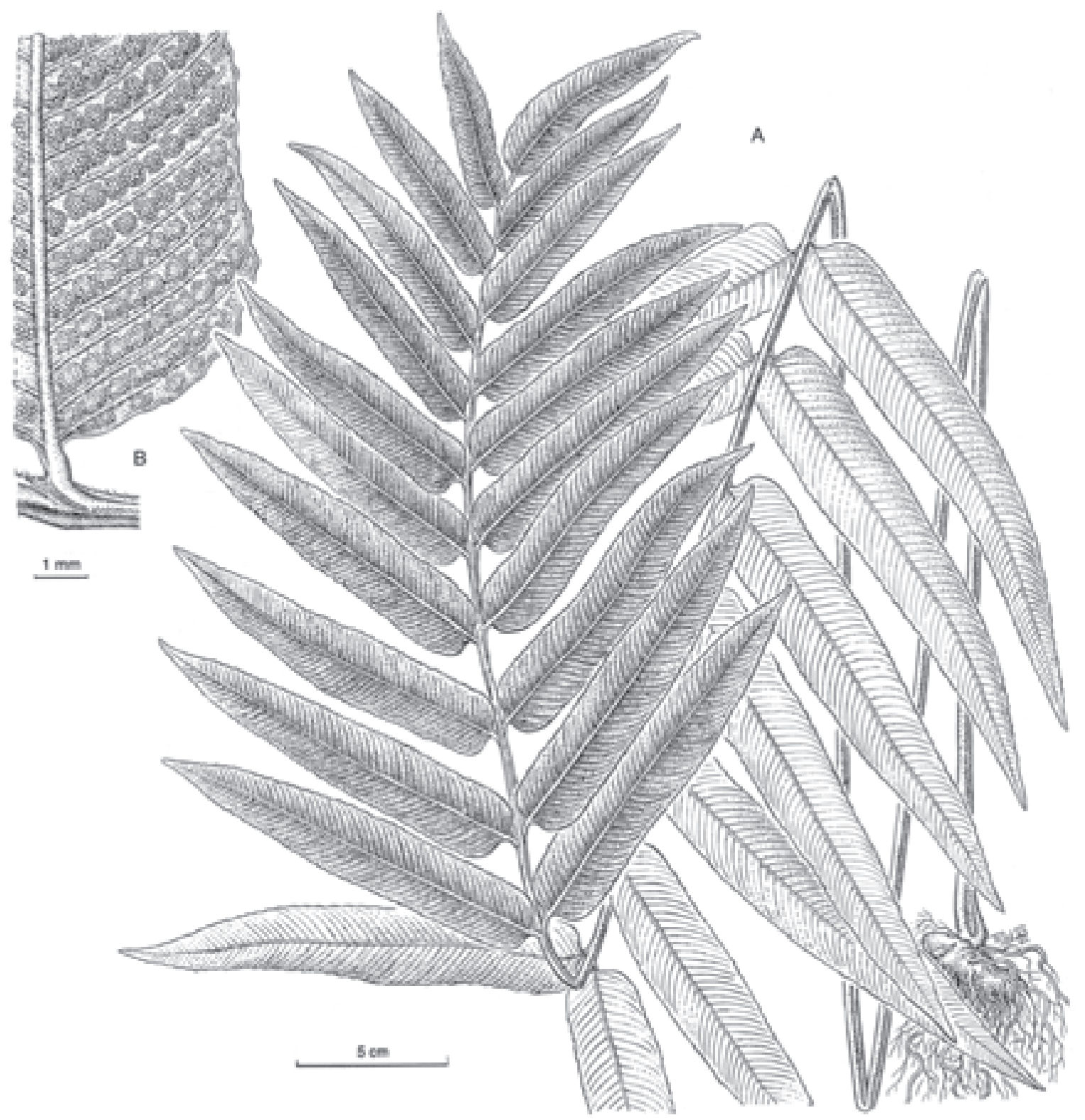

Figura 22A-B. Thelypteris salzmannii. A. Aspecto general. B. Detalle pinna fértil (Zardini \& Tellería 32197). 
49. Thelypteris serrata (Cav.) Alston, Kew Bull. 1932: 309. 1932. Meniscium serratum Cav., Descr. pl.: 548. 1802.

\section{Figura 23}

Descripción e iconografía: Ponce (1988: 382); Smith (1992: 71).

Distribución y ecología: Desde Florida (USA), Antillas, sur de Mexico hasta Panamá, Colombia a Guyanas y Bolivia, Brasil, Paraguay y N de Argentina. Helecho terrestre o palustre, vegeta a orillas de ríos y en pantanos.

Materiales examinados: BRASIL. GoIÁs: $19^{\circ} 57^{\prime} \mathrm{S}$, $52^{\circ} 01^{\prime} \mathrm{W}$, Rod. Aporé-Serranópolis, ca. $23 \mathrm{~km}$ de Aporé, 1-VIII-1995, M.R. Pietrobom-Silva 2290 (MBM). Mato Grosso: Rosário do Oeste, córrego do Custódio, estrada para Cuiabá, $14^{\circ} 20^{\prime} \mathrm{S}, 56^{\circ} 25^{\prime} \mathrm{W}$, 300-350 m, 17-VII-1991, P.G. Windisch \& W. Oliveira 6512 (SI); Salto do Céu, estrada Nova Fernandópolis a Salto do Céu, ca. $20 \mathrm{~km}$ após Cristinólpolis, 15¹0'S, 58¹6'W, 28-XII-1994, P.G. Windisch et al. 7794 (SI); Dourados, Fazenda de Carambá, Estrada Maracajú, $35 \mathrm{~km}$ N from Dourados, 650-700 m, 11-III-1978, K. Mizoguchi 524 (MO, UC); Cocalinho, Bacia do Rio Araguaia, ca. $9 \mathrm{~km}$ da balsa, MT-326, ca. $240 \mathrm{~m}$, ca. 14²0'S, 51ํ1' W, 23-X-1992, P.G. Windisch 7084 (SI). Minas Gerais: Marliéria, PFE Doce, Salão Dourado, 15-VI-1995, A. Salino 2146 (UC). PARAGUAY. Amambay: P.N. Cerro Corá, 22-VIII-1980, A. Schinini \& Bordas 20333 (CTES, MO), 18-IX-1980, M.S. Foster 80-2-30 (UC), Arroyo Aquidabán Nigui, 22³9'S, 5603'W, 300 m, 20-II-1982, J. Solomon et al. 7089 (MO, PY, UC), camino al monumento, 5-I-1988, E.E. Zardini et al. 4056 (FCQ, G, MO), Cerro Tuyá, ad 300 m, 9-II-1982, J. Fernández Casas \& J. Molero 6109 (MO). CANINDEYú: “in palude pr. Igatimí”, 1898-1899, E. Hassler 4835, 5476 (G, UC), Sierra de Amambay, 1907-1908, E. Hassler \& Rojas 10164 (G); Sin indicación de departamento. Paraguay septentrionalis, 1905, K. Fiebrig $5113 a(\mathrm{G})$; idem, P. Jörgensen 4607 (MO); Yuquerí?, 1885-1895, E. Hassler 1539 (G, UC) $1539 a(\mathrm{G})$. Alto Paraguay: Río Tapiracuai, 26-XII-1958, A.L. Woolston 1048 (UC). CORDILlERA: Co. Zanja Jhú, $1 \mathrm{~km}$ E from R 1 to Atyra, $26^{\circ} 13^{\prime} \mathrm{S}$, 5709'W, 25-VI-1988, E.E. Zardini 5159 (FCQ, G, MO), Valenzuela, 17-XII-1950, G. J. Schwarz 11091 (LIL); $1 \mathrm{~km}$ E of Nueva Colombia on road to Atyra,

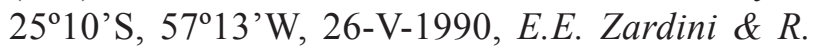
Velázquez 20450 (MO), 20511 (MO, UC). ItAPUA:
Yacyreta dam island reserve, $27^{\circ} 29^{\prime} 20^{\prime}$ 'S, 56 45'17' 'W, 5-XII-2002, E.E. Zardini \& $R$. Gamarra 59258 (UC). PARAGUARI: Yaguarón, II-1877, B. Balansa 324 (G, PY); Co. Chololo, 3-IX-1976, A. Schinini 13390 (CTES); Parque Nacional Ybycu'i, along tributary ayo. Mina, NE corner of park, $26^{\circ} 03^{\prime} \mathrm{S}$, 5650'W, 14-XII-1988, E.E. Zardini 8757 (G, MO, PY); NW of park, 27-I-1989, E.E. Zardini \& Velásquez 10424 (G, MO, PY); along tributary ayo. Mina, 10-III-1989, E.E. Zardini \& Velázquez 11718 (G, MO, PY); 5 km N of administr. area, 4-IV-1989, E.E. Zardini 12668 (G, MO, PY); Pirayú, entrada al pueblo, 15-I-1989, F. Mereles 2479 (FCQ, G); 10 km de Paraguarí, camino a Peribebuy, 6-II-1966, $A$. Krapovickas et al. 12442 (CTES). CAAZAPÁ: Tavai, estero de entrada al pueblo, 26ํ'10'S, 55²0'W, 20-XII-1988, F. Mereles 2342 (G, MO); prop. de la familia Centurión, $26^{\circ} 10^{\prime} \mathrm{S}, 5^{\circ} 20^{\prime} \mathrm{W}, 17-\mathrm{III}-1989$, I. Basualdo 2260

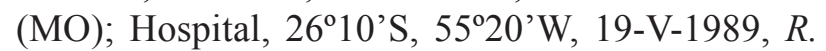
Degen 1545 (FCQ). CONCEPCIÓN: In regione calcarea cursus sup. r. Apa, 1912-1913, E. Hassler 11628 (G). SAN PEDRo: Río Corrientes, ayo. Retama, 19-VI-1977, A. Krapovickas \& A. Schinini 32578 (CTES). Alto Paraná: Reserva Biológica Itabó, 2-VI-1988, G.C. Marmori 1382 (CTES).

\section{Thelypteris subg. Steiropteris}

Subgénero neotropical con unas 21 especies, se distribuye desde el sur de México y Antillas hasta Bolivia, Paraguay y sur de Brasil. Su grupo más afín es Goniopteris (Smith 1980, 1992). En el área se hallan cinco taxones, dos endémicos.

50. Thelypteris decussata (L.) Proctor var. brasiliensis (C. Chr.) A.R. Sm., Univ. Calif. Publ. Bot. 76: 15. 1980. Dryopteris decussata (L:) Urb. var. brasiliensis C. Chr., Kongel. Danske Vidensk. Skr., Naturvidensk. Afd. 7, 10: 161. 1913.

Descripción: Smith (1980: 15).

Distribución y ecología: Especie común de sudeste de Brasil, también se encuentra en Minas Gerais.

Material examinado: BRASIL. MinAs GeraIs: Juiz de Fora, 1986, L. Krieger 3585 (UC, UFJF no visto)

51. Thelypteris gardneriana (Baker) C.F. Reed, Phytologia 17: 278. 1968. Nephrodium gardnerianum Baker, Fl. Bras. 1(2): 474. 1870.

Descripción: Smith (1980: 19).

Distribución y ecología: Ecuador, Bolivia y centro- 
sudeste de Brasil. Bosques montanos, alrededor de los $1.000 \mathrm{~m}$, sobre piedras en cascadas y arroyos.

Materiales estudiados: BRASIL. Espírito SAnto: Castelo, Braço do Sul, 9-VIII-1948, A.C. Brade 19210 (MO). Minas Gerais: Ouro Preto, Itacolomí da Serra, 28-XII-1950, J. Badini 2771 (MO); Ouro Preto, XI-1910, Caluçaz(?), F.M. Gomes 4117 (R).

52. Thelypteris hatschbachii A.R. Sm., Univ. Calif. Publ. Bot. 76: 22. 1980.

Figura 24
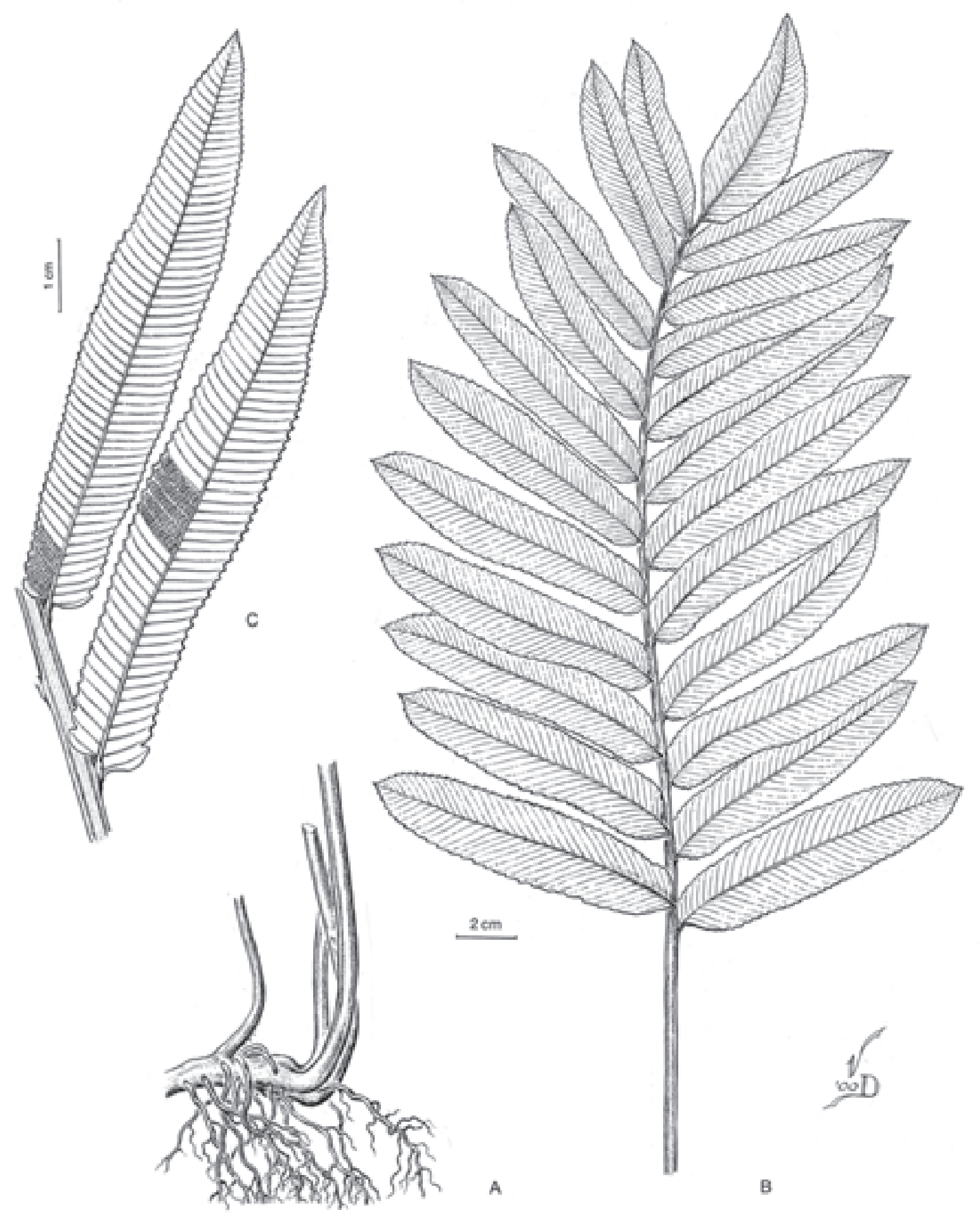

Figura 23A-C. Thelypteris serrata. A. Rizoma. B. Lámina. C. Pinnas fértiles (Hassler 11628). 
Descripción e iconografía: Smith (1980: 22).

Distribución y ecología: Endémica del nordeste y centrosudeste de Brasil. En bosques montanos y en galería.

Materiales estudiados: BRASIL. BAHIA: Camaca, $2 \mathrm{~km}$ a S de Camaca, estrada para Pau-Brasil, 23-IV-1983, A.M. de Carvalho et al. 1886 (SJRP). Minas Gerais: Ouro Preto, 5-V-1895, F.M. Gomes 2524 (R).

53. Thelypteris mexiae (C. Chr. ex Copel.) Ching, Bull. Fan. Mem. Inst. Biol. Bot. Ser. 10: 252. 1941. Dryopteris mexiae C. Chr. ex Copel., Univ. Calif. Publ. Bot. 17: 32, fig. 6. 1932.

Descripción: Smith (1980: 28).

Distribución y ecología: Endémica del nordeste y centro-sudeste de Brasil. En bosques y quebradas.

Materiales estudiados: BRASIL. MinAs GerIAs: Viçosa, Agricultural Lands, $690 \mathrm{~m}$, hill NW of main buildings, 14-VII-1930, Y. Mexia 4858 a (MO, UC); Viçosa,
Agricultural College, 725 m, 25-VII-1930, Y. Mexia 4904 (MO, UC); Viçosa, Agricultural College land, 690 m, near E boundary 25-III-1930, Y. Mexia 4514 (MO, UC isotipos).

54. Thelypteris leprieurii (Hook.) R.M. Tryon var. leprieurii, Rhodora 69: 6. 1967. Nephrodium leprieurii Hook., Sp. fil. 4: 106. 1862.

Figura 25

Descripción e iconografía: Smith (1980: 24).

Distribución y ecología: Se distribuye en Panamá, Guayanas, Trinidad, Venezuela, Colombia a Bolivia y norte, centro-sudeste de Brasil y Paraguay. En bosques primarios, palustre o en la barrancas de arroyos.

Materiales examinados: BRASIL. MAto Grosso: Colider, Fazenda Geo-açu, 15-I-1988, A. Salino 318 (SJRP, UC). PARAGUAY. CANINDEYÚ: Carapa (Yku'a), 11-X-1996, B. Jiménez. \& G. Marín 1628 (BM).

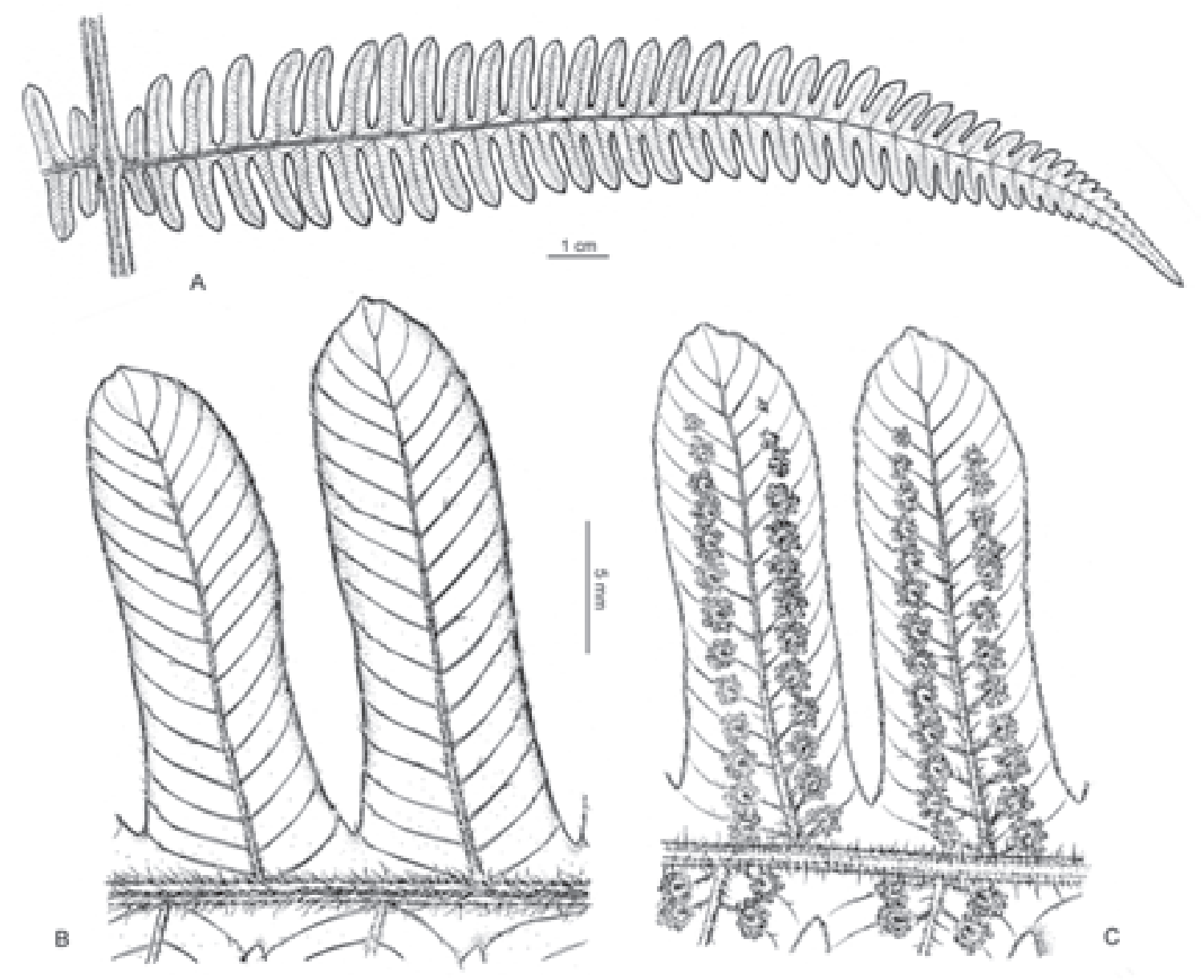

Figura 24A-C. Thelypteris hatschbachii. A. Pinna. B. Segmentos cara adaxial. C. Segmento cara abaxial (Carvalho et al. 1886). 
Se caracteriza por los ejes con pelos 1-celulares, aciculares y setiformes de diferentes longitudes (ca. $0,2 \mathrm{~mm}$ long.) y por los soros medios o subcostales con indusios acicular-pilosos.
55. Thelypteris leprieurii (Hook.) R.M. Tryon var. glandifera A.R. Sm., Univ. Calif. Publ. Bot. 76: 25. 1980.

Figura 25C
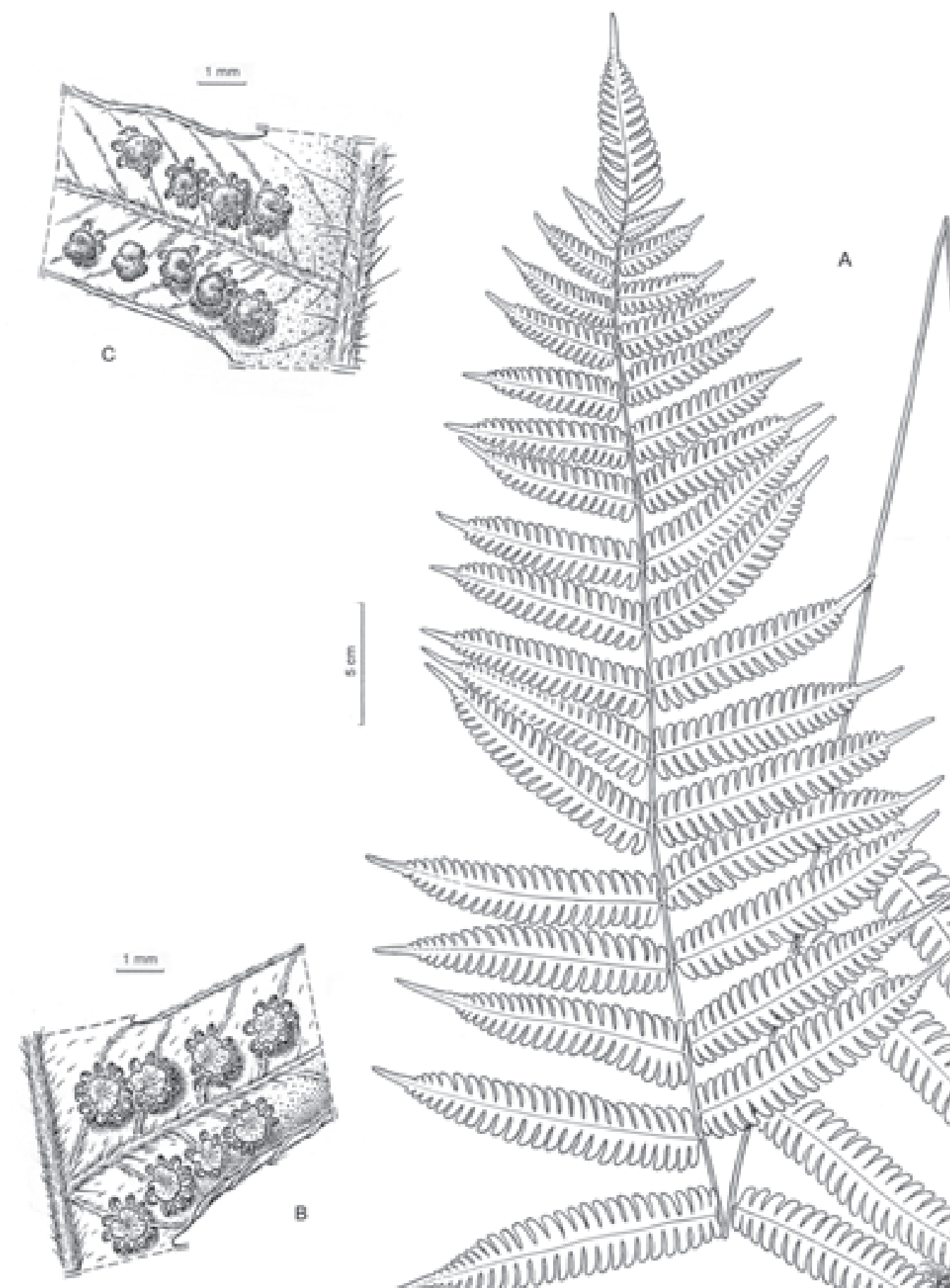

A
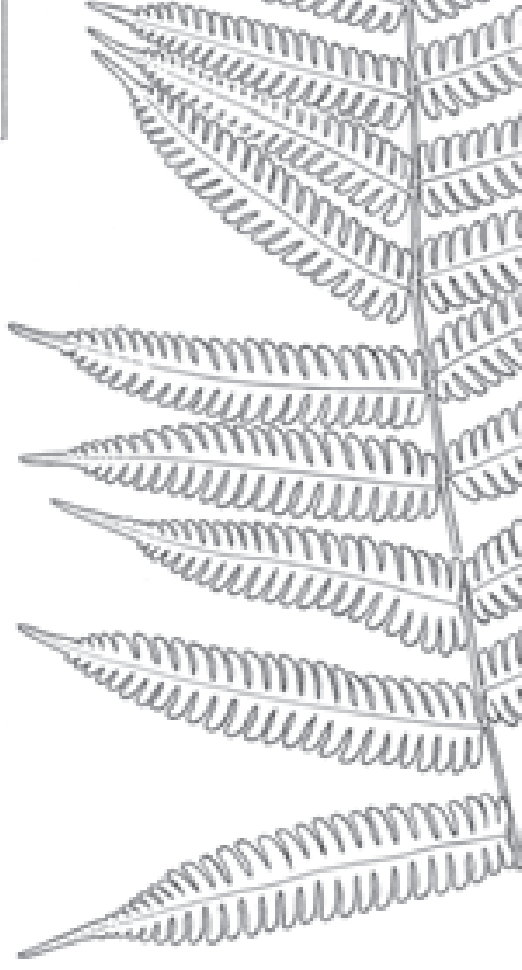
Descripción e iconografía: Smith (1980: 25).

Distribución y ecología: Se encuentra en Perú, Bolivia y Brasil (centro-sudeste). Cerrado con bosques en galería, orillas de cascadas y arroyos.

Materiales estudiados: BRASIL. Goiás: Aporé, Rodovia GO-184 Aporé-Serranópolis, ca. 58 km de Aporé, $19^{\circ} 03^{\prime} \mathrm{S}, 52^{\circ} 01^{\prime} \mathrm{W}, 620 \mathrm{~m}$, Rio Cachoeira do Corrente, 10-VI-1993, M.R. Pietrobom-Silva 867 (SJRP); idem, Anderson 10145 (UC)

Se distingue por los indusios con pelos glandulares, subsésiles.

\section{Agradecimientos}

Se desea agradecer a los herbarios BM, CTES, G, FCQ, K, P, PY y UC por la atención brindada durante las visitas a esas instituciones $\mathrm{y}$, que junto con los herbarios B, BHCB, C, ICN, HB, LP, MO, PY, R, $\mathrm{RB}, \mathrm{S}, \mathrm{SJRP}$ y SP, prestaron el material para estudio y enviaron imágenes de los especímenes históricos. Un cordial agradecimiento a Alan R. Smith por su apoyo en conocimientos y hospitalidad. Un sincero reconocimiento a Paulo G. Windisch, Alexandre Salino y Márcio Pietrobom-Silva por sus colecciones que constituyen una parte muy importante de este trabajo y a Vladimiro Dudas y Francisco Rojas del Instituto de Botánica Darwinion por sus ilustraciones. Se agradece el apoyo recibido de los proyectos (PICT 0212, PIP 4120/96, PIP 2514/01) financiados por la Agencia de Promoción Científica y el Consejo Nacional de Invetigaciones Científicas y Técnicas.

\section{Literatura citada}

Abbiatti, D. 1964. Estudios sobre Pteridofitas austroamericanas de los géneros Thelypteris, Cyclosorus y Goniopteris Darwiniana 13: 537-567.

Cabrera,A.L. \& Willink, A. 1973. Biogeografía de América Latina. Serie Biología, Monogr. 13. Secretaría General de la Organización de los Estados Unidos.

de la Sota, E.R. 1977. Pteridofitas. In: A.L. Cabrera (ed.). Flora de la Provincia de Jujuy. Colección Científica, Instituto Nacional Tecnología Agropecuaria 8: 1-275.

Holttum, R.E. 1971. Studies in the family Thelypteridaceae III. A new system of genera in the Old World. Blumea 19: 17-52.

Moran, R.C. 1995. The importance of mountains to Pteridophytes, with emphasis on Neotropical montane forests. In: S.P. Churchill, H. Balslev, E. Forero \& J. L. Luteyn (eds.). Biodiversity and Conservation of Neotropical Montane Forest. The New York Botanical Garden, Bronx, pp. 359-363.
Oliveira P. \& Marquis, R.J. 2002. The cerrados of Brazil and natural history of neotropical savanna. Columbia University Press, New York.

Peña-Chocarro, M.C., Jiménez, B., Marín, G. \& Knapp, S. 1999. Helechos de Mbaracayú. The Natural History Museum, London.

Ponce, M.M. 1988(1987). Revisión de las Thelypteridaceae (Pteridophyta) argentinas. Darwiniana 28:317-390.

Ponce, M.M. 1995. Las especies austrobrasileñas de Thelypteris subgen. Amauropelta (Thelypteridaceae, Pteridophyta). Darwiniana 33: 257-283.

Ponce, M.M. 1998. Novedades en Thelypteris subg. Amauropelta (Thelypteridaceae) de Brasil y Paraguay. Novon 8: 275-279.

Salino, A. 2000. A new species of fern genus Thelypteris (Thelypteridaceae) from southeastern Brazil. Novon 10: 74-77.

Salino, A. 2002a. Thelypteridaceae (Polypodiophyta) do Estado de São Paulo: Macrothelypteris e Thelypteris subgêneros Cyclosorus e Steiropteris. Lundiana 3: 9-27.

Salino, A. 2002b. New species and combinations in Thelypteris subg. Goniopteris (Thelypteridaceae). Brittonia 54: 331-339.

Salino, A. \& Semir, J. 2003. Notas sobre duas espécies de Thelypteris Schmidel (Thelypteridaceae - Pterophyta) do Brasil. Acta Botanica Brasilica 17: 515-521.

Salino, A. \& Semir, J. 2004. Thelypteris subg. Amauropelta (Kunze) A.R. Sm. (Thelypteridaceae - Pterophyta) no Estado de São Paulo, Brasil. Lundiana 5: 83-112.

Smith, A.R. 1971. Systematics of the neotropical species of Thelypteris section Cyclosorus. University of Calififornia Publications in Botany 59: 1-137.

Smith, A.R. 1980. Taxonomy of Thelypteris subgenus Steiropteris, including Glaphyropteris (Pteridophyta). University of California Publications in. Botany 76: 1-38.

Smith, A.R. 1983. Flora of Ecuador, No. 18. PolypodiaceaeThelypteridoideae: 1-148. House of the Swedish Council, Stockholm.

Smith, A.R. 1992. Thelypteridaceae. In: R.M. Tryon \& R.G. Stolze (eds.). Pteridophyta of Peru. III. Fieldiana, Botany, new series 29: 1-80.

Smith, A.R. 1993. Thelypteridaceae. In: A.R.A. Görts-van Rijn (ed.). Flora of the Guianas. Serie B: Ferns and allies. 6 pp. 77-114.

Smith, A.R. 1995. Thelypteridaceae. In: P.E. Berry, B.K. Holst \& K. Yatskievich (eds.). Flora of the Venezuelan Guayana 2. Pteridophytes, Spermatophytes Acanthaceae-Araceae. Missouri Botanical Garden. St. Louis \& Timber Press, Portland, Oregon, pp. 315-326.

Smith, A.R. \& Cranfill, R. 2002. Intrafamilial relationships of the theypteroid ferns (Thelypteridaceae). American Fern Journal 92: 131-149. 